\begin{abstract}
Title of Dissertation: $\quad$ RWANDA AND THE MORAL OBLIGATION OF HUMANITARIAN INTERVENTION

Joshua James Kassner, Doctor of Philosophy, 2007

Dissertation Directed by: $\quad$ Professor Christopher W. Morris

Department of Philosophy
\end{abstract}

In 1994, nearly one million Men, women, and children were slaughtered because of their ethnicity. The tragedy of the Rwandan genocide has caused many to question the international community's choice not to intervene. I use the Rwandan genocide as a means of discussing international morality and the role of morality in international relations.

The first half of my project focuses on humanitarian intervention as an issue of global ethics. I argue that the international community, as a collection of duty-bearing states, had a moral obligation to intervene in Rwanda. To defend this proposition I must first establish the conceptual possibility of global ethics. In that vein, I begin by arguing against various skeptical arguments made by communitarians, relativists, and political realists. Having made the conceptual room for global ethics, I then develop a weak moral principle in support of the moral obligation of humanitarian intervention by identifying the set of conditions under which no one could reasonably deny that such an obligation exists. I next explain how states can and why they on occasion do bear that obligation. Lastly, I argue that the Rwandan genocide fulfilled such conditions; as a consequence, not only was intervention permissible, it was obligatory.

The second half of my project is concerned with the role moral demands should play in the practical deliberations of states. Many international relations scholars contend that questions of intervention are largely determined by the right of nonintervention which 
precludes other states from considering reasons for action that would require intervention. Against such scholars I argue that the role the right of nonintervention played in the practical deliberations of states during the Rwandan genocide was, and remains, unjustified. In the alternative, I argue that we ought to adopt a rebuttable presumption in favor of nonintervention. Such a rule would serve the same goals as the right of nonintervention, but without the unjustified preclusion of moral reasons for action. I conclude that the presumption of nonintervention would have been rebutted during the Rwandan genocide, and that the international community ought to have intervened. 


\title{
RWANDA AND THE MORAL OBLIGATION OF HUMANITARIAN INTERVENTION
}

\author{
by \\ Joshua James Kassner \\ 2007 \\ Dissertation submitted to the Faculty of the Graduate School of the \\ University of Maryland, College Park in partial fulfillment \\ of the requirements for the degree of \\ Doctor of Philosophy \\ 2007
}

Advisory Committee:

Professor Christopher W. Morris, Chair

Professor Samuel Kerstein

Professor Judith Lichtenberg

Professor David Luban

Professor Joe Oppenheimer

Professor Mortimer Sellers 


\section{Dedication}

To Stephanie Kassner, whose love, support, and patience has never waned.

To my parents and in-laws who didn't flinch when I told them that I was leaving the practice of law to become a philosopher.

To the countless millions whose basic rights are violated every day. 


\section{Acknowledgments}

This project has consumed my intellectual life for the better part of five years. The kernel of an idea was formulated in the Spring of 2002 during a course I took in conjunction with the University of Maryland's Committee on Politics, Philosophy, and Public Policy. The impetus was our reading of Philip Gourevitch's book, We Wish to Inform You that Tomorrow We Will be Killed with Our Families: Stories from Rwanda (New York: Farrar, Straus, and Giroux, 1998). Joseph Oppenheimer raised a provocative question regarding the occurrence of genocide; and, for better or worse, from that day I have spent much of my time and effort pondering one question that grew from the discussion that day - what ought the international community have done?

My initial thoughts and proposal were met with invaluable skeptical and constructive criticism. Some of which no doubt remains. The project was too large, too ambitious, and slightly wrongheaded. But, other than that, it had promise. I would not have completed this project without the guidance, criticism, and time so many were willing to give. There are three individuals in particular to whom I owe many thanks.

Despite his schedule and even with his frustration at my less than concise writing style (still a work in progress), Christopher Morris has guided me through this project. He wisely counseled me to alter my initial proposal as it would have required volumes to complete. He has always found time to chat, challenge, and point me in the right direction.

Without Judith Lichtenberg I may never have ended up at the University of Maryland. It was a discussion with her that influenced my decision to turn down a funded position to attend Maryland as an unfunded student. She has always been kind and supportive, even when expressing her concerns about my work. She helped me to see certain objections that I had initially overlooked. Specifically, she believed that my initial proposal would have fallen prey to the "Peter Singer problem" of being overly burdensome, and for that reason unjustifiable.

Samuel Kerstein's analytic scrutiny has made this a much stronger project than it would have been without his input. During my defense of the project he recommended an entire shift in methodology. Without that change, the end product may have been interesting, but not likely as compelling. Sam and I continue to disagree about certain aspects of my argument, but that is what makes him so valuable as a critic, he holds no punches.

I would also like to thank David Luban and Mortimer Sellers for their willingness to sit on my committee. I know they are both very busy individuals and I truly appreciate the time they have taken in reviewing and critiquing my project. I would also like to note that Mortimer Sellers has been a tremendous influence on my development as a philosopher; from the days I spent in his class on Jurisprudence until now.

Lastly, I want to thank David Lefkowitz, Matt King, and Craig Derksen for allowing me to bend their ears and pick their brains about the many ideas that were, at any given moment racing through my mind. Each of the individuals acknowledged have helped me become a better writer, academic, and philosopher. 


\section{TABLE OF CONTENTS}

Chapter 1 Introduction and Brief History of the Rwandan Genocide

p. 1

1.1 Introduction

p. 1

1.2 The Rwandan Genocide

p. 1

1.3 My Project: The International Community's Failure to

Fulfill the Moral Obligation to Intervene in Rwanda ......

p. 6

1.4 Overview

p. 11

Chapter 2 The Current Debate over Humanitarian Intervention

p. 29

2.1

Introduction

p. 29

2.2 Skepticism Over International Morality

p. 30

2.3 The Debate Over Humanitarian Intervention ....

p. 40

2.4

Conclusion

p. 56

\section{Chapter 3 The Moral Obligation of Humanitarian}

\section{Intervention Defined}

p. 57

3.1 Introduction

p. 57

3.2 Why a Standard of Reasonable Deniability

p. 58

3.3 The Constitutive Elements of a Moral Obligation of Humanitarian Intervention ....

p. 65

3.4 The Basic Right to Physical Security as the Basis for the Moral Obligation of Humanitarian Intervention

p. 87

3.5 Charity or Justice

p. 109

3.6 Defending the Basic Right to Physical Security ...

p. 124

3.7 Conditions from the Objections of the Skeptic, the Communitarian, and the Instrumental Argument

p. 127

3.8 Additional Conditions from Practical and Epistemic Concerns

p. 132

3.9 Conclusion: A Moral Obligation to Intervene in Rwanda

p. 135

\section{Chapter 4 The Normative Framework of International Relations}

\section{Operative in 1994: A Critical Assessment}

4.1 Introduction

4.2 The Importance of Interdisciplinary Efforts in Political Philosophy

4.3 The Normative Framework of International Relations, State Sovereignty and the Right of Nonintervention

p. 144

4.4 Justifying the Right of Nonintervention ...

p. 155

4.5 Critically Assessing the Justificatory Arguments

\section{Chapter 5 A Reconstruction of the Normative Framework} of International Relations

5.1 Introduction 
5.3 Reasons in Support of a Presumption of Nonintervention ....... p. 182

5.4 Reconstruction of the Normative Framework and Implications

\section{Chapter 6 Conclusion: An All-Things-Considered Obligation} to Intervene in Rwanda

p. 195

6.1 Introduction

p. 195

6.2 Application of the Reconstructed Normative Framework

p. 195

6.3 Conclusion

p. 207

Bibliography

p. 210 


\section{List of Figures}

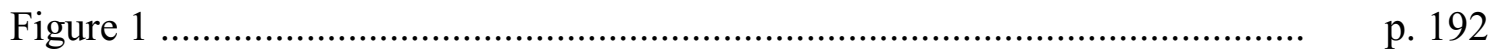

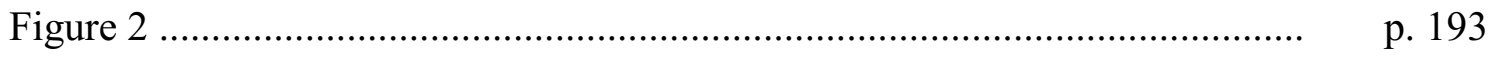

-vi- 


\section{The Moral Obligation of Humanitarian INTERVENTION AND RwANDA}

\section{Chapter 1 - Introduction And Brief History of the RW ANdan Genocide}

\subsection{Introduction}

In 1994, nearly one million Rwandans were sought out and killed simply because they were Tutsis or Tutsi sympathizers. They were the victims of genocide. The tragedy of the Rwandan genocide has since caused many to question the international community's choice not to intervene. Much of the discussion has revolved around the moral permissibility of humanitarian intervention. My focus, however, is on the identification of the conditions under which there is a moral obligation of humanitarian intervention. I argue that the Rwandan genocide fulfilled such conditions, and gave rise to a moral obligation to intervene. I also contend that the rules governing the practical deliberations of states precluded such moral obligations from consideration, and as such were a determinative reason for the international community's choice not to intervene. I argue that such rules lack sufficient justification, and I offer a reconstructed deliberative framework under which states ought to consider such moral obligations in their practical deliberations. Applying the reconstructed deliberative framework to the Rwandan genocide results in a judgment that, all things considered, the international community ought to have intervened.

\subsection{The Rwandan Genocide}

Before turning to the substantive discussion, I want to offer a brief historical account of the Rwandan genocide. Between April and July of 1994, approximately 
800,000 Rwandans were slaughtered because they were Tutsis or Tutsi-sympathizers. ${ }^{1}$ L. Gen. Romeo Dallaire and Philip Gourevitch add to that number countless others who were forced into refugee camps where they were subjected to violence, starvation, and disease. $^{2}$ Most of the killing was carried out, not by the military, but by citizens in machete-wielding mobs. Individuals were betrayed, and in some situations actually sought out and killed, by those whom they knew. For example, in one particularly egregious instance, a physician, Dr. Gerard, betrayed the Tutsis under his care. ${ }^{3}$ Gerard led a group of Hutu militiamen to his Tutsi patients, knowing and intending that the patients would be killed by the militia. ${ }^{4}$

In August of 1993, prior to the outbreak of violence, the Rwandan government and the Rwandan Patriotic Front ${ }^{5}$ (RPF) entered into a power-sharing agreement, the Arusha Accords. ${ }^{6}$ The Arusha Accords were intended to bring an end to a bloody civil war. ${ }^{7}$ On October 5, 1993 the United Nations approved a mandate for the deployment of

${ }^{1}$ See, Samantha Powers, "A Problem from Hell”: America and the Age of Genocide (New York: Perennial, 2003); Philip Gourevitch, We Wish to Inform You that Tomorrow We Will be Killed with Our Families: Stories from Rwanda (New York: Farrar, Straus, and Giroux, 1998); and L. Gen. Romeo Dallaire, Shake Hands with the Devil: The Failure of Humanity in Rwanda (Toronto: Random House Canada, 2003).

${ }^{2}$ See, Gourevitch, pp. 294-298. See also, Dallaire, p. 518.

${ }^{3}$ Gourevitch, pp. 26-28.

${ }^{4}$ Gourevitch, pp. 26-28.

${ }^{5}$ The Rwandan Patriotic Front was a rebel army comprised of Tutsis and moderate Hutus under the leadership of Paul Kagame.

${ }^{6}$ Dallaire, p. 53.

${ }^{7}$ Ibid., pp. 54-55. See also, Powers, pp. 340-341. 
a peacekeeping force (UNAMIR) to aid in the implementation of the Arusha Accords. ${ }^{8}$ Despite the international community's ostensible support for the mandate, UNAMIR never received the political, logistical, or military backing necessary to accomplish its mission. And, while the implementation of the Arusha Accords dragged on, Hutu extremists consolidated their power.

By April of 1994, UNAMIR had received numerous warnings from an informant within the interahamwe, a civilian militia with close ties to the Hutu extremists in the Rwandan government, that a campaign of violence against the Tutsi was about to begin. ${ }^{9}$ One particularly relevant piece of information provided by the informant was the identification of hidden caches of weapons. Dallaire contacted the United Nations and sought permission to raid the weapons caches, the very existence of which was a violation of the Arusha Accords. Instead of being given permission, Dallaire was chastised for "even thinking about raiding the weapons caches."10

On April 6, 1994, a plane carrying Rwanda’s President, Habyarimana, exploded in mid-air over the Rwandan capital Kigali. Almost immediately, violence broke out throughout Kigali. The Hutu extremists used this event and its chaotic aftermath as an excuse to seize control of the government and put the implementation of the Arusha Accords on hold. The interahamwe put the weapons they had hidden and that Dallaire had sought to confiscate to their intended use - the eradication of Tutsis.

At the request of the United Nations, Dallaire outlined a plan to halt the killing.

${ }^{8}$ Dallaire, p. 96.

${ }^{9}$ See Dallaire, pp. 141-144, 146.

${ }^{10}$ Ibid., p. 146. 
He claimed that if he were provided with a force of about 5000 well-equipped soldiers he would be able to provide safety and security to the Rwandan people, and get the implementation of the Arusha Accords back on track. ${ }^{11}$ However, even after the killing had begun, the United Nations refused to give the peacekeepers the support necessary to protect the Rwandan people. Though many at the United Nations expressed shock at what was happening in Rwanda, they did nothing to halt the killing. ${ }^{12}$

Numerous reasons were offered for the persistent refusal to intervene. One reason pressed by the Hutu-led interim government was based on the claim that Rwanda, like any other sovereign state, was presumed to enjoy the right of non-intervention. The international community could justifiably interfere in the internal affairs of Rwanda only under certain prescribed circumstances. The interim government claimed that the violence was an internal matter, and that it would soon be under control. ${ }^{13}$ This argument against intervention was pressed in the United Nations' Security Council, where Rwanda held one of the rotating seats at the time. ${ }^{14}$

Humanitarian crises are not generally recognized as providing the necessary justification for violating a sovereign state's right of non-intervention; however, under the Convention on the Prevention and Punishment of the Crime of Genocide, 1948 (“Convention"), intervention is, at the very least, permitted to prevent or stop genocide. ${ }^{15}$

${ }^{11}$ Ibid., p. 359. See also, Powers, p. 378.

12 Dallaire, pp. 374-376.

${ }^{13}$ See Dallaire, pp. 222-225.

${ }^{14}$ Ibid., pp. 145, 195.

${ }^{15}$ U. N. Convention on the Prevention and Punishment of the Crime of Genocide (1948). 
Despite this legal permission, while Tutsis died, those in the international community argued over whether the violence in Rwanda counted as genocide. ${ }^{16}$ The refusal of the United States to use the word "genocide" to describe the events in Rwanda was, at least in part, an intentional effort to avoid the possible demands of the Convention. ${ }^{17}$

Eventually, the violence in Rwanda was recognized as genocide. ${ }^{18}$ This, however, did not result in an intervention, rather many claimed that the recognition of genocide merely made intervention permissible, but did not require action. This position was captured in PPD-25, under which the United States would only intervene if the national interests of the United States were at stake. ${ }^{19}$ The killing of Tutsis continued.

By July of 1994 the RPF had gained control of Kigali and most of Rwanda, and had put an end to the ethnic slaughter in the areas under their control. At about that same time, under a mandate from the United Nations, the French deployed a sizeable military force, known as "Operation Turquoise," to provide secure areas for refugees. ${ }^{20}$ The Hutu extremists and the genocidaires were fleeing to the French safe areas, where, due to failures on the part of the French to screen the incoming refugees - making no distinction

${ }^{16}$ See Powers, pp. 358-364.

${ }^{17}$ See Powers, p. 359; quoting from a memo authored by someone in the Office of the Secretary of Defense, "1. Genocide Investigation: Language that calls for an international investigation of human rights abuses and possible violations of the genocide convention. Be Careful. Legal at State was worried about this yesterday-Genocide finding could commit [the U.S. government] to actually 'do something'”' Office of the Secretary of Defense, "Secret Discussion Paper: Rwanda," May 1, 1994; emphasis added by Powers.

${ }^{18}$ See, Powers, p. 364.

${ }^{19}$ See, Powers, pp. 377-380.

${ }^{20}$ See, Dallaire, pp. 431-436. 
between innocent refugee and genocidaire - the violence would continue. ${ }^{21}$ The justifications for Operation Turquoise were not based on the genocidal actions that had resulted in the deaths of hundreds of thousands of innocent Rwandans. Rather it was the claimed danger to international peace and security caused by the resultant refugee crisis that the French and the United Nations relied upon to justify the intervention. ${ }^{22}$ In addition, rather than protecting refugees, the intervention had the effect of protecting the genocidaires as they fled. ${ }^{23}$

\subsection{My Project: The International Community's Failure to Fulfill the Moral Obligation to Intervene in Rwanda}

Before discussing my project I would like to explain my interest in the Rwandan genocide. In 1948, in the aftermath of World War II and with the horror of the Holocaust known to the world, the United Nations sponsored the Convention on the Prevention and Punishment of the Crime of Genocide, which states,

The Contracting Parties confirm that genocide, whether committed in time of peace or time of war, is a crime under international law which they undertake to prevent and to punish. ${ }^{24}$

Yet, less than fifty years later, the most powerful states in the world allowed nearly a million innocent men, women, and children to be slaughtered in a most brutal fashion.

In some cases it wasn't even the commitment of troops or direct military action

${ }^{21}$ See, Dallaire, pp. 463-464, 471-472, 488.

${ }^{22}$ See L. R. Melvern, A People Betrayed: The Role of the West in Rwanda's Genocide (London: Zed Books Ltd., 2004), pp. 210-211.

${ }^{23}$ See, Powers, pp. 380-382. See also, Melvern, p. 214.

${ }^{24}$ U. N. Convention on the Prevention and Punishment of the Crime of Genocide (1948). 
that was at issue. For example, in May of 1994, the United States' military contemplated jamming the radio signal of Radio RTLM - a radio station broadcasting anti-Tutsi propaganda and exhorting the civilian population to kill Tutsis. ${ }^{25}$ Jamming the radio signal would have involved little more that flying a U.S. military plane over Rwandan airspace. The United States, however, decided against such action, claiming it would be too costly, and that such action contravened certain international legal conventions. ${ }^{26}$ If jamming a radio signal was outside the range of appropriate action, it is not clear what commitment to the Convention meant, or required.

In addition to the visceral reaction I had to the international community's apathy in the face of such atrocity, my interest in this project is motivated by my general interest in international morality and the role it should play in the practical deliberations of states and the international community. In seeking insight into this subject, focusing on a particular historical event has a number of advantages. First, it allows me to touch upon the major issues in, and questions associated with, international morality and its relationship to the normative framework governing the practical deliberations of states, without having to provide a complete accounting of either.

Second, using a past event as a case-in-point is advantageous because historical study renders the deliberations engaged in by the relevant actors more readily open to critical assessment. In recent years, there has been much written about the Rwandan genocide. These accounts paint a clear picture of the events which led to, and occurred during, the genocide, as well as the deliberative process engaged in by those deciding

${ }^{25}$ See, Powers, pp. 370-371. See also, Gourevitch, pp. 99-100.

${ }^{26}$ See, Powers, pp. 370-373. 
what ought to be done about the killing.

Another reason I have for evaluating the moral obligations states and the international community owed to the Rwandan people is directly related to my belief that there are circumstances under which humanitarian intervention is not only permissible, but obligatory. The Rwandan genocide presents an interesting case because it would seem that if we are ever to have duties or obligations to distant others that give rise to an obligation to intervene it would be to prevent and protect against genocide.

It might be contended that an obligation of intervention to prevent death from starvation and extreme poverty is just as likely a candidate for general acceptance as the obligation of intervention to prevent genocide. ${ }^{27}$ I would agree that we have an obligation to aid distant others when preventable starvation or extreme poverty threatens their lives, and I would agree that in certain cases where the starvation and impoverishment is due to government corruption or the theft of foreign aid ("famine through corruption") we may have an obligation to intervene. I also believe, however, that there are a number of morally significant differences between genocide, on the one hand, and famine through corruption, on the other, that make an obligation to intervene in the case of genocide more readily defensible.

First, if we assume that famine through corruption is the result of a desire for wealth or power on the part of those in control, then the motivation is one that can be dealt with through incentives, both positive and negative. In cases of genocide, however,

${ }^{27}$ I would like to thank Samuel Kerstein for pointing this out to me. See, Thomas Pogge's discussion of an obligation to act in cases of poverty in his collected works, World Poverty and Human Rights (Oxford: Blackwell Publishing, 2002), pp. 14-17, Chs. $1-4$, and 8 . 
the motivation likely involves an element of hate and/or ignorance. Incentives are unlikely to be effective as the underlying motivation is not susceptible to methods of influence that appeal to the rational self-interest of the offending party(ies). In the Rwandan genocide, the slaughter was carried out by civilians. ${ }^{28}$ Consequently, in Rwanda, it is not clear to whom such incentives would or could have been offered. Second, the intentions of the genocidaires and the motivation underlying their actions, are morally distinct from the intentions and motivation of those responsible for famine through corruption. Stealing food from a starving person in order to gain power or wealth with the knowledge that your act is likely to cause the death of the person from whom the food was stolen is certainly wrong, but stealing someone's food for the sole purpose of starving them to death for no other reason than that they are not like you is worse. It is the latter case that is morally comparable to overt and violent efforts to commit genocide. This difference may only be a matter of degree, but all that I am claiming is that an obligation to intervene to prevent or stop genocide is easier to defend than other possible sources of the obligation to intervene.

In considering the Rwandan genocide, it is easy to get lost in the sheer enormity of the tragedy. The senseless and brutal murder of an individual is swallowed by the slaughter of an entire ethnic minority. It is important, due to the circumstances of the Rwandan genocide, to be conscious of the plight of the individual victims. In Rwanda, there were no gas chambers, no machinery of death to kill large numbers at a single time. Instead, most of the victims were "murdered, not by automatic weapons but by machetes

${ }^{28}$ See Mahmood Mamdani, When Victims Become Killers: Colonialism, Nativism, and the Rwandan Genocide (Princeton, NJ: Princeton University Press, 2002), pp. 17-18. 
and clubs wielded by soldiers, mayors, police, and neighbors." 29

Many have sought to understand how people could and why they would commit such atrocities. ${ }^{30} \mathrm{I}$ am interested, however, in understanding why the international community chose not to intervene in Rwanda, and whether that choice was justified. Thus, my project is both descriptive and normative. What reasons for and against intervention were considered by states individually, and the international community collectively? What were the international community's moral obligations? What role did those obligations play in the practical deliberations of states, and what role should those obligations have played in those deliberations? Was the international community justified in limiting its efforts to threats of diplomatic sanctions and future consequences $?^{31}$

I identify the conditions under which no one could reasonably deny that an obligation of humanitarian intervention exists, and I contend that the international community, as a collection of duty-bearing states, was under such an obligation to intervene in Rwanda. This moral obligation does not, however, necessarily imply that the international community ought, all things considered, to have intervened in Rwanda.

${ }^{29}$ See, Clea Koff, The Bone Woman: A Forensic Anthropologist's Search for Truth in the Mass Graves of Rwanda, Bosnia, Croatia, and Kosovo (New York: Random House, 2004), p. 21.

${ }^{30}$ Michael Mann offers such an account. For an overview of his project, see Michael Mann, The Dark Side of Democracy: Explaining Ethnic Cleansing (Cambridge: Cambridge University Press, 2005), pp. 2-10. Mann offers a theory explaining why genocide occurs, and deals with a number of specific instances of genocide, including the Rwandan genocide.

${ }^{31}$ Prudence Bushnell, Acting Assistant Secretary of State for African Affairs, would call the Rwandan military chief to let him know that President Clinton was going to "hold him accountable for the killings." Powers, p. 370. 
There may have been countervailing reasons that, when included in the practical deliberations of states and the international community, defeated the reasons in support of intervention. In sum, my project is comprised of the following components:

(1) Discussing the Moral Obligation of Humanitarian Intervention: (A) The identification of the conditions under which no none could reasonably deny that a moral obligation of humanitarian intervention exists; and (B) a defense of the claim that such an obligation existed in the case of the Rwandan genocide; and (2) Discussing the Normative Framework of International Relations: (C) A discussion of the role moral obligations played in the practical deliberation of states in 1994; (D) a discussion of the role such obligations ought to have played in the practical deliberations of states; and (E) a defense of the claim that the international community ought, all things considered, to have intervened in Rwanda.

\subsection{Overview}

I turn now to a more detailed overview of how, in the succeeding chapters, I will answer these questions.

\subsubsection{Chapter 2 - The Current Debate over Humanitarian Intervention}

In Chapter 2, I provide an account of the current state of the debate over humanitarian intervention. Two fundamental questions define this debate. ${ }^{32}$ First, is

${ }^{32}$ Stanley Hoffmann provides a brief accounting of these issues. See Stanley Hoffmann, "Intervention: Should It Go On, Can It Go On?" from Ethics and Foreign Intervention, eds. Deen K. Chatterjee and Don E. Scheid (Cambridge: Cambridge University Press, 2003), pp. 21-30. 
humanitarian intervention ever morally justified $?^{33}$ Second, if humanitarian intervention can be justified, one must still determine "what should be done" to effect the intervention. ${ }^{34}$ My claim regarding an obligation to intervene is most directly related to the threshold question of the justifiability of humanitarian intervention.

The debate over justifiability may seem straightforward. There are arguments seeking to justify humanitarian intervention, and there are arguments intended to demonstrate that it is morally impermissible. The debate is, however, complicated by the existence of a variety of skeptical arguments in support of the claim that morality has little or no relevance to international relations. ${ }^{35}$

I will focus on three of the most widely discussed skeptical accounts. The first two come from the realist tradition. The philosophical foundations for the realist perspective on the relationship between morality and international relations can be found in Thucydides ${ }^{36}$ and Machiavelli. ${ }^{37}$ Its more contemporary proponents are international

${ }^{33}$ Ibid., pp. 23-24.

${ }^{34}$ Ibid., pp. 24-28.

${ }^{35}$ For a thorough discussion of such skeptical accounts, see Marshall Cohen, "Moral Skepticism and International Relations," Philosophy and Public Affairs, Vol. 13, No. 4 (Autumn, 1984), pp. 299-346.

${ }^{36}$ Thucydides, "The Melian Dialogue," The History of the Peloponnesian War (London: Penguin Books, 1972), pp. 400-408.

${ }^{37}$ Niccolo Machiavelli, The Prince (Arlington Heights, IL: Harlan Davidson, Inc., 1947). 
relations scholars like Hans Morgenthau ${ }^{38}$ and Kenneth Waltz. ${ }^{39}$ The positions of these scholars will be discussed in Chapter 2.

First, under one strand of political realism, the realist argues that international relations is a descriptive and predictive enterprise, and that the goal of international relations scholarship should be the understanding of relationships of power and how they affect world politics. In understanding the actions of states, normative demands on the practical deliberations of states, including moral obligations owed to distant others that are borne by states, are irrelevant.

Second, unlike the descriptive realist, the normative realist concedes that normative theory has a role to play in international relations, but what states ought to do is a matter of strategic advantage, not moral obligation. ${ }^{40}$ The normative realist contends

${ }^{38}$ Hans Morgenthau, Politics among Nations, $4^{\text {th }}$ Ed. (New York: Alfred A. Knopf, Inc., 1967).

${ }^{39}$ Kenneth N. Waltz, Theory of International Relations (Reading, MA: AddisonWesley Publishing Co., 1979).

${ }^{40}$ The official position of the United States' government during the Rwandan genocide was that the United States would intervene only if it had a national interest at stake. Specifically, PPD 25 required U.S. interests to be at stake before support for intervention would be allowed. See, Powers, pp. 344-346, 377-380. For a discussion of this understanding of international relations and its implications for the obligations borne by states, see Charles R. Beitz, Political Theory and International Relations (Princeton, New Jersey: Princeton University Press, 1999), pp. 28-34. See also, David Hume's discussion of "Justice". David Hume, An Inquiry Concerning the Principles of Morals Section III (1751) (La Salle, Illinois: Open Court Publishing Company, 1966), pp. 15-38. It is important to note that I am avoiding the use of terms like "Realist" or "NeoRealist." My understanding is that the Neo-realist is committed to the study of international relations as a matter of scientific or descriptive inquiry, and that the champion of this trend in realism is Kenneth Waltz, and that Hans Morgenthau and Hedley Bull are the arch-Realists. However, the division I am concerned with is related to the understanding of realism as either a descriptive or a normative project, and the wide array of realist accounts has caused me some confusion. So to avoid spreading the confusion, I have chosen to use more straightforward descriptive terms for the realist traditions I am discussing. I apologize to any international relations scholars who may 
that the international arena is like a Hobbesian state of nature. Since there is no world sovereign, states are in a constant state of war. As such there is no justice, and no normative demand on the actions of states other than prudence.

One final and more moderate form of skepticism over international morality is found in the work of David Hume. If the normative realist is correct, and international relations is like a Hobbesian state of nature, then Hume would likely agree that in international relations there is no justice and no moral obligations borne by states. ${ }^{41}$ Justice, for Hume, is artificial and instrumental to the welfare of men, and justice only arises through the conventions that establish society. ${ }^{42}$ Hume concedes that there is no world sovereign, but claims that there is an international society. ${ }^{43}$ As such, Hume contends that there is an international morality, but that it is concerned only with the relations between princes or sovereigns.

After offering reasons for why such skeptical accounts are not determinative of the matter, I will focus on the ongoing debate over intervention that centers around the claim that there are moral reasons that weigh decisively against intervention. As Fernando Teson points out, in these arguments the noninterventionists recognize that an injustice is being done, and may even agree that something ought to be done to alleviate the suffering of those whose rights are being violated, but they claim that military

find my terminology unnecessarily cumbersome.

${ }^{41}$ Hume, A Treatise of Human Nature 3.2.2 (1737) (Oxford: Oxford University Press, 2000), p. 315. See also Hume, An Enquiry Section III (that there is no justice in a society of ruffians), pp. 18, 19.

${ }^{42}$ Hume, A Treatise, 3.2.1, p. 307. See also Hume, An Enquiry Section III, p. 19.

${ }^{43}$ Ibid. 
intervention is morally impermissible. ${ }^{44}$

Under one argument, it is claimed that states are under a moral obligation to obey international law, and the right of nonintervention and its correlative duty to refrain from intervening into the internal affairs of another state are mandated by international law. ${ }^{45}$ Others offer relativist objections, claiming that intervention is based on the arbitrary priority given to Western values over those of the culture of the target state. ${ }^{46}$ Michael Walzer, offering a communitarian argument, contends that intervention actually violates the rights of political communities to self-determination. ${ }^{47}$ Lastly, it is often claimed that non-intervention is instrumentally valuable as a means to achieving certain goals of international morality. ${ }^{48}$

\subsubsection{Chapter 3 - The Moral Obligation of Humanitarian Intervention Defined}

In Chapter 3, I will identify what I believe are the conditions under which no one could reasonably deny that a moral obligation of humanitarian intervention exists. In identifying such conditions I am seeking to establish the conditions under which humanitarian intervention is clearly obligatory. With an account of such conditions in

${ }^{44}$ Fernando Teson, "The Liberal Case for Humanitarian Intervention" from J. L. Holzgrefe and Robert O. Keohane, eds., Humanitarian Intervention: Ethical, Legal, and Political Dilemmas (Cambridge: Cambridge University Press, 2003), p. 95.

${ }^{45}$ See Teson, pp. 108-111. See also Mark W. Janis, An Introduction to International Law, $3^{r d}$ Ed. (New York: Aspen Law \& Business, 1999) (that article 2 of the Charter of the United Nations forbids intervention into the internal affairs of another state), pp. 185, 257.

${ }^{46}$ See Teson, p. 100.

${ }^{47}$ Michael Walzer, "The Moral Standing of States," Philosophy and Public Affairs, Vol. 9, No. 3 (Spring, 1980), 209-229. See also, Teson, p. 104.

${ }^{48}$ Janis, pp. 159-160. 
hand, I will assess the degree to which the circumstances of the Rwandan genocide fulfilled those conditions.

If I was only concerned with establishing a moral obligation to intervene in Rwanda, there are a number of principles upon which I could rely to make such an argument. For example, Thomas Pogge discusses how the principle of rectification can give rise to reparative obligations to act. ${ }^{49}$ There is ample evidence that the ability of the genocidaires to perpetrate the genocide in Rwanda was due in large part to actions by France, Belgium, and Egypt. ${ }^{50}$ Thus, at the very least, the principle of rectification could arguably provide the basis for a moral obligation to intervene borne by those who violated their duty not to harm the Rwandan Tutsis.

While I acknowledge the promising nature of such an approach, it makes it necessary that the bearer of the obligation have contributed to the present suffering which gives rise to the obligation. I am concerned with defending a moral obligation of humanitarian intervention that is not dependent on anything other than the plight of individuals - a distinctively humanitarian moral obligation. I will argue that the violation of the basic human right to physical security can, under certain conditions, give rise to a

${ }^{49}$ See Thomas Pogge, World Poverty and Human Rights. See also Pogge, "Human Rights and Human Responsibilities," from, Pablo De Greiff and Ciaran Cronin, eds., Global Justice \& Transnational Politics: Essays on the Moral and Political Challenges of Globalization (Cambridge, Massachusetts: The MIT Press, 2002). Another possible principle supporting intervention could be Peter Singer's consequentialist equal consideration of interests which he advocates in "Famine Affluence and Morality." Peter Singer, "Famine, Affluence, and Morality," Philosophy \& Public Affairs 1:2 (1972), pp. 231-232. See also Peter Singer, "Outsiders: Our Obligations to Those Beyond Our Borders," The Ethics of Assistance: Morality and the Distant Needy (Cambridge : Cambridge University Press, 2004), pp. 11-32.

${ }^{50}$ Melvern, p. 5. 
moral obligation of humanitarian intervention. If correct, the obligation of humanitarian intervention would depend on nothing other than the duties correlative to the basic human right to physical security.

It is important to the success of my project that one have an understanding of the task I have set for myself. I am seeking to identify that set of conditions under which no one could reasonably deny that a moral obligation of humanitarian intervention exists. But, what do I mean by that set of conditions under which no one could reasonably deny that such an obligation exists? This is not simply a matter of identifying the necessary and sufficient conditions for the obligation to exist, though the identification of those conditions does play a part. Necessary and sufficient conditions for the existence of something identify the threshold for the object's existence. No more is required, and no less will fulfill the conditions. However, identifying the conditions under which no one could reasonably deny that such an obligation exists requires more.

The moral obligation of humanitarian intervention is a reason for action. As such, depending on the circumstances, it can exist in a number of different forms. First, it may exist as $a$ reason for action to be entered in to the practical deliberations of an agent - one amongst many moral reasons for action relevant to one's determination of what ought to be done in a particular circumstance. Second, it may exist as an all things considered reason for action - as an outcome of practical deliberation. In which case it is determinative of what an individual ought to do. In the end, ascertaining the conditions under which no one could reasonably deny that a moral obligation exists is a matter of identifying the existence conditions for both a reason for action and those conditions under which it would be the all things considered reason for action. 
In light of the preceding discussion, the first step in identifying the conditions under which no one could reasonably deny that a moral obligation of humanitarian intervention exists involves the identification of the conditions for the existence of such a moral obligation as a reason for action. As with any obligation, what must be first understood is what it is an obligation to - what is the content of the obligation? $?^{51}$ Is it an obligation to do something, or to refrain from doing something? Second, one must determine the scope of the obligation. Much like the scope of a right, the scope of an obligation "consists of the class of things whose normative positions are stipulated by the [obligation]. ${ }^{, 52}$ Who are the bearers of the obligation and to whom is the obligation owed? In identifying the content and scope of an obligation we will have identified the normative relationship that exists between the obligation bearers and those to whom the obligation is owed.

In addition, an obligation is supposed to play a particular role in our practical deliberations. In many instances our obligations may contradict one another, or be met by countervailing reasons which direct us to act against the obligation. Thus, it is also important to understand the nature and strength of the obligation in question. The nature and strength of the obligation will depend on the basis for and content of the obligation. For example, an individual might make two promises. The first is a promise to meet someone for lunch at a particular time, and the other is an oath to serve the community as a firefighter. The time arrives for the lunch date, but at the exact same time a fire is raging and the individual is called to fight the fire. Though both obligations are

\footnotetext{
${ }^{51}$ Sumner (discussing the constitutive elements of a right), pp. 11, 13.

${ }^{52}$ Ibid., p. 11.
} 
promissory the content of the promise to the community to fight fires outweighs the content of the promise to meet someone for lunch.

The basis for the obligation can also have a determinative effect on the nature and strength of the obligation. Take, for example, an obligation to refrain from stealing. One can have an obligation to refrain from stealing that has both a moral and a legal basis.

The obligations have the same content. They both demand that one not steal; however, in weighing the various reasons for action the legal obligation could be defeated by either moral or non-moral countervailing reasons, but the moral obligation could only be defeated by morally weightier countervailing reasons.

After identifying the existence conditions for a moral obligation of humanitarian intervention as a reason for action, I will identify the circumstances under which the moral obligation of humanitarian intervention would be an all-things-considered reason for action. In identifying those circumstances I evaluate and incorporate relevant aspects of various objections to the moral permissibility of humanitarian intervention discussed in Chapter 2. Specifically, I will seek to identify the concerns underlying such objections which could serve as bases for the reasonable rejection of the moral obligation of humanitarian intervention, and incorporate such objections into the conditions which must be met for the obligation to be an all-things-considered reason for action.

Lastly in Chapter 3, with the conditions under which no one could reasonably deny that an obligation of humanitarian intervention exists identified, I will assess whether the circumstances of the Rwandan genocide fulfilled such conditions and thus gave rise to a moral obligation to intervene. I argue that the circumstances of the Rwandan genocide fulfilled those conditions, and was a paradigm case for the obligation 
of humanitarian intervention.

\subsubsection{Chapter 4 - The Normative Framework of International Relations Operative in 1994: A Critical Assessment}

In Chapter 4, I turn to the second component of my project, the normative framework of international relations. The normative framework of international relations is that set of rules that governs the practical deliberations of states in their deliberations about what actions they ought to take when acting in the international arena. ${ }^{53}$ Its use determines what reasons are relevant for consideration by states and the international community.

It is through the application of the normative framework of international relations that states arrive at their all things considered "ought" judgments. It is through our understanding of the practical deliberations of states that we will understand why the international community chose not to intervene in Rwanda. The international community and the individual states of which it is comprised may have failed to deliberate about Rwanda. Assuming the accounts provided by Gourevitch, Powers, and Dallaire are accurate, it is clear that some deliberation occurred. Even if such deliberation had not occurred, this would not undermine the claim that intervention should have occurred. Rather, it would be an additional failure of the international community, not an objection to the claim that the normative framework of international relations operative in 1994 was flawed. Second, the international community may have determined that it ought to intervene, but chose not to against its, collective, better judgment. Again, the historical

${ }^{53}$ Deen K. Chatterjee and Don E. Scheid refer to this as the "normative context of international relations." See, Deen K. Chatterjee and Don E. Scheid, "Introduction", from, Deen K. Chatterjee and Don E. Scheid, Ethics and Foreign Intervention (Cambridge: Cambridge University Press, 2003), p. 4. 
facts of the matter belie such an explanation.

Lastly, the practical deliberations of individual states and the international community may have been flawed. Inappropriate weight may have been given to the reasons relevant to the deliberations, or the very structure of the reasoning may have been flawed. Both possibilities seem to have occurred, but I will focus on the latter as it was likely a cause of the former. I will provide a descriptive account of the normative framework of international relations operative in 1994, and an explanation of how the application of that framework led to the decision by the international community not to intervene in Rwanda. I will then critically assess the various arguments that might be offered in defense of the normative framework, so understood.

Two aspects of the normative framework of international relations operative in 1994 are relevant to the critical assessment and must be understood for this critical project to begin. Specifically, one must have an understanding of the structure of the framework, and the implications that structure had for the reasons relevant to the practical deliberations of states at the time. Discussion of the implications will occur throughout; however, with regard to the structure, there are at least two questions that must be addressed. What is the scope of the framework? And, what are the substantive rules and presumptions governing the framework?

The scope of the normative framework of international relations operative in 1994 was limited to those political institutions that possessed sovereignty. This understanding of the scope of the normative framework of international relations has its historical 
origins in the Treaty of Westphalia, ${ }^{54}$ and is currently acknowledged in numerous instruments of international law. ${ }^{55}$ The claim of the normative realist, who contends that international relations is like a Hobbesian state of nature, is dependent on this understanding of the scope of the normative framework of international relations. ${ }^{56}$

With regards to the substantive rules and presumptions governing the normative framework of international relations operative in 1994, sovereign states were (and to a great extent are) presumed to have a right of nonintervention. ${ }^{57}$ This means that states have a protected liberty to deal with their internal affairs as they see fit. There are at least four types of justificatory arguments proffered in support of the right of nonintervention: that the right is implied by the possession of sovereignty; that the right is instrumental to the provision and protection of other rights $;{ }^{58}$ that the right is based upon the principle of

${ }^{54}$ Janis, p. 157. See also Treaties of Peace Between Sweden and the Holy Roman Empire and Between France and the Holy Roman Empire (Peace of Westphalia, October 14, 1648), 1 C.T.S. 119-356.

${ }^{55}$ U.N. Charter art.2, para. 1. See also Declaration on Principles of International Law Concerning Friendly Relations and Co-Operation Among States in Accordance with the Charter of the United Nations, Oct. 24, 1970.

${ }^{56}$ See, Beitz, pp. 36-37.

${ }^{57}$ Janis, pp. 157, 159-160. See also Beitz, pp. 65-66.

${ }^{58}$ See Michael Walzer, Just and Unjust Wars: A Moral Argument with Historical Illustrations, $3^{r d} E d$. (New York: Basic Books, 2000) (that the right of a people to selfdetermination is protected by the right of nonintervention), pp. 87-91. See also, Mill, "A Few Words on Nonintervention," Dissertations and Discussions, Vol. III (London: Longmans, Green, Reader, and Dyer, 1867). Alternative versions are identified by Michael J. Smith and Stanley Hoffmann. See Michael J. Smith, "Humanitarian Intervention: An Overview of the Ethical Issues" from, Joel H. Rosenthal, ed., Ethics \& International Affairs (Washington, D.C.: Georgetown University Press, 1999), p. 274; and see Stanley Hoffmann, "Sovereignty and the Ethics of Intervention" from, Stanley Hoffmann, ed., The Ethics and Politics of Humanitarian Intervention (Notre Dame, Indiana: University of Notre Dame Press, 1996), p. 23. 
autonomy; ${ }^{59}$ that the right is based on principle of anti-paternalism. ${ }^{60}$

Each of these arguments claim, at the very least, to justify a strong presumption against intervention. The presumption is rebuttable if, but only if, the actions of a state are a threat to international peace and security. Intervention to alleviate a humanitarian crisis may be permitted under this rule, but not because of the humanitarian crisis itself. Rather intervention would be allowed if the humanitarian crisis posed a sufficient threat to international peace and security. The violation of human rights is only a contingent matter in such circumstances. Thus, the effect of the right of nonintervention is to preclude from consideration moral reasons for action that are based on humanitarian/moral concerns internal to another state.

Lastly, I offer a critical assessment of the normative framework of international relations operative in 1994 . With regard to the scope, the claim that only sovereign states are the subjects of and actors in the framework can be understood in both descriptive and normative terms. It may be claimed that, as a matter of fact, sovereign states are the only relevant actors within and subjects of the normative framework of international relations. This claim fails. As Charles Beitz has pointed out, there are "coalitions [of states],

${ }^{59}$ See S. I. Benn and R. I. Peters, The Principles of Political Thought: Social Principles and the Democratic State (New York: Free Press, 1965) (right of nonintervention based upon a Millian understanding of the value of autonomy), pp. 429431. And see R. J. Vincent, Nonintervention and International Order (Princeton, New Jersey: Princeton University Press, 1974), p. 345.

${ }^{60}$ See Benn and Peters (analogy between the principle of anti-paternalism for individuals, and a principle of anti-paternalism for states in the international arena), $p$. 431. See also William Hall, International Law (analogy between individuals and states); and see Jovan Babic, "Foreign Armed Intervention: Between Justified Aid and Illegal Violence" from Alexander Jokic, ed., Humanitarian Intervention: Moral and Philosophical Issues (Petersborough, Ontario: Broadview Press, 2003) (aggregative version), pp. 45-70. 
alliances [between states] and secondary associations" such as nongovernmental organizations that are treated as actors in international relations. ${ }^{61}$

It may, however, be argued that the scope of the normative framework of international relations ought to be limited to sovereign states. One such argument would be that international relations, and by implication the normative framework of international relations, should only be concerned with the provision and protection of international peace and security, and that a necessary means to the provision and protection of international peace and security is that international relations be limited to sovereign states. Thus, it ought to be the case that the scope of the normative framework of international relations is limited to sovereign states.

That sovereignty was intended to be a means of achieving certain goals of international relations, specifically, international peace and security seems to be historically correct. I disagree, however, with the contention that sovereignty as the defining characteristic of the scope of the normative framework of international relations is either necessary or sufficient for the provision and protection of international peace and security. ${ }^{62}$ Nor do I agree with the underlying contention that international peace and security is the only concern of international relations. Sovereignty does not, in and of itself, entail that states and only states are the subjects of, and actors in, the normative

${ }^{61}$ Beitz, pp. 36-40.

${ }^{62}$ I have found David Luban's discussion of the nature of sovereignty very illuminating, although I believe that he and I take different tacks in our criticism of the traditional legalist understanding of sovereignty and its anti-cosmopolitan basis. See David Luban, "The Romance of the Nation-State," Philosophy \& Public Affairs, Vol. 9, No. 4 (Summer, 1980), pp. 392-397. See also David Luban, "Just War and Human Rights" reprinted in Charles R. Beitz, et. al., A Philosophy \& Public Affairs Reader: International Ethics, pp. 199-202. 
framework of international relations.

I turn next to the right of nonintervention and the supposed rule against intervention for humanitarian reasons to which the right of nonintervention is taken to give rise. Some contend that the right of nonintervention is implied by the possession of sovereignty. As a consequence, it is claimed that sovereign states enjoy the right of nonintervention. I argue that the relationship between sovereignty and the right of nonintervention is not an inherent and necessary logical implication, but rather is the result of legal or conventional design intended to effect or is justified by its instrumental value in effecting particular purposes. ${ }^{63}$

I then critically assess various arguments offered as justifications for the right of nonintervention that do not rely on the claimed intrinsic relationship between sovereignty and the right of nonintervention. I contend that only the instrumental justification succeeds, but that it does not give rise to a rule against humanitarian intervention. Rather, the rule governing humanitarian intervention must be based on the degree to which adhering to the demands of the right would protect international peace and security, and that it is merely one consideration among many to be weighed in the deliberations of a state when determining whether to intervene in the internal affairs of another state. Perhaps most important to my project, I contend that it does not preclude from consideration reasons for intervention based on moral obligations borne by states and

${ }^{63}$ It is at this juncture that I part ways with Luban. He contends that "we should be able to define jus ad bellum directly in terms of human rights, without the needless detour of talk about states." Luban, "Just War and Human Rights," p. 201. Luban seems to render states irrelevant if they fail the test of legitimacy. Though I do not necessarily disagree with Luban, I am not so sure that one needs to make such a strong claim to demonstrate the weakness of our current understanding of state sovereignty and the right of nonintervention. 
owed to individuals.

\subsubsection{Chapter 5 - A Reconstruction of the Normative Framework of International Relations}

In Chapter 5, I offer a reconstruction of the normative framework of international relations. The reconstructed version of the framework will build upon the discussion in Chapter 4 of the criticisms levied against the normative framework of international relations operative in 1994. Under the reconstructed account neither sovereignty nor the right of nonintervention stand as a bar against the inclusion of moral obligations owed to individuals in the practical deliberations of states and the international community.

Even assuming that the critical assessment of the normative framework of international relations operative in 1994 offered in Chapter 4 is valid and the reconstructed version of the framework is generally correct, it might be argued that under the reconstructed account the choice not to intervene in Rwanda was permissible or even that the international community ought all things considered to not have intervened.

There are a number of concerns that many would claim made nonintervention, at the very least, permissible. Samantha Powers identified at least three concerns raised by those in the international community opposed to intervention - futility, perversity, and perfidy. ${ }^{64}$

The concern over futility is straightforward. Intervening in the internal affairs of another state to alleviate a humanitarian crisis may be futile. The concern over perversity is based upon the claim that an intervention may produce more suffering and human rights violations than it would prevent. Finally, as to the concern over perfidy, it has been contended that disgruntled minorities might provoke a state to use violence so that they,

\footnotetext{
${ }^{64}$ Powers, pp. 460-473.
} 
the minority, could entice an intervention to aid in their cause.

In Chapter 5, I will explain the role such concerns play in the practical deliberations of states and the international community. They are reasons against intervention to be weighed against the reasons for intervention. They do not, however, preclude interventions in all cases. I shall demonstrate below that the nature of the reasons for intervention, when given their proper due in the reconstructed version of the normative framework of international relations and weighed against the countervailing reasons against intervention, render the choice not to intervene in Rwanda unjustified. ${ }^{65}$

\subsubsection{Chapter 6 - Conclusion: An All Things Considered Obligation to Intervene in Rwanda}

The purposes of Chapter 6 are quite simple and straightforward. First, I provide an account of what has been accomplished with regard to our understanding of the role international morality, and specifically the obligation of humanitarian intervention, should have played in the deliberations of the international community over what to do about the genocide in Rwanda. In addition, Chapter 6 also includes an assessment of the possible implications this project has for international morality and international relations more generally.

\subsection{Conclusion}

In summary, my hypothesis is that the international community, as a collection of

${ }^{65}$ It is important to note that I am assuming a Razian account of practical reasoning. Under the classical account, we are balancing reasons of the same order against one another. Under the Razian account, there are first order reasons for and against the performance of an action, but there are also second-order exclusionary reasons. Joseph Raz, Practical Reason and Norms (Oxford: Oxford University Press, 1999), pp. 35-42. Second-order exclusionary reasons are reasons for excluding certain first-order reasons. Raz, pp. 35-40. 
duty-bearing states, ought to have intervened to prevent or halt the genocide in Rwanda. This all things considered ought judgment is based upon the duty we bear, individually and collectively, to protect each individual's basic right to security. In the case of the Rwandan genocide, fulfillment of this duty required that the international community intervene to prevent or stop the genocide and the circumstances were such that there was an obligation to do so. The normative framework of international relations should have allowed states to take such moral obligations into consideration, but did not. As a result, while the international community stood idly by, the Hutu extremists were allowed to slaughter hundreds of thousands of innocent men, women, and children. 


\section{Chapter 2 - The Current Debate Over Humanitarian Intervention}

\subsection{Introduction}

Are there any circumstances under which humanitarian intervention is an all things considered moral obligation? Normatively prior to any such obligation, however, is permissibility. If humanitarian intervention is not morally permissible, then the discussion of obligation is moot. In this chapter I will focus on the debate over the moral permissibility of humanitarian intervention. The identification and explication of various objections to the moral permissibility of humanitarian intervention serves two purposes:

1. To provide background information for the succeeding discussion; and

2. To identify the relevant aspects of various objections to be incorporated in the identification of the conditions under which no one could reasonably deny that an obligation of humanitarian intervention exists.

What do I mean by humanitarian intervention? As Stephen A. Garret has pointed

out,

The terms "humanitarian" and "intervention" are typically embued with such a variety of nuances and differing interpretations that to join them together into a single concept almost inevitably produces ambiguity and perhaps even tension, especially since both words inherently carry a lot of emotional baggage. ${ }^{66}$

For the purpose of my project, I will accept a definition offered by J. L. Holzgrefe.

Humanitarian intervention is

the threat or use of force across state borders by a state (or group of states) aimed at preventing or ending widespread and grave violations of the fundamental human rights of individuals other than its own citizens, without the permission of the state within

${ }^{66}$ Stephen A. Garrett, Doing Good and Doing Well: An Examination of Humanitarian Intervention (Westport, Connecticut: Praeger Publishers, 1999), p. 1. 
whose territory force is applied. ${ }^{67}$

It is important to note that the definition offered does not require that the only motivation for intervention is humanitarian. It would be disingenuous, however, to call an intervention humanitarian if humanitarian considerations were not determinative of the choice to intervene.

\subsection{Skepticism Over International Morality}

One additional matter that must be addressed before I can turn my attention to the current state of the debate over the moral permissibility of humanitarian intervention is skepticism over the possibility of international morality. Such skeptical arguments rest on the proposition that morality doesn't apply (normatively or descriptively) to states or the international community, or at least not in the same way it does to individuals. If such arguments are correct, then discussion of the moral permissibility of humanitarian intervention is chimerical. I need not, nor do I intend to, demonstrate that such arguments are flawed; I need only demonstrate that such arguments do not preclude the possibility of an international morality.

\subsubsection{Descriptive Political Realism}

The descriptive political realist is the most skeptical over the relevance of international morality to international relations. The skepticism of the political realist is based on the proposition that all forms of prescriptive normative theory are inapplicable to the relations between states. ${ }^{68}$ The philosophical foundations for descriptive political

${ }^{67}$ J.L. Holzgrefe, "The Humanitarian Intervention Debate," from Holzgrefe and Keohane, Humanitarian Intervention: Ethical, Legal, and Political Dilemmas, p. 18.

${ }^{68}$ Roger D. Spegele, Political Realism in International Theory (Cambridge: Cambridge University Press, 1996), p. 19. 
realism are found in Thucydides" "Melian Dialogue" where it is claimed that the relations between states are defined by each state's desire for power and promotion of its selfinterest. It is the hierarchical relations of power that determine what will or will not happen in the international arena. ${ }^{69}$ Thus, according to the descriptive political realist, international relations is a descriptive enterprise that should be focused on understanding these power relationships and the behavior they cause and ought not be concerned with what states ought or ought not do. ${ }^{70}$

Since the skepticism of the descriptive realist is based upon the claim that normative theory is irrelevant to understanding international relations, if states are capable of acting on the outcomes of practical deliberation which are normative judgments, the skepticism fails. The actual behavior of states in the international arena would seem to indicate that states can and often do engage in practical deliberation and act on normative judgments. The realist bears the burden of explaining why normative theory is in actuality irrelevant to our understanding of this phenomena.

It may be claimed that this apparent capacity to act on the outcome of practical deliberation is nothing more than epiphenomena - the babbling of the brook. For the descriptive realist to be correct, however, it must be the case that states are incapable of doing anything but acting in accordance with the imperatives of power. Failures to do so are an indication that states are capable of acting in ways other than in accordance with such imperatives. The fact that states do often fail to act according to the imperatives of

${ }^{69}$ Thucydides, pp. 400-408. See also Mervyn Frost, Ethics in International Relations: A Constitutive Theory (Cambridge: Cambridge University Press, 1996), pp. 53-54.

${ }^{70}$ Morgenthau, p. 5. See also Frost, p. 53. 
power undermines the claim of the descriptive realist.

In addition, for the skepticism of the descriptive realist to be correct, the imperatives of power must govern the actions of states much like the laws of physics govern the interactions of physical objects. ${ }^{71}$ However, when we talk about the actions of states we are talking about the actions of governments that control such states, and not about natural forces. Governments are comprised of individuals making decisions. ${ }^{72}$ The actions of governments are based upon those decisions which involve the weighing and balancing of reasons for action. Thus, to the extent that individuals are capable of acting for reasons, so too are governments. It may be the case that more often than not states do act according to the imperatives of power, but they only do so after it has been determined that this is how they ought to act. The stringent skepticism of the realist fails to preclude the possibility of international morality.

It should be noted that what I am arguing for is not a matter of determining preferences. The importance of this disclaimer is derived from the strength of Kenneth Arrow's "Impossibility Theorem." ${ }^{.73}$ States can act on normative reasons even if such reasons are not based on the determination of a social preference. In addition, Arrow's theorem was intended to demonstrate the impossibility of devising a method of aggregating individual preferences into a social preference. I am concerned with our

${ }^{71}$ Frost, p. 54 (that Kenneth Waltz argues that international relations is a "spontaneous system" beyond the control of individual agents and states). See also Morgenthau, p. 245 (that the rejection of normative theory is inevitable).

${ }^{72}$ Gerald Elfstrom, Ethics for a Shrinking World (New York: St. Martin's Press, 1990), (that agents that comprise institutions can change the goals, policies, and actions of the institution), p. 31 .

${ }^{73}$ See Kenneth Arrow, Social Choice and Individual Values, $2^{\text {nd }}$ ed. (New York: Wiley, 1963). 
moral obligations, not our preferences. However, if the determination of a preference is required for an agent to act, and I am not making a claim about whether it is or not, one might contend that our inability to identify the preference of a state undermines the claim that states can act and deliberate in ways similar to individuals. ${ }^{74} \mathrm{I}$ am not, however, making the claim that states act and deliberate like individuals; rather, the decision to act by a state is made by individuals, and as such, is capable of being influenced by normative considerations.

\subsubsection{Normative Realism}

The normative realist concedes that normative theory has an important role to play in the relations between states. ${ }^{75}$ However, the normative realist argues that, due to the fact that international relations is like a Hobbesian state of nature, the demands of morality are not applicable to states in the international arena. ${ }^{76}$ For Hobbes, the state of nature is a pre-societal condition in which the inhabitants are in a constant state of war. ${ }^{77}$ Individuals would do better if they would all adhere to the demands of justice; however, it would be irrational for an individual to act on such demands without assurance that others would do so as well. ${ }^{78}$ What is needed, according to Hobbes, is a common power to

\footnotetext{
${ }^{74}$ I want to thank Joe Oppenheimer. His identification of the ambiguity in my claim brought to light a potentially troubling confusion.

${ }^{75}$ Spegele, p. 19.

${ }^{76}$ Cohen, p. 319. See also Gordon Graham, Ethics and International Relations (Oxford: Blackwell Publishers, 1997).

${ }^{77}$ Thomas Hobbes, Leviathan (1651) (Oxford: Oxford University Press, 1996), Ch. 13, pp. 82-85.

${ }^{78}$ Ibid., Ch. 14 p. $86-89$.
} 
enforce the demands of justice. ${ }^{79}$ Without such a common power each individual's liberty right to self-preservation is paramount. ${ }^{80}$ Thus, the fundamental prescriptive norm in the state of nature is prudence, and the demands of justice and morality are inapplicable until a common power is established that can enforce such demands. ${ }^{81}$

Since there is no world sovereign to enforce the demands of justice and morality the international arena is like a Hobbesian state of nature. ${ }^{82}$ As Hobbes notes in his discussion of international relations, "The notions of Right and Wrong. Justice and Injustice have there no place. Where there is no Common Power, there is no Law, no Injustice. Force and Fraud, are in warre the two Cardinall Vertues." ${ }^{93}$

Two conditions must be met for the normative realist's skeptical argument to succeed. First, it must be the case that the Hobbesian argument about the role of morality in the state of nature is correct. Second, for the analogy to hold it must be the case that states in the international arena are analogous to individuals in the state of nature. The normative realist fails on both accounts. First, the Hobbesian argument is supposed to demonstrate either that the demands of justice don't exist in the state of nature, or that such demands are perpetually ineffective without the assurance of a common power. Regarding the claim that assurance is a necessary condition for the existence of justice, the possibility that the demands of justice might conflict with the liberty right of self-

\footnotetext{
${ }^{79}$ Ibid., Ch. 13, p. 84.

${ }^{80}$ Ibid., Ch. 14, pp. 86-89.

${ }^{81}$ Ibid., Ch. 14, p. 87.

${ }^{82}$ See Beitz, p. 32. See also Cohen, p. 319. See also Gordon Graham, Ethics and International Relations (Oxford: Blackwell Publishers, 1997).

${ }^{83}$ Hobbes, Ch. 13, p. 85.
} 
preservation does not demonstrate that such demands don't exist. All that can be claimed is that self-preservation trumps or outweighs such demands if and when they conflict.

As to the argument that Hobbes has demonstrated the demands of justice to be perpetually ineffective in the state of nature, this argument is based upon the proposition that for the demands of justice to be effective one needs to be assured that others will also adhere to the demands of justice. For Hobbes, the fundamental right of nature is the right of self-preservation - "By all means we can, to defend ourselves." ${ }^{.84}$ It is this right that, depending on the circumstances, either leads to or trumps the fundamental law of nature, "to seek Peace, and to follow it." ${ }^{"}$ For Hobbes, what needs to be assured before the demands of justice are practically effective is self-preservation. If such assurance is required, for it to be the case that morality is ineffective in the state of nature it must be the case that such assurance cannot be attained in any instance in which the demands of justice would arise, and that the only way to have such assurance is through the establishment and maintenance of a common power.

Regarding the former condition, the assurance required is too demanding. It is highly unlikely that even a common power could provide such assurance. However, if Hobbes means something less, it does not follow that such lesser assurance could never be had in the state of nature. It is certainly possible, and I would contend reasonable, to expect that on at least one occasion in the state of nature two individuals could meet and be assured that neither was a threat to the self-preservation of the other. As to the latter condition, Hobbes's argument demonstrates how a common power might be good at

\footnotetext{
${ }^{84}$ Ibid., Ch. 14, pp. 86-87.

${ }^{85}$ Ibid.
} 
delivering the requisite assurance, but Hobbes fails to demonstrate that a common power is necessary or sufficient for such assurance.

Lastly, even if the Hobbesian argument regarding the role of justice and morality in the state of nature is correct, for the skepticism of the normative realist to be correct the analogy between individuals in the state of nature and states in the international arena must hold. Charles Beitz has identified four criteria which must be met for "this analogy to be acceptable". ${ }^{86}$ Specifically, Beitz claims that,

1. The actors in international relations are states. 2. States have relatively equal power (the weakest can defeat the strongest).

3. States are independent of each other in the sense that they can order their internal (i.e., nonsecurity) affairs independently of the internal policies of other actors.

4. There are no reliable expectations of reciprocal compliance by the actors with rules of cooperation in the absence of a superior power capable of enforcing these rules. ${ }^{87}$

It is important to note that for the analogy to hold it must be the case that as a matter of fact the four conditions identified by Beitz are met, and not just that they could be met.

Beitz notes that the "radical individualism of Hobbes's state of nature helps to make plausible the prediction of a resulting state of war because it denies the existence of any other actors ... that might mediate interpersonal conflict, coordinate individuals' actions, insulate individuals from the competition of others, share risks, or encourage the formation of less competitive attitudes." ${ }^{188}$ States, however, are not the only actors in the

${ }^{86}$ Beitz, p. 36.

${ }^{87}$ Ibid.

${ }^{88}$ Ibid., p. 37. 
international arena; consequently, the first condition is not met. ${ }^{89}$ Beitz points out that the second condition, that states "have relatively equal power", is also unsupported by empirical facts. ${ }^{90}$ Even the proliferation of nuclear weapons has failed to render the power states have sufficiently equal. ${ }^{91}$ Beitz points to the economic interdependence of states to demonstrate how the third condition is not fulfilled, and specifically to how the domestic economy of one state can be drastically affected by the domestic economic and political affairs of another state. ${ }^{92}$ Lastly, regarding the condition that there must be "no reliable expectations of reciprocal compliance by the actors with rules of cooperation in the absence of a superior power capable of enforcing these rules," Beitz notes that international relations are "characterized by high degrees of voluntary compliance with customary norms and institutionalized rules. ${ }^{93}$ Such compliance and the expectations that underlie it are had without a common power. The skeptical argument of the normative realist fails.

\subsubsection{The Humeian Objection}

Justice for Hume is instrumental and conventional. ${ }^{94}$ Like Hobbes, Hume

${ }^{89} \mathrm{Ibid}$., p. 37 (that it is obvious that there have been "coalitions, alliances, and secondary associations").

${ }^{90}$ Ibid., p. 40-42.

${ }^{91} I b i d .$, p. 41.

${ }^{92}$ Ibid., pp. 42-43.

${ }^{93}$ Ibid., pp. 46-47.

${ }^{94}$ Hume, A Treatise 3.2.1, pp. 307-309. 
contends that there is no justice or injustice in the state of nature. ${ }^{95}$ However, for Hume, justice does not require a sovereign or common power, rather justice requires a conventional agreement providing protection for private property, and the stability of possessions. ${ }^{96}$ The agreement is binding because having such stability of possessions is better for everyone involved. ${ }^{97}$

It is not clear whether Hume intends his argument to be about the existence conditions for justice or an argument about the necessary conditions for justice to be applicable. If the former the following must be true. First, it must be the case that justice does not arise unless there exists the stability of possessions. Second, that such stability can only be attained through conventional agreement. It is not clear that Hume has provided the necessary support for either proposition. Even if Hume is correct, Hume's argument only applies to distributive justice. Thus, it remains to be demonstrated either that distributive justice exhausts the domain of justice or that the existence of justice as it relates to the harm to or help owed to others is dependent on a similar conventional agreement.

On the other hand, Hume states, "[b]y rendering justice totally useless, you thereby totally destroy its essence, and suspend its obligation on mankind."98 This is a claim about the practical effectiveness of justice, and not whether it exists. The claim must be that for justice and the moral demands it makes to be applicable, there must be a

${ }^{95}$ Hume, A Treatise 3.2.3, p. 322. See also Hume, An Enquiry Section III, pp. 18, 19 (that there is no justice in a society of ruffians).

${ }^{96}$ Hume, A Treatise 3.2.1, pp. 308-309.

${ }^{97}$ Ibid.

${ }^{98}$ Hume, An Enquiry Section III, p. 19. 
convention which provides for the stability of possessions. At best, Hume has

demonstrated that distributive justice requires a conventional basis: he has not, however, demonstrated that distributive justice exhausts justice. He has also failed to argue that we are morally permitted to harm others or not help them unless there is a conventional agreement to the contrary. It may be the case that having a convention makes it more likely that individuals will respect justice and the moral demands it makes, but it is not clear that a conventional agreement is necessary for justice to be applicable.

Hume, however, denies that the international arena is like a Hobbesian state of nature. Rather, Hume contends that the international arena is a society governed by a set of conventional rules. ${ }^{99}$ However, as Marshall Cohen points out, Hume contends that the moral demands implied by justice that apply in international morality are weaker. ${ }^{100}$ Specifically, Cohen states,

Since the mutual interest in abiding by the fundamental rules of justice is weaker, the moral obligation arising from it must partake of this weakness and we must necessarily give greater indulgence of a prince or minister who deceives another than to a private gentleman who breaks his word of honor. ${ }^{101}$

Hume allows for international morality. However, as Hume's understanding of justice is conventional, the scope of justice under Hume's understanding is determined by the convention upon which justice is based. Justice in the international arena, according to Hume, is based upon a conventional agreement amongst sovereigns. Even if Hume is correct in claiming that justice in the international arena is not as stringent as in domestic

${ }^{99}$ Hume, A Treatise 3.2.11, pp. 362-364. See also Cohen, pp. 329-331.

${ }^{100}$ Cohen, p. 329.

${ }^{101}$ Ibid., pp. 330-331. See also Hume, A Treatise 3.2.11, pp. 362-364. 
society, this fails to preclude the possibility of an international morality.

\subsection{The Debate Over Humanitarian Intervention}

Returning to the question whether humanitarian intervention is ever morally justified, the noninterventionist argues that there are moral considerations that weigh decisively against intervention. This is not to say that noninterventionists deny that an injustice is being done, nor do they claim that no action should be taken. Rather, the contention is that even if an injustice that demands action is occurring, military intervention is impermissible. ${ }^{102}$

In the discussion that follows I will address and outline a number of noninterventionist objections and arguments. Though I do not answer these arguments I do explain why I take certain objections and their underlying arguments to be irrelevant to the debate over the moral justifiability of humanitarian intervention.

\subsubsection{The Obligation to Obey International Law as an Objection to Humanitarian Intervention}

It is claimed by some that states have a legal obligation to refrain from interfering in the internal affairs of other states, and since there is a moral obligation to obey the law, there is an obligation to refrain from humanitarian intervention. There are three distinct arguments upon which this contention may rely. I will deal with two of these arguments in this section, and bracket a discussion of the third argument until later as it is an instrumental argument, and I will discuss such arguments below. ${ }^{103}$

102 Teson, p. 95.

${ }^{103}$ In this particular case, international law is intended to provide international peace and security. It is claimed that such goals are best served by a prohibition on intervention. See Smith, p. 274. 
The first argument is one alluded to by Fernando Teson, but not fully explored in his discussion. ${ }^{104}$ The argument is based on the claim of certain legal positivists that there is an inherent obligation borne by the subjects of a system of laws to obey the laws of that system. ${ }^{105}$ It is important to note that the positivist argument with which I am presently concerned is but one positivist account, as understood by Teson, amongst many. The obligation to obey in this instance is not a moral obligation, but an explicitly legal one. The legal obligation is a second-order exclusionary reason. ${ }^{106}$ More importantly, it is claimed that legal obligations are content-independent and that "they require the subject to set aside his own view of the merits and comply nonetheless." ${ }^{107}$ In the case of humanitarian intervention, it is contended that international law prohibits humanitarian intervention, and from this it is concluded that states should abide by the legal demand that they not intervene for humanitarian reasons rather than consider each case on its own merits.

There are a number of problems with this argument. First, as Leslie Green points out, that legal obligations should supplant the reasoning of the subjects of the law is a

\section{${ }^{104}$ Teson, p. 111.}

${ }^{105}$ See Leslie Green, "Legal Obligation and Authority", The Stanford Encyclopedia of Philosophy (Spring 2004 Edition), Edward N. Zalta (ed.), URL = $<\mathrm{http} / /$ plato.stanford.edu/archives/spr2004/entries/legal-obligation/>, p. 3. See also H.L.A. Hart, "Legal and Moral Obligation," in A.I. Melden, ed., Essays in Moral Philosophy. (Seattle: University of Washington Press, 1966), pp. 82-107; and see Hart, Essays on Bentham (Oxford: Clarendon Press, 1982), pp. 254-255.

${ }^{106}$ Green, p. 3. The exact nature of second-order exclusionary reasons will be discussed in greater detail below. However, it should suffice for my present purposes to note that such reasons preclude the consideration of other reasons. More importantly, the reasons precluded may be, in isolation from the exclusionary reason, relevant to the practical issue being decided.

${ }^{107}$ Ibid. 
claim of the law. ${ }^{108}$ But, is the claim justified? To answer this question one must engage in an evaluation of the merits of the law's claim that it ought to be followed simply because it is the law. In so doing, one evaluates the underlying substantive bases for the law's claimed authority, thus undermining the claimed content-independence of legal obligations. If the positivist is correct, and legal obligations are pre-emptive, it is a descriptive fact about existing law. The question of the moral justifiability of humanitarian intervention is left unaddressed. Humanitarian intervention is only contingently legally impermissible. If the law were otherwise, then humanitarian intervention might be permissible. If, in particular cases, there is a moral obligation to intervene for humanitarian reasons then perhaps the law should be changed. ${ }^{109}$

Lastly, the argument requires that the law is clear on the matter of humanitarian intervention. This is far from the truth. Looking first to treaty law as a source of international law, though the U.N. Charter and other instruments of international law express a prohibition on intervention, many other treaties and conventions - the Universal Declaration of Human Rights and the Convention on the Prevention and Punishment of the Crime of Genocide - emphasize the importance of human rights and expressly permit action for humanitarian reasons.

The second argument is based upon the claim that states have a moral obligation to obey international law and that international law prohibits such intervention. As Teson notes, this argument "locates the obligation to obey the law outside international law itself: there is a moral reason to comply with international law where doing so leads to

${ }^{108}$ Ibid., p. 3.

${ }^{109}$ Teson, p. 111. 
sometimes undesirable or even immoral outcomes."110 Here the moral obligation to obey the law is grounded in political authority and political obligation.

Thus, the question becomes, are states obligated to obey international law as a matter of political obligation? One might contend that states are under such obligations in much the same way an individual in domestic society might be. The most widely discussed theories of political obligation come in two forms - non-voluntarist and voluntarist theories. ${ }^{111}$ The non-voluntarist theories share one common feature that makes them an unlikely source of political obligations for states in the international arena. As Green notes, "[a] theory of political obligation is non-voluntarist if its principles justifying legal authority do not invoke the choice or will of the subjects among its reasons for thinking they are bound to obey."112 International law is grounded in the express or tacit consent of states - the laws themselves depend for their existence on specific consent to the demands of particular laws or the expression of such consent through the treatment of custom and practice as law. For this reason I will not discuss non-voluntarist arguments further.

Alternatively, voluntarist theories are based on the proposition that political obligations could be grounded in the subjects' voluntary assumption of such obligations. Two of the most prominent theories are the consent theories of Hobbes ${ }^{113}$ and Locke. ${ }^{114}$

${ }^{110}$ Ibid., pp. 108-109.

${ }^{111}$ Green.

${ }^{112}$ Ibid., p. 7.

${ }^{113}$ Hobbes, Ch. 17.

${ }^{114}$ John Locke, Two Treatises of Government (1698) (Cambridge: Cambridge University Press, 1988), Ch. 8. 
The common feature of such theories is that the subject agrees to give up its rights to a sovereign for regulation and adjudication. It is this aspect of consent theory that renders it inapplicable for international law. There is no such sovereign of the appropriate sort in international law.

A more promising approach would be one based upon H.L.A. Hart's claim that "when a number of persons conduct any joint enterprise according to rules and thus restrict their liberty, those who have submitted to these restrictions when required have a right to a similar submission from those who have benefitted by their submission." 115 As Leslie Green points out, however, this is not enough to give rise to an obligation, for it may be the case that the beneficiary was either an unwilling beneficiary or unaware of the enterprise, in which case it would be unreasonable to require that the beneficiary contribute to or adhere to the rules of the enterprise. ${ }^{116}$ For this reason, Green notes that such benefits must be accepted if they are to give rise to an obligation.

I will assume that states in the international arena are engaged in a joint enterprise governed by rules, that the enterprise provides states with benefits that they accept, and that one of the rules governing the enterprise is a prohibition on intervention. For the sake of argument, I am ignoring the changing and ever-evolving character of the "they" who are members of the enterprise. ${ }^{117}$ I am seeking to present the argument in its strongest form. In so doing, I hope that my criticisms carry greater weight. Even making such assumptions, the argument still fails to demonstrate that intervention for

${ }^{115}$ H.L.A. Hart, “Are There Any Natural Rights?” The Philosophical Review, Vol. 64, No. 2 (Apr., 1955), pp. 175-191, 185.

${ }^{116}$ Green, p. 12.

${ }^{117}$ I must credit Joe Oppenheimer with this potential criticism. 
humanitarian reasons is morally impermissible. Even if states do bear political obligations to adhere to the demands of international law as a matter of fairness, this again assumes that the law on humanitarian intervention is clear. Second, fairness would only seem to demand adherence to those rules related to the benefit provided. The ostensible benefit provided by international law is international order. At first glance, it may seem that nonintervention is related to the provision of international order; however, if we assume that one of the reasons for seeking international order is that it is necessary for individuals to enjoy their human rights or that international order is instrumental to human flourishing, refraining from intervening in cases where mass violations of basic human rights are occurring would undermine, not promote, those goals.

Third, unlike the positivist argument discussed above, the political obligation from fairness is but one moral obligation amongst many. It does not supplant the agent's evaluation of the merits of the case; rather the moral obligation to obey the law is merely an additional moral obligation to be taken into consideration by the agent in its practical deliberations. For it to be the case that such an obligation renders intervention for humanitarian reasons morally impermissible, it must be the case that such obligations exhaust the moral space, or that they always outweigh other competing moral obligations. It is doubtful that obligations of fairness that arise between states exhaust the relevant moral space especially when it comes to the treatment of individuals. Such an obligation does not preclude from consideration countervailing moral considerations weighing in favor of humanitarian intervention.

In addition, the strength of the obligation to which the principle of fairness gives rise must depend on the value of the purpose or goal of the enterprise. A conspiracy to 
commit murder may provide each member of the conspiracy with some obligation owed to others in the conspiracy who have already carried out their obligations according to the rules of the conspiracy, but the strength of that obligation is weakened by the very purpose of the enterprise. So, even if we assume that international order is the benefit to be provided by international law, the strength of the obligation to obey the law will depend on the value of promoting international order in any particular instance.

In the end, we can concede that states can have political obligations, and that they are demands of fairness; yet it is not the case that such demands render intervention for humanitarian reasons morally impermissible. The question of the moral permissibility of humanitarian intervention can not be circumvented by arguments in support of the claim that there is a legal obligation borne by states to obey international law.

\subsubsection{Relativism, Communitarianism, and the Instrumental Argument as Objections to the Moral Justifiability of Humanitarian Intervention.}

I turn now to an explication of the relativist, communitarian, and instrumental objections to the moral permissibility of humanitarian intervention. The relevant notion of relativism is based upon the proposition that there are no moral principles accepted by all cultures (cultural relativism), and the further proposition that the validity of moral claims is dependent on cultural acceptance. ${ }^{118}$ From these two premises the relativist concludes that there are no universal moral principles, and that morality is simply what the relevant society or culture says is right or wrong, good or bad.

The relativist objection would run as follows: The rationale underlying

${ }^{118}$ See James Rachels, The Elements of Philosophy, $3^{r d}$ Ed. (Boston: McGraw-Hill College, 1999), pp. 22-25. See also Chris Gowans, "Moral Relativism", The Stanford Encyclopedia of Philosophy (Spring 2004 Edition), Edward N. Zalta (ed.), URL = $<$ http://plato.stanford.edu/archives/spr2004/entries/moral-relativism/>. 
humanitarian intervention involves an external moral judgment about the immoral or unjust nature of certain internal practices being engaged in by a state or society. Therefore, to be morally justified, humanitarian intervention requires that the moral judgment be based on moral principles that are culturally neutral. This condition could be fulfilled by principles that are based on an overlapping consensus, or it could be fulfilled by principles that are universally valid. According to the moral relativist, however, cultural relativism is true, and there is no overlapping consensus upon which culturally neutral principles could be found. Validity for the relativist depends on cultural acceptance; consequently, if there is no overlapping consensus, the possibility of universal validity is precluded. As a consequence, there is no possibility of a moral justification for humanitarian intervention.

There are numerous reasons for rejecting the claims of the moral relativist. First, the implications of the relativist argument are uninviting. There would be no basis for cross-cultural dialogue about the morality of particular practices. More importantly, there would be no basis for moral judgment regarding violations of individual freedom and security, provided the underlying practices are culturally accepted. For example, if the slavery of a minority is culturally accepted, or the culture accepts forced female genital mutilation of twelve year old girls, then those practices are beyond moral reproach both internally and externally. More pertinent to this project, it seems absurd to think that cultural acceptance could make genocide moral.

There are also numerous conceptual problems with moral relativism, many of which the reader is no doubt familiar. Here I will mention only one - What is required for cultural acceptance? It can't be enough that the practices engaged in by the state, 
and/or the empowered are not met with open resistance. If that were the case, a brutal dictator with a small but efficient military could terrorize a people into submission through violent oppression, and such coercive actions would morally justify themselves.

But what counts? A bare majority of the population? A consensus? In a pluralist society is a single individual's choice of what is moral or immoral, right or wrong, sufficient?

Does the acceptance have to be informed or rational? At the very least, it would seem to be necessary that all affected by the practice are informed, uncoerced, and maintain an internal perspective with regards to the practice - meaning that they acknowledge the rightness of the practice and that they would criticize others for not adhering to the practice. $^{119}$

In addition, both premises upon which the moral relativist objection is based are open to criticism. Cultural relativism is not uncontroversial. Some point to the fact that the Universal Declaration of Human Rights was passed without a single dissenting vote. Others claim that the relativist position is often raised by those in power who benefit from the very practices being scrutinized, and that there is much greater consensus than the oppressors would have us believe. Lastly, cultural relativism is an empirical claim about the comparative situation of various moral codes throughout the world. If overlap between those codes exists then cultural relativism fails to preclude shared moral beliefs.

The second premise is also highly suspect. It is a claim about the nature of morality and justice. Unlike cultural relativism which is either true as a matter of descriptive fact or it is not, the claim that moral validity depends on cultural acceptance

\footnotetext{
${ }^{119}$ H.L.A. Hart, The Concept of Law, Second Edition (Oxford: Oxford University Press, 1994), pp. 56-57.
} 
requires an argument. Simply relying on the descriptive fact of cultural relativism, assuming it is true, is not enough. The argument for the second premise must demonstrate that the truth of a theory or explanation relies on the acceptance of the culture in which the theory or explanation is proposed. We would never accept such a claim in the sciences. For example, string theory is either true or it is not. Neither agreement nor disagreement on its validity settles the issue.

The relativist might object that science provides us with a method for determining the truth or falsity of the claims made by those in the field, but that there is no such analog in ethics. Such a claim, however, would rely on the very conclusion the relativist is seeking to prove - that there are no universal moral truths, only culturally valid moral truths, and thus no possibility of cross-cultural criticism and dialogue. It is through the proffering, criticism, and defense of moral judgments that we test our moral judgments. The relativist cannot rely on the truth of relativism to prove the truth of an underlying premise.

But what can we learn from relativism? There is diversity and disagreement amongst the moral codes of the world. The fact that such disagreement exists is relevant because it raises doubts about the correctness of our moral judgments. However, it would be impractical and inappropriate to require certainty in such matters. Rather, in cases of disagreement over a moral principle or its application we should test its validity by assessing whether anyone could reasonably reject the principle at issue. ${ }^{120}$ In the end, I believe this will provide an account of what Michael Walzer has called "thin" morality -

${ }^{120}$ T. M. Scanlon, What We Owe to Each Other (Cambridge, Massachusetts: Harvard University Press, 1998), pp. 191-197. A more detailed explication of my use of reasonable rejection to will be provided in the succeeding chapters. 
the moral minimum that we owe to one another. ${ }^{121}$

Turning now to the communitarian objection, there are a variety of communitarian arguments, but they share at least two things in common. Communitarians contend that the emphasis of liberal theorists on individual liberty as the paramount moral and political concern is misplaced, and that the value of community and communal rights should be given greater weight in our moral and political reasoning. ${ }^{122}$ The second shared characteristic is that the value of community is based upon the claim that community is necessary to individual human flourishing. ${ }^{123}$

Michael Walzer contends that the "state is presumptively, though by no means always in practice, the arena within which self determination is worked out and from which, therefore, foreign armies have to be excluded."124 The underlying argument offered to justify the presumption is based upon Walzer's contention that individuals have a right to develop or determine the community in which they live, ${ }^{125}$ and that for the purposes of international relations the state should be presumed to fit with the community

${ }^{121}$ Michael Walzer, Thick and Thin: Moral Argument at Home and Abroad (Notre Dame: University of Notre Dame Press, 1994).

${ }^{122}$ See Jean Hampton, Political Philosophy (Boulder, Colorado: Westview Press, 1997), p. 170. See also Michael Sandel, Liberalism and the Limits of Justice (Cambridge: Cambridge University Press, 1982) (that liberal views are based upon abstracted notions of individuals that abstract away anything that defines the lives of real people), p.187.

${ }^{123}$ Hampton, p. 183. See also Alisdair MacIntyre, After Virtue (Notre Dame: Notre Dame University Press, 1981) (that individuals can only flourish within a community), p.187.

${ }^{124}$ Michael Walzer, "The Moral Standing of States”, pp.209-229, p. 210.

${ }^{125}$ Ibid., p. 211. 
and thus be a result of the exercise of the rights of individuals. ${ }^{126}$ The presumption of fit between the state and the community is justified, according to Walzer, because foreigners have "no direct experience" of the development of the community. ${ }^{127}$ Walzer further contends that this presumption leads to another which also weighs against intervention that if an intervention were attempted those residing in the state would feel obligated to defend the state. ${ }^{128}$

As Walzer admits, his argument fails to support an absolute prohibition on humanitarian intervention. ${ }^{129}$ If I was not so concerned with explaining the deficiencies in his argument, I might agree with much of Walzer's conclusion. Humanitarian intervention is impermissible, according to Walzer, due to the presumptive fit between the people as a community and the government. If there is no fit then intervention for humanitarian reasons could be morally permissible. However, since we in the outside world don't have "direct experience" of the cultural, moral and historical development of the community we must presume that such fit exists unless it is "radically apparent" that it does not. ${ }^{130}$ For Walzer, such a lack of fit is radically apparent when any one of his three "rules of disregard" are applicable. ${ }^{131}$ Most relevant to the debate over humanitarian intervention is Walzer's rule that "interventions can be justified whenever a government

\footnotetext{
${ }^{126}$ Ibid., p. 228.

${ }^{127}$ Ibid., p. 212.

${ }^{128}$ Ibid.

${ }^{129}$ Ibid.

${ }^{130}$ Ibid., p. 214.

${ }^{131}$ Ibid., pp. 216-218.
} 
is engaged in the massacre or enslavement of its own citizens or subjects." ${ }^{{ }^{132}}$

David Luban has pointed out many of the gaps in and flaws of Walzer's reasoning, as well as the problematic nature of many of Walzer's empirical and historical assumptions. ${ }^{133}$ For the purposes of the present discussion I would like to focus on Luban's concession to Walzer that "the lack of fit between government and people should be 'radically apparent' to justify intervening, because intervention based on misperception is horribly wrong." ${ }^{134}$

Walzer and Luban agree that community is important, and that if there does exist a fit between the individuals as a community and the government that this is at least a weighty, if not pre-emptive, reason weighing against intervention. They further agree that the lack of fit which might permit humanitarian intervention has to be known to a great degree of certainty.

Walzer and Luban disagree, however, over Walzer's epistemic justification for the presumption that the requisite fit exists between the community and the government. Walzer contends that the international community must presume the fit exists. Luban accepts that in some circumstances under which we do not have access to information about a particular community and its relation to its government we should give the government the benefit of the doubt, but this is not the same as a general presumption that we are always ignorant. ${ }^{135}$ As Luban points out, in most cases we do have access to the

${ }^{132}$ Ibid., p. 217.

${ }^{133}$ Luban, "Romance of the Nation-State," pp. 392-397.

${ }^{134}$ Ibid., p. 395.

${ }^{135}$ Ibid., p. 395. 
information relevant to the determination of fit, thus Walzer's presumption is unjustified. For that reason, whether or not such fit exists should be treated as an open question.

The last objection to the moral permissibility of humanitarian intervention that I would like to address is instrumental in nature. It is claimed that achieving and maintaining international peace and security requires a rule against intervention. To understand this objection one must first understand what is meant by international peace and security.

Understanding international relations as essentially concerned with the relations between states helps to understand the relevant notions of peace and security. ${ }^{136}$ A broad notion of peace could include peace internal to a state. This understanding of peace, however, is too broad. The relevant notion of peace presumes that the only relevant actors are sovereign states, and threats to the peace, are threats to the peace between states - "international peace." Similarly, international security refers to the security of a state from aggression or intervention. A state is secure if other states, individually or collectively, refrain or are prevented from engaging in either aggressive action toward the state or intervention into the internal affairs of the state.

If we understand the goal of international peace and security as essentially concerned with peace and security between sovereign states, it becomes readily apparent how a rule of nonintervention may be instrumental to achieving and maintaining international peace and security. In light of this understanding of international peace and security, the instrumental argument such as that found in Kant's claim that peace between states requires that "[n]o state shall forcibly interfere in the constitution and government

${ }^{136}$ Janis, p. 161 ("that the key actor on the world's stage was the sovereign state"). 
of another state" ${ }^{137}$ seems incontrovertible. Intervention into the internal affairs of another state is by its very nature a threat to the peace between and the security of states.

This argument is institutionalized in the Charter of the United Nations. Article 1 of Chapter I of the Charter identifies as one of the purposes of the United Nations the maintenance of international peace and security. ${ }^{138}$ Article 2 of that same chapter identifies as one of the principles which serves the purpose of maintaining international peace and security, a rule requiring each state to "refrain in their international relations from the threat or use of force against the territorial integrity or political independence of any State" - a rule of nonintervention. ${ }^{139}$

There are a number of questions begged by the instrumental argument. First, are the only relevant actors in the international arena sovereign states? If not, then international peace and security ought not be limited to the peace between and security of states. A second question comes from the fact that there are at least two possible interpretations of the argument, one strong and one weak. Is the relationship between the rule of nonintervention and international peace and security one of necessity or one of efficacy? The strong claim, which seems to be implied by Kant's statement, is that international peace and security is not possible without a rule against intervention. The weak claim is that a rule against intervention makes international peace and security more likely.

${ }^{137}$ Immanuel Kant, Toward Perpetual Peace from Immanuel Kant, Practical Philosophy, Mary J. Gregor, ed. (Cambridge: Cambridge University Press, 1996), pp. 311-351, p. 319.

${ }^{138}$ U.N. Charter Ch. I, art.1, para. 1.
${ }^{139}$ U.N. Charter Ch. I, art.2, para. 4. 
No matter how we answer the second question there are a number of questions related to the value of international peace and security. The rule of nonintervention, assuming that it is either weakly or strongly instrumental to international peace and security, is justified by the instrumental role it plays in achieving and maintaining the goal of international peace and security. Thus, the value of the rule of nonintervention is dependent on the value of international peace and security.

It is unlikely that either the weak or the strong interpretation of the instrumental argument will support an absolute moral prohibition on humanitarian intervention. Under the weak interpretation, there may be instances in which the goal of international peace and security could be served, or at least not be hindered, by intervention. Consequently, if we know that nonintervention will not serve international peace and security in a particular case and there are other moral considerations weighing in favor of intervention it would be morally permissible to intervene.

On the other hand, if the strong interpretation is adopted it needs to be demonstrated that international peace and security is the paramount moral consideration in the international arena and /or that it either precludes from consideration all reasons for intervention or invariably outweighs such considerations. This is an unlikely proposition that needs to be defended by the instrumentalist. It is far more likely that international peace and security is itself instrumental to other values such as the provision and protection of human rights, individual human flourishing, and communal rights. The best that the instrumentalist can hope for is a presumption of nonintervention not a prohibition. Nonetheless, what we do learn from the instrumentalist is that there is value in the state system. 


\subsection{Conclusion}

The underlying moral claim of this project is that there are circumstances under which no one could reasonably deny that a moral obligation of humanitarian intervention exists. However, for there to exist a moral obligation of humanitarian intervention it must be the case that humanitarian intervention is not morally prohibited. In this chapter various accounts ranging from the skepticism of the realists to a number of prominent objections to the moral permissibility of humanitarian intervention have been discussed. I have endeavored to demonstrate that none of these arguments support the conclusion that humanitarian intervention is either chimerical or morally prohibited. I have also sought to identify those salient features of such objections which will serve as the basis for the identification of considerations to be taken into account in the next chapter. Such features will be employed in the identification of the conditions under which no one could reasonably deny that a moral obligation of humanitarian intervention exists. 


\section{Chapter 3 - The Moral Obligation Of Humanitarian Intervention Defined}

\subsection{Introduction}

Having demonstrated that none of the arguments discussed in Chapter 2 show that humanitarian intervention is morally impermissible, I turn now to the identification of the conditions under which no one could reasonably deny that a moral obligation of humanitarian intervention exists. The argument and methodology employed is not unlike that used by Ernest J. Weinrib in his defense of a duty of easy rescue, wherein Weinrib sought to demonstrate that under certain circumstances an individual is under a duty to perform a rescue. ${ }^{140}$

The strength of this approach is found in the weakness of the principle defended. If we are ever to have an all things considered moral obligation to intervene it will be under the conditions I identify. If successfully defended, the resultant principle serves at least two important purposes. It would have implications for what states can be morally obligated to do in the international arena. In addition, it would serve as the gateway for broadening the debate over humanitarian intervention to include questions of the limits of the obligation to intervene.

In identifying the conditions under which no one could reasonably deny that a moral obligation of humanitarian intervention exists, I first identify the constitutive elements of the moral obligation at issue. In identifying the constitutive elements of an obligation one identifies the existence conditions for the obligation in question. ${ }^{141}$ The (1980).

${ }^{140}$ Ernest J. Weinrib, “The Case for a Duty to Rescue,” 90 Yale Law Journal 247

${ }^{141}$ Sumner (discussing the constitutive elements of a right), pp. 11, 13. 
identification of the constitutive elements is not intended as a set of sufficient conditions for the existence of an all-things-considered moral obligation of humanitarian intervention; rather they define the set of conditions sufficient for such an obligation to exist as a reason for action to be considered in the practical deliberations of states.

Having delineated the constitutive elements of a moral obligation of humanitarian intervention and provided a basis for the existence of such an obligation, I shift my focus to the determination of those additional conditions which may be required if, due to areas of reasonable disagreement, the obligation of humanitarian intervention is to be an all things considered moral obligation. Lastly, there are a number of objections that, though not raised as objections to the permissibility of humanitarian intervention, could provide the basis for an objection to a moral obligation to intervene in any particular instance.

\subsection{Why a Standard of Reasonable Deniability}

Before proceeding with a discussion of the constitutive elements of a moral obligation of humanitarian intervention, I think it prudent to discuss why I have chosen to employ a standard of reasonable deniability. Before explicating those reasons, it must be understood that the standard of reasonable deniability has both a weak and a strong implication for the resolution of a debate over a matter of moral disagreement. If we adopt the perspective of an individual defending their position, one need only be sure that one's position is not unreasonable. If this can be accomplished then one need not give up his position. This is a burden that is more easily overcome. However, if one is concerned with demonstrating that another's objection to one's position is unreasonable, one must demonstrate the unreasonableness of the objection, a much more difficult task.

One might contend that very little is gained by employing a standard of reasonable 
deniability. Specifically, one might contend that the proposed standard of reasonable deniability is merely a "stand-in" for a standard of wrongness, and that as a pragmatic matter there is nothing that distinguishes the one from the other. There is certainly some truth to this charge as reasonable deniability is intended to serve as a threshold for the justified rejection of a position held by another. Thus, reasonable deniability could be understood as a standard for determining when we are justified in claiming that another's position is wrong.

There are important differences, however, between a standard of wrongness simpliciter and a standard of reasonable deniability. If what we mean by a standard of wrongness is that the objector is objectively wrong, such a standard requires too much. I would certainly agree that if we know the other to be wrong, then we are justified in rejecting or ignoring their objection. However, we rarely have such epistemic certainty about a disputed matter of morality. Thus, if we were to employ a standard of wrongness we would not likely ever be justified in rejecting another's position.

Reasonable deniability, on the other hand, focuses instead on whether one's detractors and/or objectors are entitled to hold the position they do for the reasons they do. Such a standard does not require that we discern substantive wrongness to be justified in rejecting our detractors' or objectors' position. A standard of reasonable deniability is a matter of rationality, not objective truth. This should not be confused with the claim that reasonableness upon which the standard of reasonable deniability is based is the same as rationality. I will explain the difference below.

The fact that a standard of reasonable deniability is broader than a standard of wrongness does not undermine its strength. If an individual is not justified, for reasons of 
theoretical rationality or intersubjective justification, in holding the beliefs he / she does, it seems clear to me that we are justified in rejecting his / her position or objection. In other words, if one does not have good reason for believing $X$ or for believing certain implications one takes $X$ to have, then we are justified in rejecting his / her position based on $X$.

There are two reasons for my decision to employ this standard, one rhetorical and the other philosophical, both of which derive from the following considerations:

First, I presume that reasonable disagreement over the rightness or wrongness of humanitarian intervention exists; and, Second, one of the core purposes of this project is to make a case for an all things considered moral obligation to intervene which would convince skeptics who doubt the possibility of such an obligation.

Though certainly not a weighty analytic reason for employing a standard of reasonable deniability, there is good rhetorical reason for employing such a standard. As noted, one of the goals of this project is to justify the existence of a moral obligation of humanitarian intervention to skeptics. How the discussion over the existence of such an obligation is framed can have a dramatic effect on the nature of the dialogue. To claim that those who disagree with me are simply wrong because they disagree with me about certain fundamental matters turns the discussion into a confrontation.

The philosophical reason for employing a standard of reasonable deniability is grounded in the justificatory aspect of the project. It is apparent that there is significant, and often reasonable, disagreement over matters of morality. Recognizing the existence of such disagreement does not commit one to moral relativism. The existence of such 
disagreement does, however, heighten the importance of the burden of justification. In the case of actions that interfere with the lives of others, the intervener must be able to justify their action to those who would deny its moral permissibility, and to justify their action to those affected by the intervention.

I am well aware that this standard may simply beg the question as to what is reasonable or what counts as an unreasonable rejection or denial. I do not intend to answer that question fully here. However, to remove as much ambiguity as I can, I offer the following skeletal outline of the standard of reasonable deniability. Recalling the dual aspects of the standard - a reasonable basis for one's own position and a demonstration of that one's detractors have failed to be reasonable - one must understand what it means to be reasonable. First, though related to one another, the reasonable is not the same as the rational. As a standard of evaluation, the rational is a matter of understanding. In other words, to act rationally, or be rational in one's beliefs, there need only be the right sort of connection between one's bases for those beliefs or actions.

Reasonableness is a standard of evaluation that applies to both the beliefs that one holds and the implications that one takes those beliefs to have, including actions based on such beliefs. Whereas rationality is a matter of understanding others given their beliefs, reasonableness is a matter of justification that applies even to those beliefs that serve as the starting point for one's theoretical and practical deliberations. Rationality does have a role to play in assessing reasonableness. One way in which one can fail to be reasonable is if he / she is failing to be rational. The beliefs an individual holds, and the implications they take those beliefs to have, must meet certain minimum standards of theoretic rationality. 
In assessing the rationality of one's actions or beliefs, the question we are asking is whether in light of one's beliefs do their actions or other beliefs make sense? Take for example the following:

$A$ believes: $\quad$ If $X$, then $Y^{*}$;

$X$

Therefore $Y$

* $Y$ could be an action or a belief.

However, in reality, it could be the case that:

1. It is not the case that the claimed sufficient relationship between $X$ and $Y$ exists; and/or

2. It is not the case that $X$.

In either case $Y$ does not follow as a matter of substantive truth, but $A$ could be rational in both cases, provided $A$ is not aware of 1 . or 2 . We could understand $A$ 's contention that $Y$. Nonetheless, $A$ 's belief that $Y$ would be unreasonable.

Reasonable claims, beliefs, or actions are those that can be intersubjectively justified. What this means is that to be holding a reasonable belief we must be able to offer good reasons for our beliefs (upon which our actions and other beliefs are rationally based). This obviously begs the question as to what counts as a good reason. First, it must meet minimum standards of theoretic rationality. All that I intend this to mean is that the reason is coherent in relation to, and consistent with other reasonable beliefs; and that it is sensitive to new information - that it is subject to change if new information demonstrates that it is not a good reason.

In addition, due to the intersubjective nature of the standard of reasonableness, a 
good reason must be a reason that could be accepted by others. Here, "could" is not intended as mere possibility. An agent could accept any reason. Rather, what is meant is that one could accept the reason in light of their prior reasonably held commitments and beliefs. I am aware of the circle here, but I believe it to be a virtuous and not a vicious circle. What counts as reasonable, and offering reasons for our actions and beliefs, should be thought of as an ever-evolving process. The circular reasoning invoked here is both self-reinforcing and self-critical. To be reasonable one must offer reasons that others could accept given their own reasonable commitments.

Perhaps a more concrete example may help to explain what I mean by a standard of reasonable deniability. Imagine that Frank is a fan of his college football team. He always wears the same sweatshirt when he watches his team play. He believes that they will win if he puts on the sweatshirt at just the right time before the game starts. Frank's actions are rational because one could make sense of his actions based upon his subjective beliefs about his sweatshirt-wearing ritual. But Frank's actions are not reasonable. One need not accept Frank's underlying beliefs because they fail minimum conditions of theoretical rationality. In this particular instance his belief that his sweatshirt-wearing ritual affects the game is irrational, and for that reason his actions are unreasonable.

A more distinctively moral example may be in order to help explain how one might be unreasonable due to a failure to deliberate rationally. Such failures could include improper weighting of the options available, proper weighting but miscalculation, proper weighting and calculation but weakness of the will, or internal inconsistency. Imagine that an individual, Gertrude, is faced with a choice between saving her favorite 
car and saving a red-headed child. ${ }^{142}$ If she chooses the car because she believes her car is simply more valuable than the child's life, then one could reasonably reject her claim because her assessment of the relative weight of the competing values is unjustified.

What if Gertrude responds that she believes her evaluation to be correct. Is she being reasonable? Or, can you reject her position as unreasonable? One might contend that with regard to values it is impossible to make such determinations. Though I am not able to provide a determinative argument against this objection, there are a number of reasons which can be mustered to support my claim that Gertrude's weighting is improper, and that her position is unreasonable. Reasonableness is a matter of justification. The relevant question is whether her claim that she places a higher moral value on her car would not only explain her actions but justify them to those harmed? However, the claim simply makes her actions understandable from the perspective of rationality. It does not justify her actions. In addition, as reasonableness is an intersubjective standard of justification, to be reasonable Gertrude must take into account what others may or may not accept as a basis for assessing an objects moral value.

Alternatively, if she admits that the car is not as valuable as the child's life, but reaches a moral judgment that she ought to save the car, something in her calculations has gone awry. Not only is her action irrational, it is unreasonable. Gertrude may also appropriately weigh the alternatives, reach the correct moral decision as to what she ought to do, but fail to act accordingly. Lastly, she may offer a more substantive argument for

${ }^{142}$ Peter Singer employs a similar example to demonstrate that an individual ought to sacrifice their expensive car to save a child, and as a consequence, ought to donate to poverty and famine relief. See Peter Singer, One World (New Haven, Connecticut: Yale University Press, 2002), pp. 186-187. 
her choice to save her car. Let us assume that she also believes that human life is inherently valuable and ought to be respected and preserved; however, she hates redheads and thinks that they all deserve to die. Thus, the red-headed child ought not be saved as a matter of morality. Her belief in the sanctity and value of human life is inconsistent with her belief that red-headed children deserve to die. Without further argument, Gertrude is unjustified in her belief that red-headed children deserve to die. This inconsistency renders her choice of action unreasonable.

From the previous discussion, it should be apparent that a standard of reasonable deniability has certain advantages. Under such a standard one is justified in rejecting an objection to one's position that does not require the same epistemic certainty required by a standard of wrongness. For this reason the adoption of such a standard is likely to prove useful in the resolution of certain moral debates. In the end, however, I believe that the conditions I identify for a moral obligation of humanitarian intervention are reasonable and thus cannot be rejected. In addition, I believe that I am correct, even if I am unable to demonstrate that my possible detractors are unreasonable. This may, in the end, be all that I can hope to attain.

\subsection{The Constitutive Elements of a Moral Obligation of Humanitarian Intervention}

The first task in identifying the conditions under which no one could reasonably deny that a moral obligation of humanitarian intervention exists is to delineate the constitutive elements of such an obligation. For an obligation of humanitarian intervention to count as a moral obligation of humanitarian intervention it must be able to accommodate the elements delineated. In determining what the constitutive elements are I look first to Wesley Hohfeld. Hohfeld understands the constitutive elements of a norm 
or rule by looking to the relations of which it is comprised. ${ }^{143}$ Specifically, what is the content of the relationship that defines the norm, and what is the scope of the norm? In addition, as moral obligations are supposed to play a normative role in our practical deliberations, to fully understand a moral obligation one must also understand its nature and strength.

\subsubsection{Content and Scope}

According to Hohfeld the content of a norm is constituted by the substance of the normative relationship that exists between those whose relationship is defined by the norm. ${ }^{144}$ Conversely, the scope of a norm is constituted by those agents whose normative relationship is defined by the norm. I will separate the questions of scope and content, but I intend that they be understood as two parts of a whole.

Before proceeding, I would like to note that there are a number issues that I am avoiding. First, I do not make a distinction between duty and obligation. Richard Brandt claims that our ordinary usage of "obligation" and "duty" indicate that the two terms are not equivalent and that each attach to different agents and have different bases. ${ }^{145} \mathrm{I}$ am concerned with the function moral demands play in our practical deliberations, and I do not find any reason to conclude that our usage of such terms in ordinary language effects the fact that they serve similar roles in our practical deliberations. In addition, as it has

${ }^{143}$ Wesley Newcomb Hohfeld, Fundamental Legal Conception as Applied in Judicial Reasoning (Westport, CT: Greenwood Press Publishers, 1978), pp. 35-36.

${ }^{144}$ Ibid., pp. 35-36.

${ }^{145}$ Richard B. Brandt, "The Concepts of Obligation and Duty," Mind, New Series, Vol. 73, No. 291 (July, 1964), 374-393, 375-376. See also A. John Simmons, Moral Principles and Political Obligations (Princeton, NJ: Princeton University Press, 1979) (that he is accepting Brandt's distinction), p. 11. 
become the common language for those discussing rights and obligations, I am relying on Hohfeld's categorization and terminology for my analysis of a moral obligation of humanitarian intervention. Hohfeld defines obligations by reference to duty. To follow Brandt on this terminological matter would render the Hohfeldian framework ambiguous and ill-suited for its intended purpose.

Nor do I address Thomas Nagel's concern over the possibility of global justice. ${ }^{146}$ I argue that the moral obligation of humanitarian intervention can be considered to be a matter of justice. Nagel, on the other hand, contends that justice is dependent on the existence of certain social and political institutions, and that the demands of justice are owed only to others who participate in or are governed by such institutions. ${ }^{147}$ Despite his rejection of universal global justice, he does not deny that other moral obligations may exist that are based upon the moral minimum we each owe to one another. Nagel calls such obligations "basic humanitarian duties." ${ }^{148}$ As a practical matter, the difference between Nagel and myself on this point seems largely terminological. I will offer reasons for thinking that justice includes such basic humanitarian duties, but the defense of a moral obligation of humanitarian intervention does not depend on this proposition being correct.

Returning to the discussion of the moral obligation of humanitarian intervention,

${ }^{146}$ Thomas Nagel, "The Problem of Global Justice," Philosophy \& Public Affairs, 33, No.2 (2005), pp. 113-147.

${ }^{147}$ Nagel, p. 126 (that he rejects the "cosmopolitan" conception of global justice and prefers a "political" conception of global sovereignty which requires institutions and under which the reach of justice is limited to those who participate in or are governed by the institution).

${ }^{148}$ Ibid., p. 125. 
what is the content of a moral obligation? In answering this question, a good place to start is with Cicero's discussion of obligations as his understanding, though vague, is particularly relevant to the task at hand. ${ }^{149}$ For Cicero, understanding the content of a moral obligation involves two aspects. ${ }^{150}$ First, there is the conceptual question, what is an obligation? And second, the practical question, what is the function or role of an obligation?

According to Cicero, in answer to the first question, moral obligations fall into two categories - the intermediate and the absolute. ${ }^{151}$ An intermediate obligation is a "plausible reason" for action. ${ }^{152}$ An absolute obligation is that which is right, the right thing to do. ${ }^{153}$ A moral obligation of humanitarian intervention has elements of both intermediate and absolute obligations. It is a special type of reason for action, but it is one far more demanding than just a plausible reason.

Moral obligations, for Cicero, are derived from one of four virtues. ${ }^{154}$ Of particular interest to this discussion are those obligations derived from the virtue of community. The virtue demands that we give each his due, either as a matter of justice or beneficence. ${ }^{155}$ A moral obligation of the sort with which we are concerned is an 2000).

${ }^{149}$ Cicero, On Obligations, P. G. Walsh, tr. (Oxford: Oxford University Press, ${ }^{150}$ Ibid., Book One, p. 5.

${ }^{151}$ Ibid.

${ }^{152}$ Ibid.

${ }^{153}$ Ibid.

${ }^{154}$ Ibid. pp. 7-9.

${ }^{155}$ Ibid., pp. 9-10. 
obligation based upon giving each his due. The vagueness in Cicero's account makes a more specific delineation of the content of a moral obligation difficult. As Hohfeld has demonstrated, obligations are complex, and in order to understand their content one must assess and understand the normative elements which comprise the norm in question. ${ }^{156}$

Looking to Hohfeld for more clarity, Hohfeld offers a detailed classification of the core elements of norms divided into jural correlatives and jural opposites. ${ }^{157}$ It is the jural correlative with which I am most concerned because it is the correlative which defines the norm. For Hohfeld, the correlatives were duty and right, privilege and no right, power and liability, and immunity and disability. ${ }^{158}$ It is important to note that the first two correlative relations are concerned with the relations themselves and the second two are concerned with an agent's ability to change the existing normative relations.

To understand the nature of a moral obligation in Hohfeldian terms, we must first ascertain whether a moral obligation is a privilege or a duty; and second what the nature of the jural correlative is. Despite the fact that Hohfeld seems to take the meaning of duty to be a given, one can discern from his discussion that a duty, as opposed to a privilege, is binding. ${ }^{159}$ For Hohfeld, a privilege is a lack of a duty. ${ }^{160}$ One who has a privilege is free to do, or to do otherwise, and the reasons for or against an action governed by a privilege are "ordinary" in the sense used by Cicero. A moral obligation is a demand on one's

\footnotetext{
${ }^{156}$ Hohfeld, p. 35 .

${ }^{157}$ Ibid., p. 36.

${ }^{158}$ Ibid.

${ }^{159}$ Ibid., pp. 36-38, 44-45.

${ }^{160}$ Ibid. pp. 44-45.
} 
practical deliberations that deserves consideration distinct from that given to an ordinary reason. In Hohfeldian terms, an obligation must be a duty and not merely a privilege.

The jural correlative of a duty is a right. ${ }^{161}$ Regarding the correlative right, it is not clear that Hohfeld means this as a claim right. Under a claim right, the individual holding the right must exercise the right for it to give rise to a correlative duty. In this case, we would be talking about a power, something Hohfeld thinks is distinct from a right. ${ }^{162}$ It is true that a power can give rise to a duty and its correlative right, but this is different from the right that exists as a correlative to an extant duty. ${ }^{163}$ As the content of a moral obligation is constituted by a Hohfeldian correlative relationship of a duty and a right, the right would justify a demand that the duty correlative to the right be fulfilled; however, the right need not be exercised for such a duty to exist.

In Hohfeldian terms, the specific content of the moral obligation of humanitarian intervention consists of a duty to intervene militarily into the internal affairs of a sovereign state to prevent a humanitarian crisis from occurring or to stop it once it has begun, and a correlative right held by those who are suffering to demand such action on the part of the duty-bearer. In addition, and though this may seem excessive, the moral obligation of humanitarian intervention is moral and humanitarian in nature. With regards to the content of the obligation, what this means is that the relationship is a moral, as opposed to a practical or legal, one, and that the relationship is based on distinctly humanitarian concerns. The former characteristic may be more readily understood, as for

${ }^{161}$ Ibid. pp. 36-38.

${ }^{162}$ Ibid. pp. 50-51.

${ }^{163}$ Ibid. p. 58. 
the distinctly humanitarian nature of the obligation, this means that the obligation to intervene is for reasons related to the suffering of individuals as individuals. For the moment this description of the humanitarian nature of the obligation will suffice, but I hope to make it more clear as the discussion proceeds.

Delineation of the scope of the moral obligation of humanitarian intervention is a fairly simple matter, especially in light of the fact that the content has been determined. The scope of an obligation is constituted by the parties to the normative relationship governed by the obligation - who owes the obligation and to whom is it owed. The obligation to intervene is borne by states individually and the international community as a collection of duty-bearing states, and it is owed to the individuals or groups of individuals who are suffering due to the actions or inactions of their governments. Though it may be obvious, the correlative right to intervention is held by those individuals who are suffering from some moral offense against their persons.

One might wonder why the duty is borne by sovereign states as opposed to individuals. I will discuss this in greater detail below, but I take it to be a limitation on an obligation that one must be able to accomplish what the obligation demands for it to be the case that one is under the obligation. Humanitarian intervention can only be accomplished by a collective cooperative effort of a large scale, an effort individuals as individuals cannot accomplish, but of which states are capable.

\subsubsection{Strength}

An obligation is a relationship between obligor and obligee. To understand the constitutive elements of an obligation one might think that all that need be identified is the content and scope of the obligation, leading one to question the relevance of the 
identification of the strength of the obligation. One of the reasons I chose to begin this analysis with a discussion of Cicero's understanding of obligations is that Cicero understood that there are two fundamental aspects of an obligation, the conceptual and the practical. ${ }^{164}$ Understanding the former may take us a long way to understanding the constitutive elements of an obligation, but if we fail to account for the latter, we will have a less than complete understanding of the obligation itself. The practical aspect of an obligation is concerned with the role an obligation ought to play in our practical deliberations. To understand the strength of an obligation we must understand its role in our practical deliberations.

Under the classic account of practical deliberation, we as rational creatures, when confronted with the question of what we ought to do in a particular circumstance, consider the relevant reasons for and/or against particular actions. The goal of such deliberations are to determine "what ought to be done on the balance of reasons." 165 The metaphor of balancing reflects the idea that reasons have a weight, and that the weightier reason (or set of reasons) should determine how we ought to act in a particular circumstance. Under this classic account of practical deliberation, reasons are all firstorder reasons, some weightier than others, and practical deliberation is merely a matter of balancing such reasons to determine what ought to be done. Thus, the strength of a reason is a matter of comparative value or weight.

However, as Joseph Raz has argued, there are a number of phenomenological

${ }^{164}$ Cicero, p. 5 (that obligations provide moral guidance derived from the conceptual aspect of the obligation).

${ }^{165}$ Joseph Raz, Practical Reason and Norms, p. 36. 
reasons for rejecting the idea that practical deliberation is concerned solely with the weighing and balancing of reasons of a single order. ${ }^{166}$ Raz contends that there are both first and second-order reasons, and that the second-order reasons are often exclusionary in their effect. ${ }^{167}$ Thus, according to Raz, there are two aspects of the strength of a reason, its nature and its weight. I will adopt the Razian framework for understanding practical deliberations for a number of reasons. In addition to the phenomenological reasons Raz relies upon, the Razian framework more readily accommodates the Hohfeldian understanding of a moral obligation. Also, the framework governing the practical deliberations of states in the international arena is more easily understood if thought of in Razian terms.

To fully understand the Razian account of practical deliberation one must understand how conflicts of reasons are dealt with under the Razian account. Conflicts between reasons of different orders are resolved by a calculation different from the resolution of conflicts between reasons of the same order. ${ }^{168}$ First order reasons are reasons for or against action, and conflicts between them are resolved by balancing the respective weights of the reasons at issue. ${ }^{169}$ Second order reasons are reasons for or against the consideration of first-order reasons, and conflicts between second-order reasons are also resolved by the balancing of their respective weights. ${ }^{170}$ The resolution
${ }^{166}$ Ibid.
${ }^{167}$ Ibid.
${ }^{168}$ Ibid., pp. 35, 46-47.
${ }^{169}$ Ibid., p. 35.
${ }^{170}$ Ibid., pp. 46-47. 
of conflicts between first and second order reasons is more complicated. The function of a second-order exclusionary reason is to preclude from consideration certain first-order reasons either for or against an action. Thus, as Raz notes, the conflict will almost always be resolved in favor of the second-order reason. ${ }^{171}$

A complete understanding of the strength of the moral obligation of humanitarian intervention involves an understanding of both its nature and weight as a reason. Despite this, in discussing the strength of the moral obligation of humanitarian intervention my focus will be on the nature of the obligation to the exclusion of a discussion of its weight. One consideration in favor of this approach is derived from the discussion of the various conflicts that arise between reasons and the manner by which such conflicts are resolved. The first thing that one must determine in the case of a conflict is the nature of the reasons subject to the conflict. Are both first-order? Are both second-order? In either of these scenarios the resolution is a matter of determining the balance of reasons through an assessment of the relative weight of the reasons at issue. However, if the reasons to the conflict are of different orders, then if the first-order reason is within the scope of the second-order reason's exclusionary effect it will be precluded from consideration and its weight rendered irrelevant. ${ }^{172}$

An additional reason for focusing on the nature of the reason to the exclusion of its weight can be discerned from the following consideration. With regard to the identification of the constitutive elements of the moral obligation of humanitarian

${ }^{171}$ Ibid.

${ }^{172}$ Ibid. (that "in most situations [the second-order reason's] weight is not in question. It prevails in virtue of being an exclusionary reason."), p. 79. 
intervention only a discussion of the nature of the obligation is necessary to the discussion of the strength of the obligation. In seeking to identify the constitutive elements, I am trying to identify its existence conditions, a conceptual matter. Practical deliberation is based upon a particular logical structure. Under the Razian account that structure involves reasons of different orders. From the perspective of practical rationality, understanding the existence conditions for determining what counts as an obligation requires that one understand where an obligation fits in the logical structure which governs practical deliberation. The weight of a reason is a matter of substantive value and not logical structure. The nature of a reason, on the other hand, is defined by the role a reason plays in that logical structure, thus determining the nature of an obligation is more relevant to the task at hand.

Lastly, unlike the weight of a reason, the nature of a reason can be understood in isolation from other reasons. The nature of an obligation does not depend on anything other than the logical role it is to play in our practical deliberations. Is it a first or second order reason? The weight of a reason, on the other hand, is relative. It can only be understood in relation to other reasons of the same order. Thus, a definitive identification of the weight of a reason would be a practical problem as the relative weight of a reason will vary in each instance in which it arises. Though there is no explicit discussion of the weight of the moral obligation of humanitarian intervention much can be inferred from the discussion in the succeeding sections of this chapter.

At first glance it may seem that an obligation is merely a weighty first-order reason to act in accordance with the demands of the obligation. A moral obligation does have a first-order component, but it seems infelicitous, if we take the existence of such 
obligations seriously, to say that the first-order aspect completely explains the nature of a moral obligation. Consider the following example. Imagine that an individual (Albert) promises to help (Beatrice) move a large stone out of Beatrice's field. The day arrives for Albert to fulfill his promise. He recognizes that the promise gives him a first-order reason for helping Beatrice, but in his deliberations he weighs that reason against the fact that someone has just offered him two tickets to see his favorite cellist perform at the local park in a once a year event. When combined with the many other reasons against helping Beatrice, Albert decides to go to the concert. He sees Beatrice the next day. She asks for a justification, and Albert provides an elaborate spreadsheet of his calculations because that is the kind of guy Albert is. He demonstrates to Beatrice that his weighing of the relevant first order reasons clearly leads to the conclusion that he ought, all things considered, to have gone to the concert and refuses to apologize to Beatrice for anything because he acted as he ought to have.

I hope that the reader finds that Albert's conduct and explanation leave something to be desired. Albert is correct in his conclusion that the promise includes a weighty firstorder reason to fulfill the demands of the promise, but he fails to recognize that the resultant promissory obligation also has a second-order component. It precludes from consideration certain first-order reasons, such as those that may arise when one offers you a competing and pleasant alternative. A promissory obligation is a second-order exclusionary reason, as well as, a first-order reason.

One alteration in our story may help one understand this exclusionary component of moral obligations. Imagine that Albert had visited Beatrice to seek her release from the promise. Albert again presents Beatrice with the spreadsheet, and tries to get her to 
concede that a weighing of the first-order reasons indicates that Albert ought to go to the park and see his favorite cellist perform. To his surprise, she does see that the first-order reasons weigh in favor of Albert going to the performance, but that she still thinks Albert ought to fulfill his promise because many of the reasons cited by Albert are simply not relevant in light of the promise made. This response by Beatrice makes perfect sense to me, and I don't believe that Albert would be justified in feeling resentment against Beatrice.

A moral obligation is both a first-order reason to act in accordance with the demands of the obligation, and a second-order reason to exclude from consideration certain first-order reasons against acting in accordance with the demands of the obligation. The strength of the second-order component of a moral obligation will depend upon its weight relative to other second-order reasons, ${ }^{173}$ and the strength of the first-order component will depend upon the relative importance of the values served by or basis for the obligation. ${ }^{174}$

\subsubsection{Basis}

We can conclude, from the discussion of the constitutive elements of a moral obligation of humanitarian intervention, that an obligation must have the following characteristics to count as such an obligation:

1. In order to accommodate the content, it must be a positive obligation to intervene that has its basis in reasons that are distinctively moral and humanitarian in nature;

${ }^{173}$ Ibid., pp. 46-47.

${ }^{174}$ Ibid., p. 77. 
2. To accommodate the scope, it must be borne by states individually and the international community as a collection of duty-bearing states, ${ }^{175}$ and it must be owed to individuals or groups of individuals; and

3. To accommodate the nature and strength, it must be both a second-order exclusionary reason to preclude from consideration first-order reasons against acting in accordance with the demands of the obligation, and a first-order reason to act in accordance with the demands of the obligation.

The fact that we can conceive of such an obligation fails to justify a claim to its existence.

First, one might contend that there is a utilitarian justification for a moral obligation of humanitarian intervention. According to Mill, an action is right and morally obligatory if it tends to promote overall utility. ${ }^{176}$ For Mill, as for other utilitarians, the utilitarian principle is determinative of what is morally required of an agent. At first glance, a utilitarian justification seems promising. One could certainly imagine circumstances under which utility would be promoted by intervention; consequently, according to the utilitarian principle one would be morally obligated to intervene.

${ }^{175}$ It has been suggested to me that an alteration in this condition is required. Namely that militarized charities or NGOs could bear the obligation in the same way that states can. The factual basis for this claim has been the action of the International Brigades during the Spanish Civil War. I am open to this suggestion. For the present, however, I will limit my discussion to states and the international community. My reasons are largely methodological. My project is concerned with defending a moral obligation of humanitarian intervention that could be defended against the possibility of reasonable rejection. We do not have militarized NGOs, but we do have states with the capacity to effectively engage in humanitarian intervention. The need to create the former would make what is required more burdensome and harder to defend. There are additional concerns related to the value of international peace and security, as well as other moral hazards that may be worthy of consideration.

${ }^{176}$ John Stuart Mill, Utilitarianism (Indianapolis, Indiana: Hackett Publishing Company, Inc., 1979), Ch. II, pp. 7, 11. 
There are, however, a number of reasons why utilitarianism fails to provide the necessary justification for a moral obligation of humanitarian intervention. First, though utilitarianism could provide a plausible basis for a moral obligation to intervene in particular cases in which utility would be promoted, it does not provide a basis for a moral obligation of humanitarian intervention. The humanitarian nature of the utilitarian obligation is only a contingent fact. Protecting individuals from suffering is only relevant if it promotes utility. One could imagine a situation in which a utilitarian obligation of intervention arises, and then alter the circumstances slightly and instead of intervening an agent would be morally obligated to allow the preventable suffering of individuals to continue if that would promote utility.

Second, the moral obligation of intervention justified by the utilitarian principle would fail to accommodate the scope of the moral obligation of humanitarian intervention. The moral obligation of humanitarian intervention is relational in nature. It is held by certain agents and is owed to individuals. Utilitarian obligations are not owed to anyone. The obligation is to promote utility. If an individual or group of individuals happens to benefit from the fulfillment of the obligation then so much the better for them, but they do not have a basis for a demand against the bearer of the obligation that the obligation be fulfilled.

The failure of the utilitarian principle to accommodate the scope of a moral obligation of humanitarian intervention is most clearly understood when utility can be served equally by either of two actions. Imagine that an agent is faced with performing action $A$ or action $B$. The actions are equivalent from the perspective of the utilitarian principle. Either produces the same amount of utility. $A$ involves intervention to stop the 
suffering of an individual. $B$ involves no intervention. The agent can choose $A$ or $B$ in fulfillment of the demands of the utilitarian principle, but the individual who would be helped by $A$ does not have the rational basis to demand an intervention. At best, they have a basis for a request that intervention occur.

Lastly, if an obligation of intervention is to count as a moral obligation of humanitarian intervention it must act as a second-order exclusionary reason and a firstorder reason to act. A utilitarian moral obligation of intervention is not a reason, first or second-order, to be entered into the deliberations of an agent, rather it is the outcome of such moral deliberations. For the utilitarian there are no prior existing obligations that count as reasons to be included as inputs into the practical deliberation of an agent. The only moral obligations to act are those that would promote the most utility. Certainly, none of the foregoing reasons for rejecting utilitarianism as a basis for a moral obligation of humanitarian intervention undermine the plausibility of a utilitarian justification for intervention, but they do demonstrate the inability of utilitarian theory to justify the relevant type of obligation.

The utilitarian may, conceding the inability of utilitarianism to directly justify a moral obligation of humanitarian intervention, argue that the utilitarian principle is a secondary rule governing a multitude of primary rules which are intended to fulfill the dictates of the secondary rule, and our actions should be guided by the primary rules which are justified by the fact that if they are followed they have a tendency to promote 
utility. ${ }^{177}$ This version of utilitarianism has come to be known as rule-utilitarianism. ${ }^{178}$

A moral obligation of intervention based on a rule-utilitarian justification would likely run as follows: utility would be promoted if, as a general rule, intervention occurs when certain circumstances arise. The rule utilitarian justification fails to justify a moral obligation with the necessary content for much the same reason as simple or act utilitarianism. A moral obligation of intervention may be justified by the specific primary rule at issue, but the moral justification remains the promotion of utility, and humanitarian concerns related to the suffering of individuals are only ancillary as the utilitarian demand is to promote utility.

Taking the other characteristics of a moral obligation of humanitarian intervention out of order, a rule utilitarian justification for a moral obligation of intervention arguably satisfies the third characteristic. Primary rules can conflict. In such situations the conflicting rules act as second-order reasons precluding certain first-order reasons from consideration and they are first-order reasons to engage in a particular act. The utilitarian principle is the ultimate arbiter of such conflicts, which may give credence to the claim that rule-utilitarianism must, on at least some occasions, collapse into act utilitarianism. Nonetheless, the rule utilitarian obligation of intervention performs the appropriate role in the practical deliberations of an agent.

An example may help to elucidate the point I am trying to make. Imagine that

${ }^{177}$ Ibid., pp. 23-25.

${ }^{178}$ For a brief but informative discussion of rule consequentialism, including ruleutilitarianism, see Brad Hooker, "Rule Consequentialism", The Stanford Encyclopedia of Philosophy (Spring 2004 Edition), Edward N. Zalta, URL = $<$ http://plato.stanford.edu/archives/spr2004/entries/consequentialism-rule/>. 
each of the following primary rules tends, when followed, to promote utility:

1. All other things being equal, one has an obligation to obey the law; and

2. All other things being equal, one has an obligation to disobey arbitrarily discriminatory laws.

For the rule-utilitarian, when primary rule 1 . is not in conflict with other primary rules it is determinative of what an agent ought to do. However, it may be the case that primary rules conflict, as primary rule 2 . would conflict with primary rule 1 . in any society governed by arbitrarily discriminatory laws. In such circumstances neither rule can be determinative. It is in such cases of conflict that rule-utilitarian primary rules serve the appropriate role in an agent's practical deliberations. They are entered into the practical deliberations of agents as both second-order exclusionary reasons and first-order reasons for action. Which is determinative of what an agent ought to do is determined by the degree to which either rule promotes utility - the strength of the rule from the utilitarian perspective.

A rule-utilitarian obligation of intervention would, however, lack the second characteristic of a moral obligation of humanitarian intervention. Much like a moral obligation of intervention based on simple utilitarianism, the obligation justified by ruleutilitarianism would not give rise to a justified claim to intervention by those who would benefit from the intervention. It would lack the relational component of a moral obligation of humanitarian intervention. The obligation is not owed to the beneficiaries of the obligation. It is not owed to anyone. The rule would be to intervene under certain circumstances, and the obligation to intervene would be based on the rule.

A rule-consequentialist could, however, respond that the rule requiring 
intervention should provide those who benefit from the intervention with a claim to the fulfillment of the moral obligation of intervention. The underlying justification would be that providing the beneficiaries of the rule with a right to intervention would render the rule more effective, and thus better able to promote welfare. This provides a consequentialist, if not utilitarian, reason for focusing on a rights-based justification for a moral obligation of humanitarian intervention. ${ }^{179}$

I now turn my attention to another possible justification for the moral obligation of humanitarian intervention. With respect to the justification of a moral obligation to provide greater aid to the impoverished of the world, Thomas Pogge argues that we need only look to the uncontroversial obligation we each bear not to harm others. ${ }^{180}$ The obligation, according to Pogge, is based on each individual's right not to be harmed. ${ }^{181}$ Thus, the violation of an individual's right not to be harmed gives rise to the rectificatory obligation borne by those who harmed or contributed to the harming of the individual to rectify the harm caused.

One could imagine a similar argument being made to justify a moral obligation of humanitarian intervention. If an agent harms or in some way contributes to the harm of an individual or group of individuals then that agent has a rectificatory obligation to alleviate the suffering and stop the harm. If, however, an agent does not contribute to the

${ }^{179}$ Sumner (that providing individuals with choice-protecting rights is the best way to promote welfare), Ch. 6 .

${ }^{180}$ Pogge, World Poverty and Human Rights, p. 13.

${ }^{181}$ Ibid. 
harm then they have no obligation to abate it. ${ }^{182}$ In other words, if I am not harming you nor contributing to the harm that you are suffering, then I have no obligation to help you. But if I am harming you or contributing to the harm you are suffering then I do have an obligation to abate the harm you are suffering. If the only way to abate that harm is to intervene, then fulfilling the obligation would require intervention.

But is a rectificatory moral obligation to intervene a moral obligation of humanitarian intervention? If we return to the three characteristics constitutive of a moral obligation of humanitarian intervention, the rectificatory obligation would seem to be able to accommodate the second and third. Regarding the second, scope-related, characteristic, there seems to be no principled reason as to why a rectificatory obligation could not arise between a state and an individual or group of individuals.

As to the role a rectificatory obligation would play in the practical deliberations of an agent, unlike a simple utilitarian moral obligation to intervene, a rectificatory obligation would be a reason for action to be considered in an agent's practical deliberations as opposed to an outcome of those deliberations. Thus, it is, at the very least, a first-order reason for action. Rectificatory obligations also act as second-order exclusionary reasons. Take, for example, the law of negligence in the United States. Much of tort law is built around the idea that we each have duties not to harm others. When one agent engages in unreasonable or negligent behavior and causes another to suffer an injury, under the law the negligent party has a rectificatory obligation to

182 Ibid. See also Richard A. Epstein, "A Theory of Strict Liability," 2 The Journal of Legal Studies (1973) (that there can be no legal duty to require that an individual be required to aid those who are in danger from a harm that the individual did not create), pp. 160-189. 
compensate the injured party for the harm suffered. The fact that the negligent party may have been planning on using the funds now dedicated to compensating the injured party for morally valuable projects is precluded from our consideration of whether the injured party should be compensated. I am not making a judgment as to the justifiability of such rectificatory obligations, rather I am identifying the role such obligations would play in our practical deliberations when and if they do arise.

Can a rectificatory obligation accommodate the required content of a moral obligation of humanitarian intervention. When it does arise, a rectificatory obligation would obligate the bearer of the obligation to act, and it would be based, at least in part, on the suffering of those to whom the obligation is owed. Thus, it would be both positive and based on moral concerns that are humanitarian in nature. What troubles me, however, is the following. Imagine that Kundu, ${ }^{183}$ a small state, is engaged in a genocide against a particular ethnic minority within its borders. Kundu has few resources, exports very little to the outside world, and none of the aid it has received is being used to perpetrate the genocide. If the moral obligation of humanitarian intervention is to be based on a right not to be harmed and the rectificatory obligation that arises when that duty is violated then, in this instance, there would be no moral obligation to intervene as no agent outside of Kundu had contributed to or caused the harm being suffered. The rectificatory obligation would be borne by the genocidaires.

This imagined circumstance involving a non-existent state may not be likely to occur, but it is the very possibility of such an occurrence that is troubling and which leads

${ }^{183}$ I have borrowed the name of the fictional state from an episode of the West Wing. 
me to believe that something is lacking from a rectificatory justification for a moral obligation of humanitarian intervention. For an obligation to be a humanitarian obligation, it should be directly implied by the suffering of an individual and not mediated by the violation of a prior existing duty not to harm. A rectificatory obligation is an obligation to compensate for a past or present wrong that one created or to which one contributed, and not an obligation arising directly from the suffering of individuals. This is not to deny a role for rectificatory obligations. If one contributed or caused the harm being suffered, then one has an additional obligation.

Despite the fact that neither utilitarianism nor the principle of rectification are capable of justifying a moral obligation of humanitarian intervention, both theories lend support to human rights as a basis for such an obligation. L. Wayne Sumner has argued, that there are consequentialist reasons for a rule treating people as if they had rights. ${ }^{184}$ Sumner argues that due to human fallibility and limited cognitive resources we are better able to promote welfare in the long-run if we constrain our decision-making procedures by adhering to certain rules which prevent us from assessing the welfare-promoting qualities of each individual course of action. ${ }^{185}$ As Sumner states,

However, being also aware of our commitment to the goal of maximizing welfare, we have reason to fear the temptation to make the attempt might be irresistible on each particular occasion. In order to defeat this temptation we will do well to pre-commit ourselves by announcing from the outset a requirement of acceptability for protocols whose function is to constrain acting on the basis of the cost/benefit test. ${ }^{186}$

\footnotetext{
${ }^{184}$ Sumner, pp. 174, 189-198, 201-203.

${ }^{185}$ Ibid.

${ }^{186}$ Ibid., p. 191.
} 
One such rule should be the inclusion of rights, and specifically choice protecting human rights. ${ }^{187}$ As a consequence, if Sumner is correct, then there are consequentialist, if not entirely utilitarian reasons for focusing our enquiry on the analysis of such a rights-based account.

Pogge, on the other hand, is more clearly focused on human rights as a basis for an obligation to act. However, Pogge's right not to harm and rectificatory principle as a basis fail to account for the distinctively humanitarian nature of the moral obligation of humanitarian intervention. Nonetheless, what the right not to be harmed and the principle of rectification demonstrate is the ability of a rights-based account to accommodate many of the structural characteristics of a moral obligation of humanitarian intervention.

\subsection{The Basic Right to Physical Security as the Basis for the Moral Obligation of Humanitarian Intervention}

But what would such a rights-based account look like? Here I will rely, to a great extent, on Henry Shue's understanding of a "basic right," 188 and specifically the basic right to physical security. ${ }^{189}$ For Shue, a basic right is a right the existence of which is necessary for the enjoyment of all other rights. ${ }^{190}$ So, if we have any rights at all, we must have basic rights. The right to physical security is a basic right because it is essential to the enjoyment of any other right. As to the specific characteristics of a basic right, a

\footnotetext{
p. 203.

${ }^{187}$ Ibid. ("Since we have settled on the model of rights as protected choices ..."),
}

${ }^{188}$ Henry Shue, Basic Rights: Subsistence, Affluence, and U. S. Foreign Policy, $2^{\text {nd }}$ $E d$. (Princeton, New Jersey: Princeton University Press, 1996), pp. 13-20.

${ }^{189}$ Ibid., pp. 21, 37-38.

${ }^{190} \mathrm{Ibid}$., p. 19. Sumner makes a similar argument regarding the periphery of the core of rights. One might think of basic rights as the periphery that is necessary for the core to be fulfilled. See Sumner, p. 202. 
"moral right provides (1) the rational basis for a justified demand (2) that the actual enjoyment of a substance be (3) socially guaranteed against standard threats." ${ }^{191}$ Thus, the right to physical security would provide the right holder with the rational basis for a justified demand that their physical security be socially guaranteed.

One might ask at this point, what distinguishes the right to physical security from the right not to be harmed. There must be a difference if the right to physical security is to support an obligation with the distinctively humanitarian nature that the right not to be harmed could not. The most striking difference between the two rights is related to the core of each right. The core of the right not to be harmed is a negative obligation to refrain from harming others. ${ }^{192}$ This negative obligation can give rise to a positive obligation to act, but only via the principle of rectification and after the right has been violated. The core of the right to physical security has both a negative obligation not to harm and a positive correlative obligation to insure that the physical security of others is protected. ${ }^{193}$ As a matter of practical effect, the right not to be harmed will give rise to a positive obligation to act in fewer cases.

Turning now to the issue of whether a basic right to physical security can support a moral obligation of humanitarian intervention, to accommodate the scope of a moral obligation of humanitarian intervention, the basis must support an obligation owed by states to distant others. Thus, the specific question that must be answered is whether the basic right to physical security held by distant others can serve as the rational basis for a

${ }^{191}$ Shue, p. 13.

${ }^{192}$ Pogge, World Poverty and Human Rights, p. 13.

${ }^{193}$ Shue, pp. 37-38. 
justified demand that states act to socially guarantee the physical security of those distant others against standard threats? Here I will offer an argument explaining how states could bear such obligations and demonstrate that a number of the more common objections fail to preclude this possibility.

As Shue notes, basic rights are "the morality of the depths." ${ }^{\text {"194 }}$ Basic rights are the moral minimum to which each of us is entitled, and the very least that we are owed from all others. We can justifiably demand of each individual, with the capability to do so, that they act so as to socially guarantee the enjoyment of the substance of such rights against standard threats. This may appear to be a substantive claim in need of an argument, and to a certain extent it is. In the present analysis, my goal is to defend the ability of Shue's understanding of basic rights to provide the theoretical foundations for a moral obligation of humanitarian intervention, and from that perspective this is not a substantive claim. For the moment, I will set aside the defense of the claim.

The social guarantees to which an individual is entitled may be provided by the formation of institutions like governments or legal systems. Such institutions would then, as part of their justification for existing, be required to provide the requisite socially guaranteed protection. Individual obligations correlative to basic rights do not, however, end at a state's boundaries. Basic rights are held by each individual and held against all others. ${ }^{195}$ It is important to note that this should not be confused with the claim that basic rights and their correlative obligations are absolute, just that their demands and the role they ought to play in the practical deliberations of agents is not limited by political

\footnotetext{
${ }^{194}$ Ibid., p. 18.

${ }^{195}$ Ibid., p. 19.
} 
boundaries.

In many instances to demand that individuals as individuals fulfill such obligations to distant others would be unjustified for a number of reasons. Efforts by individuals would be inefficient and likely futile. The coordination demanded for such an endeavor to be successful would prove to be overly burdensome and potentially unreasonable. What is needed is collective action on the part of a sufficient number of obligation bearers capable of providing the requisite socially guaranteed protection demanded by the right. There are a number of reasons for thinking that states are the appropriate institutions for the task. First, assuming that the only way to fulfill the obligation to provide the social guarantees for the protection of the physical security of individuals is through forced intervention, in the contemporary world states have a monopoly on the military capabilities necessary to be successful in such an endeavor. In addition, in the international arena states and the governments that control them mediate the relations between distant peoples. Therefore, if any one people, as individuals or as a collective, owe obligations to another, then states are already well-situated to carry out the task. Thus, there are practical reasons and reasons based on the structure of international relations for states to be the de facto bearers of the obligation to provide the necessary social guarantees. Lastly, to be most effective, the actions of states in their efforts at intervention will require coordination among the states themselves; providing an additional reason for states to act collectively - reasons for the international community to act as the bearers of the obligation.

There are a number of common arguments intended to demonstrate the practical or conceptual impossibility of states bearing such obligations to distant others. Here I 
will demonstrate that even if such arguments are correct they do not imply that states cannot be the bearers of obligations to distant others. David Rodin offers a critical assessment of the various ways in which states could possibly be argued to be the bearers of rights or duties. ${ }^{196}$ Rodin's primary concern is with arguments seeking to justify a state's right of self-defense. I am more concerned with the flip side of a state's normative status: can a state bear moral obligations? I believe, however, that much of the skepticism about the possibility that states can bear moral obligations to distant others can be found in the various arguments assessed by Rodin.

For Rodin, there are two ways to explain the normative status of states in the international arena. First, if a state is to be the bearer of obligations or rights its basis must be found in either reductive or analogical reasoning. ${ }^{197}$ I will not spend much time on the substance of Rodin's rejection of such arguments because he misses a third alternative that can explain how states could be the bearers of obligations.

Under the analogical argument states have rights and responsibilities in the international arena because they are like individuals in domestic society in morally relevant ways. However, as Rodin points out, such analogical arguments cannot support a state having rights or obligations as a state. ${ }^{198}$ Rather, if a state is to have such rights and responsibilities it is going to have to be based on the rights and responsibilities of those who inhabit the state - such rights and responsibilities will need to reduce to an

${ }^{196}$ David Rodin, War and Self-Defense (Oxford: Oxford University Press, 2002), pp. 122-132.

${ }^{197} \mathrm{Ibid}$., (that the right to self-defense must have either an analogical or reductive basis), p. 123

${ }^{198}$ Ibid., pp. 122-127. 
aggregation of the rights and responsibilities of the individuals who inhabit the state. ${ }^{199}$ Rodin, however, demonstrates, at least for a state's right of self-defense, that a state's right to self-defense cannot be based on such a reductive strategy because the right of individual inhabitants to self-defense would not often imply a right on the part of states to pursue a defense of the state. ${ }^{200}$ Similarly, with regard to intervention, it is not likely that one could justifiably demand of an individual as an individual that they intervene to provide the social guarantees necessary for a distant person to be able to enjoy physical security. So, if a state's obligations are to be based on the obligations of its inhabitants how could one justify such an obligation under a reductive strategy?

Rodin's argument is mistaken, however, in the claim that the only alternative is a reductive strategy. The obligation of states to intervene to provide distant others with the requisite social guarantees can be derived from the obligations individuals have to those distant others. This is different from the reductive strategy because it recognizes that states are capable of accomplishing tasks that individuals are not. Thus, a state may actually have obligations beyond those which are held by individuals, but they are derived from the obligations borne by individuals.

Each individual has the obligation to provide every other individual with the social guarantees necessary for the latter to enjoy their physical security against standard threats. Fulfilling this obligation may on occasion require intervention. In cases where intervention is required, due to the practical limitations facing individuals, the coordination problems that would hinder the effectiveness of individual efforts to provide

${ }^{199}$ Ibid., pp. 127-132.

${ }^{200}$ Ibid., pp. 131-132. 
such social guarantees, and other pressing demands that might override the individuals' obligations, the demand that individuals intervene cannot be justified. As a collective, however, the inhabitants of a state would often be able to fulfill their obligations to distant others with little cost to themselves.

States are the institutions that represent their inhabitants in the international arena and which mediate their inhabitants interactions with distant others. A function of states is that they serve to coordinate the efforts of their inhabitants to solve collective action problems. As the institution which mediates the interaction between its inhabitants and distant others to which individuals owe an obligation, there is a derivative instrumental justification for states to be the bearers of the obligation to intervene. ${ }^{201}$

This derivative strategy depends on individuals having obligations to distant others. Henry Shue outlines two arguments that are intended to demonstrate that individuals only have obligations to their fellow inhabitants. The first argument is based on the claim that one's obligations to others is based on being members of a community of sentiment - that one's obligations are based on the personal relationships that one shares with others. ${ }^{202}$ The second argument is based upon the claim that one's obligations to others is based on membership in a community of principle - that one's obligations are owed to those with whom one shares goals or a commitment to certain principles. ${ }^{203}$

One reason I have for rejecting these arguments is that it would mean that we are

${ }^{201}$ Gerald Elfstrom makes a similar argument. See Elfstrom (that in the international arena governments serve as "mechanisms" for individuals to fulfill their obligations to distant others), p. 163.

${ }^{202}$ Shue, p. 135.

${ }^{203}$ Ibid. 
permitted to harm others if they are outside of our community, an implication which I take to be morally absurd. I will assume, however, that there may exist obligations based on one's membership in either a community of sentiment or a community of principle. What remains to be demonstrated, if the arguments are to be successful in supporting such "compatriot priority", ${ }^{204}$ is that all moral obligations one owes to others are exhausted by the obligations that are reliant on membership in such communities. The fact that we, as individuals, may have additional moral obligations to those with whom we share our lives or to those with whom we share principled commitments, projects or goals, does not demonstrate that we do not have obligations to those outside of such communities.

There are also at least two practical or instrumental objections to attributing moral obligations to distant others to states. One such argument is outlined by Shue and is based on what he calls the "comparative-advantage theory of government."205 In this argument, it is acknowledged that individuals have obligations to distant others, but it is argued that the obligations, if they are to fall on any state, should fall on the state in which those to whom the obligation is owed live. The underlying reason is instrumental in nature. It is claimed that those most familiar with the local conditions are best suited to fulfill the obligation, and for that reason each state should be the bearer of obligations to its own citizens. ${ }^{206}$

${ }^{204}$ Ibid., pp. 131-139.
${ }^{205}$ Ibid., pp. 142-144.
${ }^{206}$ Walzer, "The Moral Standing of States" (that states should stay out of each other's business because only the government of a people can know what is best for that people), 
As David Luban has pointed out, this is an empirical claim that lacks support in the real world. ${ }^{207}$ Even if this underlying claim were true, it does not imply that a state cannot have obligations to distant others, only that the state in which individuals reside is the primary holder of obligations owed to such individuals. In addition, the circumstances under which an obligation of humanitarian intervention is likely to arise are instances in which the state is either an active participant in whatever is providing the threat to the physical security of individuals, or is ineffective in its efforts to fulfill its obligation to provide the requisite social guarantees. Under such circumstances, it would be unreasonable to rely on an argument that the government of that state is in a privileged position to know or do what is best.

Gerald Elfstrom presents a practical objection to the claim that states can bear obligations to distant others. ${ }^{208}$ The specific concern raised by Elfstrom is that nationalism exists and that it may be a barrier to the development of the political will necessary for the populace to support a state in fulfilling its and its inhabitants moral obligations to distant others. ${ }^{209}$ I have two responses to this concern raised by Elfstrom. First, the fact that the individual inhabitants of a state refuse to recognize their moral obligations casts a shadow over the moral character of those people, and does not in any way undermine the existence of such obligations.

But I take the heart of Elfstrom's concern to be a more complicated matter. His concern is with the practical resolution of a real world moral tragedy - in his case, global

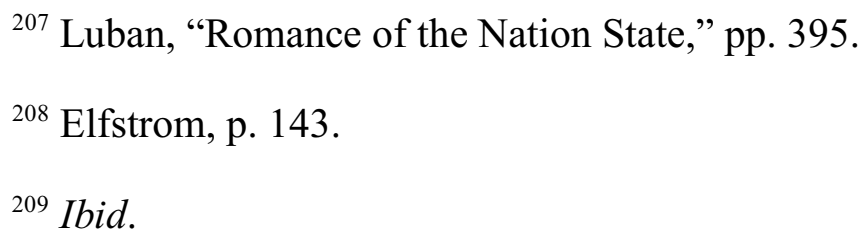


distributive justice and global poverty. Thus, if we are serious about solving the problem and not merely pointing out the relevant moral characteristics of the problem, then we will have to acknowledge such practical barriers and identify potential solutions. Though certainly not a fully developed resolution to this practical dilemma, I believe that nationalism and the national identity that it is based upon can be used to motivate individuals to support the fulfillment of their moral obligations to distant others. If such obligations are framed, not as an imposition of outsiders on the populace of a state, but rather as a matter of national interest or national pride, then nationalism may serve as a motivational tool. This does not mean that the humanitarian nature of the situation is rendered clandestine, but rather that the humanitarian aspects become the focus. It is a point of pride for a state and its inhabitants to live up to its and their moral obligations. It is a virtue to be pursued, not a burden to be avoided.

From the previous discussion we can conclude that there is good reason to believe that the basic right to physical integrity would imply an obligation that would accommodate the scope of a moral obligation of humanitarian intervention. However, throughout the discussion of the ability of a rights-based account to accommodate the scope of a moral obligation of humanitarian intervention, I have assumed a particular content of the obligation. Thus, the next question to be addressed is whether the basic right to physical security implies an obligation that accommodates the content of a moral obligation of humanitarian intervention. Answering this question requires that we first identify, with greater specificity, what a right to physical security is a right to.

Under the account I am pressing, the content of an individual's basic right to physical security would be a justified demand to have one's physical security socially 
guaranteed against standard threats. The keys to explicating the content of the moral obligations implied by the basic right to physical security lie in determining what counts as a standard threat to physical security and what duties or obligations are correlative to basic rights.

It is important, in understanding what counts as a standard threat, to understand why we ought to distinguish a standard threat from a possible threat. This is a matter of the breadth of the content of the right. Specifically, what is it a right to, and from which threats do individuals have a justified demand of socially guaranteed protection? As Shue points out, the socially guaranteed protection can't be against all threats to the substance of the right because such a demand would be too burdensome, and though not a logical absurdity it would cast doubt on the right itself since the demand is supposed to be justified. ${ }^{210}$

But what exactly is a standard threat? If a right is the basis for a justified demand on the actions of others, the threats from which individuals are entitled to socially guaranteed protection must be those from which such protection can be "justifiably demand[ed] of others." ${ }^{211}$ Shue identified a number of considerations that should matter in our assessment of whether the demanded protection from a threat would be justified. Standard threats to the substance of a right, and those from which protection should be socially guaranteed, are those that are "most common," "serious," "typical," "eradicable," and "remediable.", 12

\footnotetext{
${ }^{210}$ Shue, pp. 30-31.

${ }^{211}$ Ibid., p. 31.

${ }^{212}$ Ibid., pp. 32-33.
} 
Though instructive, this list of properties is in need of refinement. From the five properties listed by Shue one can derive three specific conditions for what counts as a standard threat. First, the claim that to be a standard threat a threat must be eradicable and/or remediable are specific instances of a more general principle that the threats which one is justified in demanding protection from are threats from which protection can be effectively provided. A threat from which protection cannot be provided cannot count as a standard threat as the demand could not be justified since the effort expended would be futile.

Second, a standard threat for Shue must also be typical and/or common. Shue can't simply mean that one does not have a right to socially guaranteed protection against threats to the substance of a right that rarely occur. For it is often those rare occurrences that are the most glaring examples of a failure to provide the necessary social protection for the substance of a right. Instead, if we look again to the underlying claim that for a right to be effective the demanded protection must be justified, requiring that the threat be common or typical would serve an epistemic role. One could not justifiably demand that the substance of one's rights be protected against an unknown threat. Thus, the threat must be known or, at least knowable. What the known or knowable threats to the substance of a right are will depend, to a great extent, on the substance of the right itself.

Shue also contends that the threat must be serious. I am not certain why seriousness is not contained in the prior properties of a standard threat. It would seem that any known or knowable and remediable threat to a basic right is serious. A serious threat would likely be one that is a direct and actual threat to the substance of the right. It would be one that is either intended to prevent the enjoyment of the substance of a right 
or with a high probability of preventing such enjoyment. A non-serious threat would be one that is not intended to prevent the enjoyment of the substance of a right and there is a low probability that it would result in the prevention of such enjoyment.

In addition, Shue contends that what may count as such a threat is likely to change as times change. ${ }^{213}$ For example, in a bygone era, smallpox may not have counted as a standard threat to health as it was not remediable by the medical techniques of the time. However, as medicine and the understanding of such diseases advanced a cure for smallpox became a reality, and arguably the threat of smallpox became a standard threat.

There is one additional and important aspect of a standard threat that I think Shue fails to recognize. If standard threats to the substance of a basic right are those from which one is justified in demanding socially guaranteed protection, the threat from which one is entitled to protection cannot be morally justified. If the threat in question is morally justified, then it is morally permissible. This would give the agent engaging in the threat a moral entitlement to engage in the underlying behavior. It would, at the very least, be paradoxical to say that a basic right gives the right holder a rational basis for a justified demand of socially guaranteed protection against a threat that the threatening moral agent has a moral entitlement in which to engage.

Thus a standard threat to the substance of a right is one against which protection can be provided, it must be known or knowable, the relationship between the threat and the substance of the right must be direct and either intended to prevent the enjoyment of the substance of a right or with a high probability of preventing such enjoyment, and the threat must not be morally justified. Ambiguity in the concept of a standard threat

${ }^{213}$ Ibid., p. 33. 
remains, and though the conditions delineated provide some guidance, a more precise understanding of what counts as a standard threat is in need of further explication. I will not engage in that project here, as the line drawn need not be precise for my purposes. If there exist threats to physical security that would give rise to a moral obligation to intervene that are clearly standard then there is no need to worry about the ambiguous fringes of the concept.

Understanding what counts as a standard threat only provides one with an understanding of one aspect of the content of a moral obligation implied by basic right. One is to be protected against standard threats, but in what way? As Shue argues, a basic right implies a moral obligation that the substance of a right be socially guaranteed $-\mathrm{a}$ right holder must be able to enjoy the substance of the right as a matter of entitlement, rather than as a matter of luck or beneficence. ${ }^{214}$ Thus, for a basic right to be fulfilled one must actually have the substance of the right provided and protected by social institutions.

Determining whether an obligation of intervention would be implied by the basic right to physical security requires that we first understand what counts as a standard threat to physical security. Harm to an individual inflicted by other human agents would seem to be an obvious candidate. Such harm is certainly a threat from which socially guaranteed protection could be provided. It is the type of threat that is known or knowable. By its very nature, such harm would be a direct threat to the physical security of right holders. However, it is the case that in many instances harm or the threat of harm to the physical security of a right holder may be justified. Thus, we must distinguish between justified and unjustified threats of harm.

${ }^{214}$ Ibid., pp. 16-18. 
For the purposes of the present project, a complete discussion of the difference between threats to physical security that are justified and threats that are not justified would be needlessly lengthy and complicated. An action is justified if it is based upon a particular type of reason, namely one that renders the action in question morally permissible. It is important to understand that my present reference to reasons is not concerned with the reasons people take themselves to have, or reasons that provide an explanation for an agent's action - subjective reasons. Rather, I am referring to a conception of objective reasons - reasons as relations between facts in the world and agents. ${ }^{215}$ Reasons that justify an action or attitude are based on the normative relationship between the agents involved. For a reason to justify an agent harming or threatening harm to another's physical security it must be based on the fact that the agent's harming or threatening harm to another's physical security is necessary to protect something of sufficient moral value. In other words:

To be justified in harming or posing a threat of harm to a holder of the basic right to physical security it is necessary that:

1. The harm or threat of harm to the physical security of others is necessary to protect something of sufficient moral value; and

2. Only that much harm or threat of harm as is necessary to serve 1 . is permitted.

A harm or threat of harm to the physical security of a holder of the basic right to physical security would be unjustified if it failed to meet either of the two identified conditions. Such an unjustified harm or threat of harm would be a candidate for a standard threat to physical security. These two conditions are not likely to exhaust the necessary and

${ }^{215}$ Joseph Raz, Engaging Reasons: On the Theory of Value and Action (Oxford: Oxford University Press, 1999), footnote 4, p. 22. 
sufficient conditions for harm or a threat of harm to be justified, but they should suffice for my present purposes. ${ }^{216}$

Regarding the content of the obligations implied by the basic right to physical security, at least two relevant questions remain. First, is the basic right to physical security capable of implying an obligation to intervene? Second, would that obligation be distinctively humanitarian? I will deal with the latter question first. An obligation that is distinctively humanitarian is, at the very least, one that is based on the suffering or circumstances of individual moral agents, and is one in which the requisite normative relationship between obligor(s) and obligee(s) is basic and does not depend on the fulfillment of additional moral conditions. Lastly, to be distinctively humanitarian, the obligation cannot be directed at the promotion of some alternate moral good. Rather, it is an obligation to the individual moral agent qua individual moral agent and not for some other purpose.

Basic rights are held by individual moral agents, the obligations implied by basic rights are directly implied by those rights without the need for any additional mediating principles, and the obligations implied by basic rights are directed simply at the fulfillment of the demands of the right and are not directed at the promotion of any alternate moral value. Obligations implied by the basic right to physical security meet all three conditions, and as a consequence, are distinctively humanitarian.

Returning to the first question raised above, is the basic right to physical security

${ }^{216}$ One could argue that not only must the moral value being protected be of sufficient moral weight, but that the person being harmed or threatened with harm must be the cause or be contributing to the threat to the moral value being protected. For an example, see David Rodin's discussion of "innocent aggressors". David Rodin, War \& Self-Defense (Oxford: Oxford University Press, 2002), pp. 80-83. 
capable of implying an obligation to intervene? The short answer is yes. Under the appropriate circumstances, if providing the socially guaranteed protection demanded by the right to physical security required intervention, then there would exist an obligation to intervene. This, however, begs the question, "What are the appropriate circumstances?" Identifying the "appropriate circumstances" will depend on the identification of a standard threat to physical security which requires intervention for physical security to be socially guaranteed. I will not propose such a standard threat now; rather, at the end of this chapter I will assess whether the genocide in Rwanda would count.

Whether the basic right to physical security is capable of implying an obligation to intervene of the requisite nature remains to be discussed. The key to understanding the nature of an obligation implied by a basic right is to be found in the fact that a basic right serves as a rational basis for a justified demand that the substance of the right be socially guaranteed against standard threats. It should be readily apparent that if a moral obligation to intervene is implied by the basic right to physical security, it would, at the very least, be a first-order reason to intervene. But, is such an obligation a second-order exclusionary reason?

There are a number of reasons for accepting the conclusion that the obligation to intervene implied by the basic right to physical security is a second-order exclusionary reason. First, Joseph Raz has proposed a phenomenological test for assessing, as a matter of descriptive fact, whether we treat a particular reason as a second-order exclusionary reason. ${ }^{217}$ According to Raz, we can determine whether we are treating a reason as a second-order exclusionary reason if the balance of first-order reasons directs that we

${ }^{217}$ Joseph Raz, Practical Reason and Norms, pp. 37-45. 
perform one action, but as a result of our practical deliberations we conclude that we ought not perform that action or that we ought to perform another action because one of the reasons is not simply to be balanced, rather it affects the very first-order reasons that are to be balanced resulting in a different practical conclusion.

An example will likely help to elucidate the test. Imagine that there is a stop sign in the middle of the desert. ${ }^{218}$ You are traveling late at night and the chance that you are going to be caught if you fail to heed the stop sign is practically nonexistent. The stop sign places you under a legal obligation to stop. Thus, you have a first-order reason to stop, but you have a number of countervailing first-order reasons to continue on without stopping. We can assume that your first-order reasons for not stopping (it is late, you are late and in a hurry, there is no one else around, etc...) outweigh your first-order reasons for stopping. You, however, choose to stop. In your explanation, you say that the fact that you had a legal obligation to stop rendered certain reasons irrelevant to your consideration of how you ought to act. If you choose not to stop, we may understand why - you are acting on your first-order balance of reasons - but, provided the law was not contradicted by a countervailing moral consideration, we would be justified in criticizing you for failing to adhere to the obligation. In this instance, we are treating the obligation to stop as a second-order exclusionary reason.

It is likely that an obligation of humanitarian intervention would pass this phenomenological test. This, however, is merely a descriptive account explaining the phenomenology associated with a second-order exclusionary reason. It is a post facto explanation rather than a way to understand how we should treat an obligation to

${ }^{218}$ I need to find the origin of this example. 
intervene when we are engaging in practical deliberation. It may be relevant that this is how we do treat such moral demands, but it cannot be determinative of how we ought to treat them. I would like, therefore, to offer additional reasons for accepting the claim that obligations are second-order exclusionary reasons.

The first consideration is an argument that our considered moral judgments about the nature of obligations reveal that they are to be treated as second-order exclusionary reasons. Let us begin with the following question: If I have an obligation to (X) why should that be thought of as a second-order exclusionary reason?

Scenario 1: Let's assume that the obligation to $X$ is an ordinary first-order reason for action, a first-order reason to $X$. This would mean that whether or not one ought to $X$ is a matter of weighing. If the countervailing reasons against $X^{\prime}$ ing outweigh the obligation to $X$, then one ought not $X$.

One problem with thinking about obligations as first-order reasons for action is that the countervailing reasons against $X^{\prime}$ ing may be entirely practical. Recall the example of Albert and Beatrice. It would at the very least be odd to say that a moral obligation to do something can be defeated by purely practical reasons, short of practical impossibility, against the performance of the action.

One might respond that obligations are simply very weighty first order reasons. I am not sure why we should believe this. Imagine that the obligation to $X$ is an obligation of reciprocity to help a neighbor finish a project. There is little left to be done, but the neighbor is expecting and relying upon your help. It is not clear why we should think of this obligation as exceptionally weighty, unless we believe that there is something distinct about obligations. Yet, it would be wrong to fail to fulfill the obligation for reasons of a 
purely practical nature, even if those practical considerations appear to be as, if not more, weighty.

Scenario 2: Let us assume instead that the obligation to $(\mathrm{X})$ is a second-order exclusionary reason precluding certain first-order reasons against $X^{\prime}$ ing from consideration in the practical deliberations of states, and a first-order reason to $X$. In this case, the obligation to $X$ is weighed against other second order reasons and it is only those first-order reasons that are not precluded by the exclusionary effect of the obligation that are weighed at the first-order.

Let us return to the example of the reciprocal obligation to help your neighbor. If your neighbor claims that you are under an obligation, then he is claiming that at least some of the purely practical reasons for failing to fulfill the obligation are precluded from consideration. Pursuant to this understanding of the nature of obligations, one could see why a weak first order obligation could still have the effect one thinks it ought to have. Admittedly, if the obligation to $X$ is a significant moral obligation whether it is a first order reason or a second-order reason may be irrelevant when factored in to our practical deliberations.

If we look to Cicero's discussion of obligations, we find an early assessment of the role obligations are supposed to play in our practical deliberations. ${ }^{219}$ Specifically, they are reasons for acting in accordance with the demands of an obligation even in the face of interests that command otherwise. ${ }^{220}$ If we look to more contemporary accounts of legal, conventional, and moral obligations, the claim to their status as obligations is

${ }^{219}$ Cicero, Book One, pp.5, 23.

${ }^{220}$ Ibid., p. 23. 
supposed to grant them a second-order exclusionary role in our practical deliberations. Take, for example, the obligations of judges in a legal system. Provided the case being decided by a judge is one to which a law applies, judges in a legal system are under an obligation to apply the law. ${ }^{221}$ What this means, according to Raz, is that a judge "regards himself as justified in acting on some reasons to the exclusion of others." ${ }^{222}$

Simply stated, our considered moral judgment reveals that one aspect of obligations is that they are second-order exclusionary reasons. The objection can only be that obligations don't exist, and not that this is not how they work. Thus, if the basic right to physical security does, under the appropriate circumstances, imply a moral obligation of intervention, then that obligation is a second-order exclusionary reason precluding certain first-order reasons against intervention from consideration.

The rejection of this somewhat strong claim about the nature of all obligations does not imply that the obligation of humanitarian intervention is not a second-order exclusionary reason. Assuming such a rejection, there are at least two arguments that can be pressed in response. First, if it can be demonstrated that all obligations correlative to rights are exclusionary reasons, then the obligation of humanitarian intervention implied by the basic right to physical security would be such an obligation. Alternatively, one could provide an argument that directly addresses the obligation of humanitarian intervention implied by the basic right to physical security.

In either case, we need to look to the role we take rights to play in our practical deliberations. I take it as fundamental to our understanding of the claim that one has a

\footnotetext{
${ }^{221}$ Raz, Practical Reason, pp. 139-141.

${ }^{222}$ Ibid., p. 144.
} 
right that we believe we have an entitlement to the substance of the right. If I claim that I have a right that $Y$ does $X$, then I am claiming that I am entitled to $Y X^{\prime}$ ing and that $Y$ is under an obligation to $X$. When claiming such a right, I am not claiming that $Y$ 's obligation to me is merely a reason for $Y$ to $X$, I am claiming that $Y$ must $X$ unless some other moral reason for action outweighs $Y$ 's obligation to me to $X$. I am claiming that the obligation $Y$ owes to me precludes her from even considering certain reasons in her practical deliberations over whether she ought to fulfill her obligation to me - that certain reasons against $X^{\prime}$ ing are simply irrelevant.

Assuming that I am correct in my claim that $\mathrm{I}$ have a right to $X$ held against $Y$, then if $Y$ were to fail to $X$ and offered no other reasons for the failure other than practical reasons short of practical impossibility, then $Y$ simply does not understand what it means to be the bearer of an obligation that is correlative to a right. If, on the other hand, $Y$ 's failure was due to the fact that $Y$ (believed that she) had a competing moral obligation that outweighed her right-based obligation to me, her failure would be justified if she properly weighted and weighed the competing moral claim.

If, however, one is not convinced of the claim that all obligations correlative to rights are second-order exclusionary reasons, I may yet succeed if I can demonstrate that there are good reasons for believing that the obligation of intervention implied by the basic right to physical security is such a reason. If we assume that human rights exist, which we must if we are to determine what role human rights ought to play in the practical deliberations of other agents, they cannot simply be ordinary reasons for action. If they were simply ordinary reasons for action one would be able to deny another's rights if a sufficiently weighty countervailing first-order reason were to arise. By their very 
nature human rights act as constraints on the practical deliberations of those who bear the correlative obligations. But how? A human right precludes others from considering certain reasons for action. Specifically, it precludes others from considering certain reasons against the fulfillment of the obligation correlative to the basic right.

It is important to note, however, that second-order exclusionary reasons are not limitless. They have limits in both their strength when compared to other second-order reasons and in the breadth of the first-order reasons they preclude. ${ }^{223}$ It could be the case that another countervailing second-order reason outweighs the second-order exclusionary reason in question, or that there are certain first-order reasons against the action that the obligation in question supports that are also outside the reach of the exclusionary aspect of the obligation. The relevance of these limitations will become more apparent when I assess whether this basic right to physical security would have implied an all-thingsconsidered moral obligation of humanitarian intervention in the Rwandan genocide.

\subsection{Charity or Justice}

There remains at least one substantial objection to a moral obligation of humanitarian intervention. More specifically, it is an objection to the role I claim such an obligation should have on an agent's practical deliberations. I have, to this point, assumed that all moral obligations are univocal in at least one sense - all other things being equal they demand consideration in one's practical deliberations. However, it is often claimed that some obligations are perfect and others imperfect, and it is only the former that carry such normative weight. I am arguing that the moral obligation of humanitarian intervention demands consideration. Many contend that obligations to

${ }^{223}$ Ibid. pp. 46-47. 
distant others are, by their very nature, imperfect obligations that admit of a wide range of discretion and as such are incapable of making the requisite demand on an agent's practical deliberations.

\subsubsection{Explaining the Objection}

The objection being considered is based on the claim that the source of an obligation is determinative of its nature and strength, and the role it ought to play in the practical deliberations of an agent. ${ }^{224}$ The underlying argument would proceed as follows:

Premise 1: Only complete obligations make non-discretionary demands on an agent's practical deliberations.

Premise 2: Only matters of justice, special relationships, or promises can give rise to complete obligations.

Premise 3: Only negative obligations can count as matters of justice. ${ }^{225}$

Premise 4: The moral obligation of humanitarian intervention is based neither on a promise nor a special relationship, and is a positive obligation.

Conclusion: The moral obligation of humanitarian intervention cannot be complete, and therefore does not make non-discretionary demands on the practical deliberations of agents.

In the discussion that follows, I will, for the sake of argument, concede the truth of Premise 1, and I will accept the claim that the moral obligation of humanitarian intervention is based on neither a promise nor a special relationship.

In the argument presented above, Premise 3 sets a standard that defines the

\footnotetext{
${ }^{224}$ Onora O'Neill, “The Great Maxims of Justice and Charity," Constructions of Reasons: Explorations of Kant's Political Philosophy (1989), pp. 219-221. See also Allen Buchanan, "Justice and Charity", Ethics 97 (1987), pp. 558-75, 561-562. The proponents of such a view range across philosophical and ethical commitments.

${ }^{225}$ O’Neill, “The Great Maxims,” pp. 219-221.
} 
boundary of justice. It is argued that the moral obligation of humanitarian intervention falls outside that boundary and for that reason cannot be a matter of justice; and as a consequence, is not capable of being complete and thus cannot make the requisite demands on an agent's practical deliberations. There are two bases for the claim that only negative obligations (obligations of non-interference) can count as matters of justice.

First, as many libertarians claim, to require more would be a violation of an individual's rights of self-ownership. ${ }^{226}$ Second, as Onora O'Neill points out, for many liberals the premise is based on the claim that positive obligations require a conception of the "good for man" or the "good life" to which we do not have epistemic access, thus no basis for action. ${ }^{227}$ Consequently, we can't require that an agent act on them.

With regard to Premise 2, its basis can be found, at least in part, in the discussion of the underlying basis for Premise 3. Obligations of justice are complete because they are determinate with regards to the scope and content of the obligation. ${ }^{228}$ Negative obligations (obligations of non-interference) are argued to be inherently determinate as they require that each of us refrain from doing certain things to every other. O'Neill, I believe, rightly points out that this does not make them determinate in the abstract, but only in their actual application, and that the determinacy of such obligations will admit of

${ }^{226}$ O'Neill, “The Great Maxims," pp. 219-221. See also, Robert Nozick, Anarchy, State, and Utopia (New York: Basic Books, Inc., 1974), pp. 32-34, 47. And see, Pogge, World Poverty and Human Rights, p. 13.

${ }^{227}$ O’Neill, “The Great Maxims," pp. 219-221. See also Sandel, pp. 1-7. And see Isaiah Berlin, Four Essays on Liberty (Oxford: Oxford University Press, 1969), pp. 118172.

${ }^{228}$ O'Neill, “The Great Maxims,” pp. 224-225. 
degrees. ${ }^{229}$ I will, however, for the sake of argument, accept the claim that obligations of justice are inherently complete. In addition, Premise 2 is based on the claim that obligations to aid that are not based on a promise or special relationship are inherently and irreparably incomplete. There are two potential bases for such a claim. First, as was discussed above, due to the plurality of conceptions of the good life and lack of epistemic access as to which is correct the content and scope remains indeterminate. Second, even if we can determine what the good life is, we are unable to determine how to promote it for any given individual and upon whom such an obligation should fall.

\subsubsection{Defending the Completeness of the Moral Obligation of Humanitarian}

\section{Intervention}

My reply to this potential objection is comprised of two distinct but related responses, either one of which could serve as the basis for a separate reply, but should also be understood jointly. In the first response, for the sake of argument, I will accept the truth of Premise 2, and argue that the moral obligation of humanitarian intervention should be considered to be a matter of justice, and thus capable of being complete. In the alternative, in the second response, I will accept the truth of Premise 3, and argue that positive obligations (to aid, of charity, of beneficence) can be complete and that the source-based distinction between perfect and imperfect obligations should be rejected.

Assuming Premise 2 is true, the next premise in the argument against the claim that consideration of the moral obligation of humanitarian intervention in our practical deliberations is nondiscretionary is that only negative obligations - obligations of noninterference or obligations to refrain from acting - count as matters of justice. Taken

${ }^{229}$ Ibid., p. 224. 
together these two premises imply that only negative obligations are nondiscretionary. In the response that follows, I am challenging the claim in Premise 3 that only negative obligations can count as matters of justice.

Justice, I take it, is the moral minimum to which we are each entitled. With this conception of justice in mind, if the moral minimum to which we are each entitled implies, either directly or indirectly, a positive obligation then the claim that being a negative obligation is a necessary condition for being a matter of justice fails and certain positive obligations may then make nondiscretionary demands on our practical deliberations. Here, I will deal explicitly with the basic right to physical security and the moral obligation of humanitarian intervention which it implies.

If we understand an entitlement to $X$ to mean that one has a claim on others to have $X$ provided, then this would mean that if $X$ was part of the moral minimum to which we are entitled that $X$ must be provided as a matter of justice. If we are entitled to anything at all we are entitled to our physical security. ${ }^{230}$ As a consequence, the physical security of each individual must be provided as a matter of justice. In some cases fulfilling this obligation may require intervention. Thus, the moral obligation of humanitarian intervention implied by the basic right to physical security as a matter of justice may directly imply a positive obligation to intervene.

One might object to this argument in, at least, two ways. First, it could be claimed that the obligation to provide physical security cannot be a matter of justice because it is a positive obligation to act. Positive obligations require a particular conception of the good life to which we do not have epistemic access, and thus cannot serve as the basis for a

${ }^{230}$ Shue, pp. 18-22. 
justified demand on others. As an objection, what is being claimed is that there are no epistemically unproblematic conceptions of the good life, and to require one to aid another based on a particular conception of the good life cannot be demanded of another and thus cannot be an action to which one could be entitled. If it can be shown that a particular obligation to aid is not epistemically problematic then it would seem that this objection would fail.

The obligation under consideration is an obligation to aid in only the most minimal sense. Specifically, it is an obligation to protect individuals from an unjustified threat to their physical security. Does this require having an epistemically problematic conception of the good life? It would seem that even the claim that the only justified obligations are those which demand non-interference are intended to protect individual conceptions of the good life. If that is the case then there is something implicitly valuable about people being able to act upon their own conception of the good life. If their physical security is threatened, then they will be unable to do so. This does not involve an epistemically problematic conception of the good life, rather it is a necessary condition of any conception of the good life that an agent's physical security be protected. ${ }^{231}$ Thus, our presumption should be that action to protect the physical security of others is fundamental unless it is demonstrated in a particular case that this is not the case.

The alternative objection is much more problematic for the line of argument I am presently pressing. The objection would challenge the claim that an entitlement of justice

${ }^{231}$ This is very similar to the argument Shue puts forward regarding our understanding of basic rights. See Shue, 21, 37-38. 
to $X$ is to have $X$ provided. ${ }^{232}$ Rather, an entitlement to $X$ as a matter of justice simply means that others refrain from interfering with your pursuit of $X$. This objection can't be based on concerns of incompleteness, as I have demonstrated that such problems will or can be resolved. This line of objection is based on a substantive claim about the nature and limits of the demands of justice. Essentially, it is the claim that to require more than noninterference would unjustifiably infringe upon the rights to liberty of those upon whom the obligation would fall. ${ }^{233}$

This objection is based upon the proposition that rights to liberty are virtually absolute, meaning that only under the most exceptional circumstances can they be infringed upon. As Nozick claims with regard to the right of self-ownership, "It will be as if an absolute side constraint prohibits their being sacrificed for any purpose." ${ }^{234}$ If, however, rights to liberty are not so demanding, one could claim that an obligation to act is a matter of justice either because it outweighs the right to liberty, or it is outside the reach of the right to liberty at issue.

The underlying conception of rights to liberty as absolute should be rejected for the following reasons. First, if all such rights are absolute, then we have no means by which we can resolve conflicts of different types of rights, for example a conflict between one person's right to liberty of action with another's right to dispose of their property as

${ }^{232}$ John Hospers, "What Libertarianism Is" from Tibor R. Machan, ed., The Libertarian Alternative: Essays in Social and Political Philosophy (Chicago, IL: Nelson Hall Company, 1974), pp. 3-20. See also Shue's discussion of the libertarian conception of justice. Shue, p. 19.

${ }^{233}$ Hospers. See also Nozick, pp 32-34, 47. And see Pogge, World Poverty and Human Rights, p. 13.

${ }^{234}$ Emphasis in original. Nozick, p. 47. 
they see fit. In addition, a conception of rights as absolute gives rise to the practical absurdity that we are forbidden from forcing a person to part with a portion of their property even if doing so would save lives. It may be the case that it would be an unjustified demand on your right to liberty if I were to claim that you had to sacrifice your life for mine, but this is not what is being claimed. Rather, the claim is that I am demanding that you sacrifice resources to support an army in stopping others from taking my life. I have not discussed the issue of conscription in order to fulfill the moral obligation of humanitarian intervention, and I will not do so here. It is an interesting question, but one that I am avoiding as it bears little on the claims I am defending here. Another reason for rejecting the conception of rights underlying this objection is that those making the objection are focused on only one half of the binary relationship that defines the normative implications of the demands of justice. The demands of justice imply negative obligations, but those obligations are based on the entitlement to noninterference held by individuals. In many cases an individual's right to bodily security - an entitlement of justice to not have their bodily security interfered with - is violated. In such cases it is not enough to look only to the fact that the obligations directly correlative to the right are negative. The right of noninterference gives rise to an obligation on all others to insure that the right of noninterference be fulfilled - it is still an entitlement to not have one's bodily security interfered with. Fulfillment of this entitlement will in some cases require intervention because the right to noninterference when violated requires positive action to stop the violation and to insure that the right not continue to be violated. To argue otherwise would lead to the unreasonable proposition that one only has a claim of assistance against those who are violating his / her rights. 
There is one additional objection which must be noted (if not responded to satisfactorily). One may, in the end, deny that a basic right to physical security is a matter of justice. In that case, those obligations that it implies cannot be matters of justice and if the source of an obligation determines whether consideration is discretionary or not, then such obligations would not need to be considered in our practical deliberations. This objection, if correct, would imply that there are no matters of justice for if there are any at all, the basic right to physical security must be one as it is necessary to the enjoyment of all others. As Henry Shue notes, the function of the basic right to physical security, as well as other basic rights, is "to provide some minimal protection against utter helplessness to those too weak to protect themselves. ${ }^{235}$ If those making this objection persist all that I can offer in response are the arguments already made and my concurrence with Shue's belief that "few, if any would be prepared to defend in principle the contention that anyone lacks a basic right to physical security." ${ }^{, 236}$

Turning now to the second response, arguing in the alternative, I will accept the truth of Premise 3, but argue that one ought to reject premise 2. The underlying claim that supports the objection being considered is that the source of the obligation determines the nature and strength of the obligation. Matters of justice are perfect and matters of charity are imperfect. This distinction is too blunt, and I will argue misconceives the relationship between completeness and justice, and that properly understood the relevant considerations entail that the moral obligation of humanitarian intervention implied by the basic right to physical security is, under the appropriate

\footnotetext{
${ }^{235}$ Shue, p. 18.

${ }^{236}$ Raz, Practical Reason and Norms, p. 21.
} 
circumstances, a perfect as opposed to an imperfect obligation.

I concede that there is a distinction between perfect and imperfect obligations.

What needs to be discerned, however, is the basis for such a distinction. How are we to determine whether an obligation is perfect or imperfect? A perfect obligation is complete, an imperfect obligation incomplete. ${ }^{237}$ So what is required for an obligation to be complete? One might think that for an obligation to be complete each of its constitutive elements must be identified with sufficient clarity. This is partially correct. To be complete one must be able to identify with sufficient clarity the scope of the obligation and its content. Completeness, however, does not depend on the identification of the nature and strength of the obligation; rather the completeness of an obligation is relevant to our determination of the nature and strength of an obligation.

A complete (or perfect) obligation is one which admits of little or no discretion. But discretion in what? A complete obligation admits of little or no discretion in our consideration of the obligation in our practical deliberations. If we know the scope and content of the obligation with sufficient specificity, and the obligation is one that places moral demands on us then we must consider it in our practical deliberations. Those who contend that the source of an obligation is determinative of an obligation's completeness, must explain how the source of an obligation can preclude us from determining to whom the obligation is owed, who bears the obligation, and what it is an obligation to do.

One might object that a complete obligation is an all-things-considered moral ought, and that only matters of justice can satisfy such a condition. ${ }^{238}$ What that would

\footnotetext{
${ }^{237}$ O’Neill, “The Great Maxims,” pp. 224-225.

${ }^{238}$ Buchanan, pp. 558-75, 561-562.
} 
mean is that only those obligations that outweigh and override all other obligations in our practical deliberations are complete. If that is what is meant by a complete or perfect obligation, then I will concede that the moral obligation of humanitarian intervention is not complete, but then neither are most moral obligations that are often take to be complete, no matter their source. Such an obligation would have to be absolute and indefeasible. Such obligations may exist, but they are not going to be the type of obligation that we typically think of as being complete. The obligation not to lie, not to kill, not to harm are all obligations in which the scope and content of the obligation is determinate, and thus one is required to consider such obligations in their practical deliberations. But none these obligations are complete if what we mean is that they always override or outweigh or override other obligations.

I think a more charitable understanding of what is meant by completeness is that an obligation is complete if ceteris paribus it would be determinative of what an agent ought to do. If this is a correct understanding, then there is no principled reason to think that only matters of justice could fulfill such a role unless obligations of justice are the only ones from which the scope and content of the obligation can be identified with sufficient clarity.

One might contend that as a matter of fact, most if not all obligations of justice are perfect in just the sense being described and most if not all obligations of charity are imperfect in just the sense described, and that this gives us good reason for the distinction. I will assume the truth of this possible claim for the sake of argument. It, however, does not provide a principled reason for distinguishing perfect from imperfect obligations based on their source. At best, it provides us with a heuristic reason for 
presuming that obligations of justice are perfect and obligations of charity imperfect.

Another objection that may be raised against the possibility of obligations of charity being complete is that an obligation of charity is problematic according to the objector because its content is going to vary from person to person because there is no universal conception of the good life, and we have no way of knowing what is good for each individual agent we encounter. Thus, the content of the obligation lacks sufficient clarity. In addition, the scope of an obligation of charity cannot be identified with sufficient clarity. It is either too broad or too narrow. In any particular case it would be unclear to whom the obligation is owed, or from whom help could be justifiably demanded. On the other hand, if the obligation is owed by each of us to everyone who is in need, the obligation becomes too burdensome and our lives and life goals are sacrificed for the good of others which in the end due to the plurality of subjective conceptions of the good life may actually do more harm than good. ${ }^{239}$

If we think that obligations should only be thought of in isolation from the everyday circumstances in which they arise, then it may be the case that obligations to act are incapable of being complete. However, it would seem that if our concern is with the effect an obligation should have in our practical deliberations about what we ought to do, then we must consider the circumstances under which an obligation arises. To assess the nature of an obligation in isolation from other relevant considerations, especially moral ones, would undermine the understanding that we are seeking to attain. If there is a single

${ }^{239}$ This is an often raised objection to Singer's principle in "Famine Affluence and Morality." Peter Singer, "Famine, Affluence, and Morality", pp. 231-232. Some versions of this objection include the following: Samuel Scheffler, "Relationships and Responsibilities", Philosophy \& Public Affairs, 26 (1997), pp. 189-209; and see Garrett Hardin, "Life Boat Ethics" from Psychology Today (September, 1974). 
instance in which an obligation of charity when viewed in light of the surrounding circumstances would identify with sufficient clarity the scope and content of the obligation then it is possible for an obligation of charity to be complete and thus perfect. If such an obligation can be demonstrated to exist one can conclude that it is not the source of the obligation that determines whether the obligation is complete. Rather, an obligation is complete if under the surrounding circumstances the scope and content of the obligation can be identified with sufficient clarity.

One example of an obligation can be found in Ernest Weinrib's argument for a duty of easy rescue. ${ }^{240}$ In short, Weinrib argues that under certain conditions one is morally obligated to aid an individual who is in need of rescue. In response to the complaint that a moral duty of rescue would be incomplete due to the fact that, in isolation, one cannot identify with sufficient clarity the scope and content of the obligation, Weinrib assesses the obligation not in isolation, but set in a particular circumstance. Specifically, Weinrib argues that in an emergency situation in which a single individual is at risk of serious harm and another individual could help and is the only one capable of helping, the nature of the emergency will identify with sufficient clarity the content the scope of the obligation. In this case, the obligation that in isolation was incomplete is rendered complete when viewed in light of the relevant surrounding circumstances.

It must be admitted that obligations of charity will be amenable to such circumstantial reconstruction to varying degrees. As a consequence, even if the possibility of such an obligation does exist, it merely allows for the possibility that the

\footnotetext{
${ }^{240}$ Weinrib.
} 
moral obligation of humanitarian intervention could be such an obligation. It remains to be determined whether there is a conceivable circumstance in which the basic right to physical security would imply an obligation to intervene in which the content and scope of such an obligation is identified with sufficient clarity. I will set this question aside for a moment and return to it again in my assessment of the Rwandan genocide, as I believe that the Rwandan genocide and its surrounding circumstance was just such an event.

Onora O'Neill offers an interesting but underdeveloped resolution to the problem of incompleteness. O'Neill argues that one can resolve the problem of incompleteness of an obligation of charity through the institutionalization of the obligation. ${ }^{241}$ In short, by institutionalizing the obligation we would, by convention, match those in need of aid with those who are capable of providing it, thus resolving one aspect of the problem of incompleteness - scope. O'Neill fails to recognize, however, the fact that the institutionalization of an obligation of charity does not address the other fundamental complaint that the content of obligations of charity cannot be identified with sufficient clarity.

There are two problems with the claim that the institutionalization of an obligation of charity would identify with sufficient clarity the content of the obligation. First, in order to institutionalize an obligation and match those in need of aid with those capable of providing it one must know the content of the obligation in advance, as that is what is being institutionalized. The content is indeterminate, according to the incompleteness objection being addressed. Institutionalization does not resolve this indeterminacy.

${ }^{241}$ O'Neill, “The Great Maxims,” pp. 224-225. 
Someone might contend that since the institutionalization of the obligation is conventional, we can choose whatever content of the obligation we want. This would, however, miss the point of the objection and also gives rise to the other flaw in this institutionalization based resolution. From the perspective of conventional systems what we can institutionalize is limited only by practical concerns. What we want from the institutionalization of a moral obligation requires more. The question is not what can we institutionalize, but what are we justified in institutionalizing. Thus, from O'Neill's argument we can take away the following lesson. Once we have identified, with sufficient clarity, the content of a moral obligation of charity, we can, through the institutionalization of the obligation, identify with sufficient clarity the scope of the obligation by matching those in need with those capable of helping.

The argument begs the question, whether the content of the moral obligation of humanitarian intervention can be justified independently. As I have argued above, I believe it can. From a rights-based perspective, if we are to have any rights at all we must have basic rights. The most fundamental basic right is a right to our physical security for without physical security one is incapable of enjoying their other rights as rights. In addition, if there is anything that is common among conceptions of the good life it must be physical security. For without the certainty that physical security provides, the possibility of a good life (by any measure) is greatly undermined.

I have been considering the objection that the moral obligation of humanitarian intervention implied by the basic right to physical security, since it is not an obligation of justice, admits of a wide range of discretion in our practical deliberations about how to discharge the obligation. The concern at the heart of the objection is that obligations to 
act admit of a wide-range of discretion, either because they are not complete or, assuming the source-dependent argument is correct, that they can't be matters of justice. I think the former concern is valid, that an incomplete obligation admits of a wider range of discretion in our consideration of the obligation in our practical deliberations. However, I hope to have demonstrated that there are good reasons for believing that the basic right to physical security and the obligations it implies are matters of justice; or in the alternative, that an obligation to act can be rendered complete either by the circumstances under which the obligation arose, or by the institutionalization of the obligation.

\subsection{Defending the Basic Right to Physical Security}

To this point my argument has been conditional. If one accepts the existence of the basic right to physical security, or human rights at all, then there may exist circumstances under which it would be unreasonable to deny that a moral obligation of humanitarian intervention exists. I have yet, however, to offer an argument for the existence of the basic right to physical security. There are, however, good reasons for our acceptance of the claim that such a right does exist.

First, we act and speak as if the basic right to physical security exists. Though not determinative of the question of whether the basic right to physical security exists, it evinces a widely held belief in the existence of such a right. In the domestic realm our legal, political, and social institutions are concerned, at least in a large part, with the promotion and protection of individuals' rights to their physical security. Upon reflection it seems to be a fundamental proposition that a community that is unable, or chooses not, to protect its inhabitants' physical security is one that is morally deficient.

In fact, our political rhetoric is not so much concerned with whether such a right 
exists, but how best to serve that right, and a condemnation of those that fail to do so. In H.L.A. Hart's terminology, we have taken the "internal perspective" on the existence of the basic right to physical security. ${ }^{242} \mathrm{We}$ are committed to the protection and promotion of physical security through the formation and maintenance of social institutions, we engage in a critical dialogue with others that is built around such commitment, and we criticize any who (or accept criticism ourselves if we) fail to fulfill the demands of the basic right to physical security.

We can also look to the international political arena for evidence in support of the belief that such a right exists. The creation of treaties and conventions dedicated to the promotion and protection of human rights evinces a belief in, if not a commitment to, the existence of the basic right to physical security. ${ }^{243}$ Here too the political rhetoric surrounding basic rights to subsistence and security takes as its starting point the existence of such rights. It is from this basic premise that critical discussions and criticism proceed.

One may recognize that there is widespread consensus as to the existence of the basic right to physical security, that there is not only rhetoric but action in accordance with the belief that the basic right to physical security exists, but deny that the right in fact exists. The denial is likely to take either of two forms. One might claim that the basic right to physical security does not exist in the form proposed by Shue upon which I have relied. An example of such a denial would be Pogge's claim that rights are rights to non-

${ }^{242}$ Hart, The Concept of Law, pp. 56-57.

${ }^{243}$ For a compilation of such international legal and political documents see Ian Brownlie and Guy S. Goodwin-Gill,eds., Basic Documents on Human Rights (Oxford: Oxford University Press, 2002). 
interference. An alternative form of denial may come from those who deny that rights talk is based on anything real.

As to the former, I have already addressed why I believe the claim that correlative to rights are only negative obligations ought to be rejected. Thus, if one believes (as Pogge does) that there are human rights, then I believe that one is committed to the acceptance of the existence of certain basic rights, including the basic right to physical security.

The alternate form of denial can be further disaggregated. One may be claiming that there is a moral minimum to which we are each entitled, but the moral minimum should not be thought of in terms of rights and correlative duties - denying the existence of a basic right to physical security, but not the existence of morality. On the other hand, one may simply be pressing a skeptical story, that morality does not exist apart from our conventions about what it is.

If one is a committed skeptic, then there is little I can offer except the following. First, our conventions seem to indicate that basic human rights are a part of our morality. Second, if one believes that lives can go better or worse, it must be the case that one way in which a life can go worse is by having one's physical security threatened when the prevention of and protection from such threats is possible. One would likely desire the protection from such threats for oneself. In addition to the fact that consistency would demand the same for others, such protection is likely to be best accomplished through social institutions that provide such protection for all. The more who are outside such social institutions the greater threat they pose to those inside.

As to the first form of denial, I believe the same considerations that lead many of 
us to believe that there is a basic right to physical security should lead others to its functional equivalent. If there is a basic moral minimum, a set of obligations that we owe to others, a line below which one should not be allowed to fall provided we are capable of fulfilling the obligation or preventing the fall, one's physical security would surely be a part of that moral minimum.

\subsection{Conditions from the Objections of the Skeptic, the Communitarian, and the Instrumental Argument}

The moral obligation of humanitarian intervention is not an all-things-considered moral obligation to act. To say that it makes a non-discretionary demand on our practical deliberations, or in this case on the practical deliberations of states, does not mean that whenever it arises we ought to act on it. Therefore, in order to understand when we are morally obligated all-things-considered to act on the moral obligation of humanitarian intervention we must understand what other moral conditions must be met and what other moral considerations must be accounted for in our practical deliberations - that set of conditions under which no one could reasonably deny that a moral obligation of humanitarian intervention exists.

In identifying these additional conditions, I begin by looking back to some of the previously discussed objections to the permissibility of humanitarian intervention. Though none imply the impermissibility of intervention, each is based on relevant considerations that should be accounted for in our assessment of whether, in any particular case, the moral obligation of humanitarian intervention is an all-thingsconsidered moral ought.

The identification of such additional conditions will serve two purposes. First, if 
we are to understand under what conditions the moral obligation of humanitarian intervention should be considered to be an all-things-considered moral ought, then as a matter of practical deliberation it would need to outweigh or preclude other relevant countervailing moral considerations. The additional conditions to be identified below are the most likely countervailing moral considerations. Second, as noted at the outset of this chapter, the project being pursued is, at least in part, a justificatory one. If I am successful in accounting for the underlying concerns of those who object, on theoretical grounds, to the moral permissibility of humanitarian intervention, continued objection on their part would be unreasonable.

\subsubsection{The Skeptic}

What conditions can be derived from the objections of the skeptics? Skeptical objections comes in various forms and from various quarters. Though the skepticism to which each is committed ranges from an outright denial of the possibility of normative theory at the international level to a claim that the obligations of international ethics placed on states are drastically weaker versions of their domestic counterparts, the tie that binds the various form of skepticism together is the priority they assign to the interest of the state. Essentially, the skeptic claims that humanitarian intervention is morally impermissible or practically irrelevant because the only effective obligations a state can have are to itself or to its own inhabitants. It can never have an effective external obligation - obligation to distant others.

However, as discussed above, the mere fact that governments have internal obligations does not preclude states from having external obligations. The strongest justification for the skeptic's claim is that a state is to serve the interests of its inhabitants 
and that acting to aid distant others sacrifices fulfillment of the internal obligations a state has to its own inhabitants to the weaker external obligations it may have to distant others.

So what do we learn from the skeptical objection to the moral permissibility of a moral obligation of humanitarian intervention? What the skeptic does rightly point out is that in many cases external obligations will require a state to sacrifice, at least to a degree, some of the resources instrumental to the fulfillment of its internal obligations. In some cases, the sacrifice required will be too great, and the moral obligation to intervene will be outweighed by the relevant internal obligations at issue. Thus, an additional condition on an all-things-considered moral obligation to intervene is that if too much is sacrificed internally it would be reasonable to reject the moral obligation to intervene. Obviously, this leave open the question as to what counts as too much. However, this is not a question that can be answered in the abstract, but will require the careful consideration of the relevant aspects of a particular circumstance.

\subsubsection{The Communitarian}

The relevant aspect of the communitarian objection to the moral permissibility of a moral obligation of humanitarian intervention is the claim that cosmopolitan theories, like the one I am pressing, fail to properly acknowledge or account for the moral value of community. The value of community comes from its necessary relationship to the pursuit of moral and political self-determination of a people. The value is such that it ought to be protected against the outside imposition of political systems or substantive moral values.

What we learn from this objection is that, as a general proposition, community does have value, and ought to be considered in our practical deliberations over our moral obligations in the international arena. This, however, does not preclude the possibility 
that under the appropriate circumstances an all-things-considered moral obligation of humanitarian intervention exists. The value of a community as a relevant countervailing consideration against the moral obligation of humanitarian intervention will depend on the existence of only a single community in the state in question, on whether a community of the relevant sort exists, and on the degree to which the community in question fulfills the functions which justify our ascription of value to a community.

The mere fact of community and the fact that intervention will interfere with or undermine the community will not automatically outweigh the moral obligation of humanitarian intervention implied by the basic right to physical security. One could, however, reasonably reject an all things considered moral obligation of humanitarian intervention if a community of moral significance is being threatened and the rights violations at issue do not warrant the harm caused to such a community.

\subsubsection{The Instrumental Argument}

The instrumental argument is that international relations are governed by the state system, and a fundamental tenet of the state system is that the sovereignty of states should be respected. Such respect includes the right of each state to be free from intervention. The state system, and the respect for state sovereignty upon which it relies and demands, is instrumental to the provision and maintenance of international peace and security. It is the instrumental relationship between the protection of state sovereignty and international peace and security that renders humanitarian intervention morally impermissible.

The instrumental nature of this argument is key to understanding its limitations. I will assume that international peace and security is worth protecting - hardly a controversial assumption. First, since the claim is that states ought to refrain from 
intervening into the internal affairs of other states to insure that international peace and security is maintained, if in any particular instance international peace and security is actually served by intervention or if intervention would not upset international peace and security then the concern over international peace and security is not a reasonable basis for an objection to intervention.

Second, since the prohibition on intervention is justified by its instrumental relationship to the provision and maintenance of international peace and security, the demandingness of the prohibition against intervention will depend on the degree to which adherence to it tends to serve the goal of international peace and security. Thus the demandingness of the prohibition is not absolute but conditional on the instrumental relationship upon which its justification is based.

Lastly, the instrumental argument assumes, but fails to demonstrate, that international peace and security - the peace and security between states - are the only relevant moral values to be considered. When properly understood international peace and security are instrumental values. The value attributed to international peace and security is justified by its instrumental relationship to the provision and protection of the rights of individuals and their communities. It is certainly possible that in some cases the maintenance of international peace and security will stand as an obstacle to the protection and / or promotion of the fundamental values upon which the justification of the value of international peace and security is based. In such cases international peace and security lacks the moral force which would in turn justify the prohibition against intervention.

Assuming the value of state sovereignty to the state system and the instrumental value of the state system to international peace and security, it would be reasonable for 
one to presume that, ceteris paribus, states ought to refrain from intervening militarily into the internal affairs of other states. This presumption could be rebutted if it could be shown that the maintenance of peace and security between states is an obstacle to the fulfillment of the values that the maintenance of international peace and security is supposed to serve, that international peace and security is outweighed by some other relevant moral consideration, or that in any particular instance international peace and security is either not implicated or is being served by intervention. Thus, one could reasonably reject an all things considered moral obligation of humanitarian intervention in any case in which the presumption is not rebutted.

\subsection{Additional Conditions from Practical and Epistemic Concerns}

There are a number of other concerns which may be raised against the moral obligation of humanitarian intervention which have yet to be discussed. In her discussion of NATO's intervention in Kosovo, Samantha Powers identifies as the most salient the concerns over perversity, futility, and perfidy. ${ }^{244}$ None, however, is an absolute objection to the permissibility of intervention, nor are they objections to the possibility of an obligation of intervention. Rather, they should be viewed as cautionary tales, warning of the moral hazards that may result from certain practical or epistemic problems associated with intervention, and as such they may serve as the bases for a reasonable rejection of an all things considered moral obligation of humanitarian intervention.

\subsubsection{Identification of Additional Practical and Epistemic Concerns}

There are at least two distinct ways in which the concern over futility is related to the possibility of an all-things-considered moral obligation of humanitarian intervention.

\footnotetext{
${ }^{244}$ Samantha Powers, pp. 461-473.
} 
First, futility is a concern related to any claimed obligation. If one's actions would be futile in achieving the goal at which they are directed, it would be reasonable for one to reject the claim that one had an obligation to engage in such actions. In the common parlance of moral philosophy, the concern over futility is related loosely to the proposition that ought implies can. Thus, it would be reasonable for one to reject an all things considered moral obligation of humanitarian intervention if the intervention was likely to be futile.

The concern over futility also relates to an all-things-considered moral obligation of humanitarian intervention in a more specific way. The criticism is that by their very nature humanitarian concerns can never be served by military action as military action is anathema to such concerns. ${ }^{245}$ However, in many instances one could not at the same time maintain that one is committed to the humanitarian values upon which the basic right to physical security relies, and claim that military intervention is inherently contradictory with that right. Military intervention may be the only way to protect and / or respect the right. So understood, the argument from futility would not provide the basis for a reasonable rejection of a moral obligation of humanitarian intervention.

Rather, what is likely meant by those who claim that military action can't serve humanitarian purposes is that the risk that more harm will be caused by military action than will be prevented is too great. This concern is what Powers calls the concern over perversity. ${ }^{246}$ Those who raise the concern over perversity claim that we are not able to predict with certainty the short or long-term results of an intervention. The risk of

\footnotetext{
${ }^{245}$ Ibid., pp. 463-466.

${ }^{246}$ Ibid., pp. 461-463.
} 
worsening the situation by military intervention and causing perverse results is too great; therefore, we should refrain from intervening.

The concern over perversity does not provide the basis for an absolute prohibition on intervention, but it highlights an epistemic uncertainty of moral significance that faces those deciding whether to act on a moral obligation of humanitarian intervention. What are the likely consequences of the intervention? In addition, the concern over perversity is a relevant consideration in one's assessment of how the intervention ought to be prosecuted and what must be done afterwards. However, the question of whether an intervention should occur is distinct from the question of how it ought to be prosecuted, a discussion of which must be saved for another occasion. Nonetheless, it would be reasonable for one to reject an all things considered moral obligation of humanitarian intervention if it is likely that the intervention will worsen the situation.

The concern over perfidy is based upon the possibility that an oppressed group may either exaggerate the nature of the oppression and violence it is being subjected to, or that it may actually use violence to provoke retaliation and a humanitarian crisis in an effort to draw the international community into an internal conflict by creating the need for a humanitarian intervention. ${ }^{247}$ The concern over perfidy is based upon the claim that the more we engage in humanitarian intervention, and the more acceptable it becomes, the more such abuses will occur. Like any slippery slope argument, it is only as good as the reasons underlying each slip in the slide. This is not to say that such concerns are unwarranted. But we need to understand the basis for the supposed slide. It is not just that more interventions will occur, but that those who are provoking the retaliation which

\footnotetext{
${ }^{247}$ Ibid., pp. 466-468.
} 
in turn leads to the intervention are being rewarded. Again, this is not a concern over the justifiability of a moral obligation of humanitarian intervention, rather it is a concern over how the intervention is prosecuted.

I am not entirely sure why this should stand as an objection to intervention on behalf of the innocents whose rights are being violated. The obligation require that those whose rights are being violated be provided the necessary social guarantees against standard threats to their security. If that means they need to be protected from both sides, then so be it. Nonetheless, I will accept, for the sake of argument, the underlying concern. Thus, one ought not reward provocateurs, as doing so may encourage others to employ a similar violent strategy. As such, one could reasonably reject an all things considered moral obligation of humanitarian intervention if, as conducted, the intervention would reward the provocateurs.

\subsection{Conclusion: A Moral Obligation to Intervene in Rwanda}

From the previous section one can infer that the following make up that set of conditions under which no one could reasonably deny that a moral obligation of humanitarian intervention exists:

1. The circumstances must be a violation of the basic right to physical security thus giving rise to the moral obligation of humanitarian intervention;

2. Fulfillment of the moral obligation of humanitarian intervention does not require the obligation bearing state to make substantial internal sacrifices;

3. Intervention would not irreparably harm the existence of a community of moral significance;

4. Intervention would not unjustifiably compromise international peace and 
security;

5. Those bearing the obligation are capable of effectively fulfilling the obligation of humanitarian intervention;

6. Intervention would not worsen the situation that the intervention is intended to resolve; and

7. Intervention would not undermine the presumption against intervention or reward provocateurs who use violence in their efforts to cause the circumstances that trigger humanitarian intervention.

It is important to note that the conditions are conjunctive. It will not be sufficient if all but one are met. Condition 1. determines whether a moral obligation of humanitarian intervention exists and must be considered in a state's practical deliberations. Conditions 2. through 7. must be met if the moral obligation of humanitarian intervention is to be an all things considered moral obligation to act the existence of which no one could reasonably deny.

\subsubsection{The circumstances must be a violation of the basic right to physical security thus giving rise to the moral obligation of humanitarian intervention}

In Rwanda during the genocide of 1994, if you were a Tutsi or moderate Hutu with Tutsi-sympathies you were constantly under the threat of violence against your person, including the threat of death. If anything is a standard threat to physical security the threat of unprovoked and unjustified violence against one's person is such a threat. The basic right to physical security provides the rational basis for a justified demand that one's physical security be socially guaranteed against such threats. Provision of such socially guaranteed protection would have required that the Hutu extremists conducting the genocide be stopped. Since the government was supporting the genocide, outside 
intervention would have been necessary to the provision of such socially guaranteed protections. The first condition is met.

\subsubsection{Fulfillment of the moral obligation of humanitarian intervention does not require the obligation bearing state to make unreasonable internal sacrifices}

Some might argue that had intervention been pursued the commitment of resources necessary to effectively accomplish the goals of the intervention would have caused an unjustified sacrifice of the internal obligations of states. To stand as a reason upon which a reasonable rejection could be based, it must have been the case that the sacrifice required would have such an unjustifiable impact on the internal obligations of each state individually and the international community as a collection of duty-bearing states.

According to Lt. Gen. Romeo Dallaire, the leader of the United Nation's Peace Keeping force in Rwanda at the time of the genocide's commencement, a force of 5000 well-armed soldiers with the necessary logistical and military support could have stopped the genocide and provided the necessary conditions for the resumption of the Arusha Accords, which would have provided Rwandans with the necessary socially guaranteed protection of their physical security. Various African nations had volunteered to man the intervention. All that was needed from the international community was the logistical and military support. The claim that this would have required substantial and unjustifiably large internal sacrifices by states is simply false, and for this reason such a claim would fail as the basis for a reasonable rejection of an all-things-considered moral obligation of humanitarian intervention in Rwanda.

\subsubsection{It must be the case that the intervention would not irreparably harm a community of moral significance}


The first question to be addressed with regard to this condition is whether Rwanda, during the genocide, counted as a community of moral significance. If it did not one need not assess this condition further as it was not deserving of protection. To be a community of moral significance, and thus deserving of protection against intervention, we must be able to identify the community in question and it must fulfill and protect the rights of its inhabitants. It is clear, that in the case of Rwanda during the genocide there was no such community, and the community that would have been protected by nonintervention were the Hutu extremists engaged in the systematic violation of the rights of Rwanda's inhabitants.

In addition, the intervention would have served to reestablish the implementation of the Arusha Accords which would have promoted and protected a community of moral significance. Thus, the claim that intervention in Rwanda would have irreparably harmed a community of moral significance would fail as the basis for a reasonable rejection of an all-things-considered moral obligation of humanitarian intervention in Rwanda.

\subsubsection{It must be the case that international security is not unjustifiably compromised by the fulfillment of the moral obligation of humanitarian intervention}

Prior to the genocide the Rwanda Patriotic Front and the Rwandan government had entered into a peace and power-sharing agreement, the Arusha Accords, which was intended to bring peace, not only to Rwanda, but to the region as a whole. The renewal of violence by the Rwandan government under the control of the Hutu extremists undermined the Arusha Accords and international peace and security. Military intervention and the reestablishment of the Arusha Accords would have increased international security, not undermined it. In addition, as a matter of historical fact, the genocide created millions of refugees, who poured into neighboring countries, further 
destabilizing the region. Thus, the claim that intervention would have undermined international peace and security is belied by the facts; and as a consequence, fails as the basis for a reasonable rejection of an all-things-considered moral obligation of humanitarian intervention in Rwanda.

\subsubsection{It must be the case that those bearing the obligation are capable of effectively fulfilling the obligation of humanitarian intervention}

The obligation to provide the socially guaranteed protection of physical security against standard threats was borne directly by individuals. It would be reasonable for one to reject the claim that individuals qua individuals were under an obligation to conduct an intervention as their effort would likely be futile. However, states are the instruments by which individuals are capable of coordinating their efforts and fulfilling such obligations. States individually, or the international community as a collection of duty-bearing states, could have provided the logistical, political and military support necessary for the intervention to be successful. As a consequence, the claim that the effort would have been futile would fail as the basis for a reasonable rejection of an all things considered moral obligation of humanitarian intervention in Rwanda.

\subsubsection{It must be the case that intervention would not worsen the situation that the intervention was intended to resolve}

One might claim that when intervention was finally attempted through Operation Turquoise, the French forces actually made the situation worse, and so it would be reasonable to conclude that intervention would have made the situation worse no matter when it was attempted or by whom. Such an assertion is belied by the facts. The French had waited until the Rwanda Patriotic Front had essentially stopped the genocide, and then the French operated under the assumption that both Tutsis and Hutus had engaged in 
mass killings despite the fact that French government officials knew otherwise. If Operation Turquoise teaches us anything it is the need to act quickly in the case of genocide and that the international community must have a real commitment to the intervention and its humanitarian goals.

\subsubsection{It must be the case that the intervention would not undermine the presumption against intervention or reward provocateurs who use violence in their efforts to cause the circumstances that trigger humanitarian intervention}

The Rwandan genocide began amidst an effort for peace. The provocation was the result of unprovoked violence against innocent civilians by the genocidaires. This does not even fit the case of perfidy. In addition, according to Dallaire, the Rwanda Patriotic Front refrained from military action until it was absolutely clear that the international community was going to do nothing. The presumption against intervention was clearly rebutted in this case and the facts of the situation would have highlighted the fact that only in extreme cases would military intervention be used. Thus a charge of perfidy would fail as the basis for a reasonable rejection of an all-things-considered moral obligation of humanitarian intervention in Rwanda.

\subsubsection{Conclusion}

In conclusion, there existed an all-things-considered moral obligation to intervene in Rwanda in 1994 to prevent the genocide from occurring or to stop it once it had begun. Each of the relevant conditions has been met, and as a consequence there is little basis for a reasonable rejection of the claim that such an obligation existed. I recognize that this demonstrates a doubt on my part as to the success of the argument. I believe that I have demonstrated that it would be unreasonable for one to reject that a moral obligation of humanitarian intervention existed as an a-things-considered obligation in the case of 
Rwanda. But, admittedly, I have not, nor do I think I have the mental capacity to, account for the multitude of arguments that have not been considered. Nonetheless, even if such an argument exists, I remain convinced that our better considered moral judgment, based on the arguments I have presented and critiqued, should lead us to the conclusion that an all-things-considered moral obligation of humanitarian intervention is possible, and that it did exist in the case of Rwanda. 


\section{Chapter 4 - The Normative Framework of International Relations Operative in 1994: A Critical Assessment}

\section{Article 2}

The Organization [the United Nations] and its Members in pursuit of the Purposes stated in Article I, shall act in accordance with the following Principles:

1. The Organization is based on the principle of the sovereign equality of all its Members.

....

4. All Members shall refrain in their international relations from the threat or use of force against the territorial integrity or political independence of any State, or in any other manner inconsistent with the Purposes of the United Nations. $^{248}$

\subsection{Introduction}

I have argued that the international community, as a collection of duty-bearing states, bore an all things considered moral obligation of humanitarian intervention to prevent or stop the genocide in Rwanda. Intervention, however, did not occur. What went wrong? One reason for the failure was not a matter of morality per se; rather the prevailing view at the time was that the rules governing the practical deliberations of states (the normative framework of international relations) precluded states from considering the moral obligation of humanitarian intervention in their practical deliberations. In this chapter, I will set forth what I have found to be the most widely discussed arguments in support of the claim that states ought not consider such moral demands in their practical deliberations. I will then critically assess those arguments. In the end, I conclude that none of the arguments are capable of justifying a principle of practical deliberation with such an exclusionary or preclusive effect.

${ }^{248}$ Charter of the United Nations art. 2 paras. 1, and 4. 


\subsection{The Importance of Interdisciplinary Efforts in Political Philosophy}

Before proceeding I would like to make a general comment about the nature and importance of this aspect of my project. The role of the political philosopher is complicated by the inherently interdisciplinary nature of the field of study. We must walk between the philosophical and the practical. We use our analytic skills to critically assess the theoretical underpinnings of claims made or positions taken in politics, ethics, law, and international relations. To have success in this endeavor, we must, for any particular problem, be able to converse in the conceptual language of one discipline, then another, and back again. ${ }^{249}$

My focus on the right of nonintervention as it relates to the practical deliberations of states is based in part on the desire to have an impact on the way states act in the international arena. To have such a desired effect, one must begin with the practical deliberations of agents. With that goal in mind, I find Onora O'Neill's discussion of the challenges that face one seeking to effect the practical/ethical reasoning of other agents to be insightful. O'Neill claims that " $[w]$ hat is needed is a theory of obligation which is not only universal and critical but accessible to the relevant agents and agencies." ${ }^{250}$

It is the notion of accessibility that is of particular relevance to my project. The critical assessment of the normative framework of international relations must be accessible to those whose decisions are governed by it. For that reason, my approach has been to identify the arguments pressed by those who seek to defend the right of

${ }^{249}$ For a discussion of the special importance of this problem to political philosophers, see Onora O'Neill, Faces of Hunger (London: Allen \& Unwin Publishers Ltd, 1986), Ch. 7.

${ }^{250}$ O’Neill, Faces of Hunger, p. 123. 
nonintervention, and critically assess those arguments on the terms presented. Taking

O'Neill's concerns to heart, I am in need of a common grounding from which the critical analysis can proceed. The discussion in this chapter is intended to bridge the terminological gap between these related but distinct disciplines.

\subsection{The Normative Framework of International Relations, State Sovereignty and the Right of Nonintervention}

To begin, one must have an understanding of what I mean by the normative framework of international relations. The normative framework of international relations (also referred to as the "normative framework") is constituted by the principles that govern the practical deliberations of states. There are two aspects of the normative framework which must be discussed - the scope of the framework and the content of its governing principles. There are many who argue that the scope of the normative framework is constituted and exhausted by sovereign states. In his discussion of the role of human rights in international relations, David P. Forsythe has noted that "it has been widely believed that the state, not the individual is the basic unit." ${ }^{251}$ As to international law Michael Byers notes,

States are usually considered to be the only holders of full legal personality. In principle, all States have the same degree of legal personality, and in that sense all States are formally equal. ${ }^{252}$

Finally, but less approvingly, Charles R. Beitz has pointed out that the presumption that states are the only relevant actors in international relations is taken to be necessary in

${ }^{251}$ David P. Forsythe, Human Rights in International Relations (Cambridge: Cambridge University Press, 2000), p. 3.

${ }^{252}$ Michael Byers, Custom, Power and the Power of Rules (Cambridge: Cambridge University Press, 1999), p. 75. 
contemporary international political theory. ${ }^{253}$

As to the content of the normative framework, "the core principle has been said to be state sovereignty and non-interference in the domestic affairs of states" - a right of nonintervention possessed by all sovereign states held against all other sovereign states. ${ }^{254}$ How exactly state sovereignty is related to non-interference will be discussed below.

The conflict between the normative framework of international relations and the moral obligation to intervene in Rwanda should be apparent. The moral obligation to intervene in Rwanda was based upon the basic human right to physical security held by, and correlative duties borne by, individuals. Since the scope of the normative framework extends only to sovereign states, the concerns of individuals as individuals were beyond the scope of the normative framework. Thus, violations of the Rwandan Tutsis' individual rights to physical security were not, in and of themselves, relevant reasons for states to consider in their practical deliberations.

More readily apparent is the conflict between the right of nonintervention and the moral obligation of humanitarian intervention. Under the normative framework, the only generally accepted exceptions to the right of nonintervention are threats to international order. $^{255}$ If the internal actions of a state pose a threat to international order, then intervention may be permissible to protect international order. Violations of the basic

${ }^{253}$ Beitz, pp. 36-37.

${ }^{254}$ Forsythe, p. 3.

${ }^{255}$ See Janis, p. 157. See also Treaties of Peace Between Sweden and the Holy Roman Empire and Between France and the Holy Roman Empire (Peace of Westphalia, October 14, 1648), 1 C.T.S. 119-356. The Charter of the United Nations also provides some guidance here, as Chapter 7 interventions are conducted to preserve or establish international peace and security. And see Smith (that establishment of sovereignty converted chaos of pre-Westphalian world into order)p. 274. 
right to physical security, which would trigger the moral obligation of humanitarian intervention, would not necessarily pose a threat to international order. Thus, when the basic right to physical security is being violated but international order is not threatened, intervention is not justified under the normative framework.

Though the normative framework is in the process of changing, many hold fast to the basic principles which led the international community to choose not to intervene in Rwanda. To determine what went wrong in Rwanda in 1994 and to insure that it not happen again, one needs to understand the nature of the normative framework operative in 1994. In particular, one must understand the notion of state sovereignty relevant to international relations, the right of nonintervention, and the various relationships that are thought to connect the two.

\subsubsection{State Sovereignty}

Under the normative framework of international relations, the possession of sovereignty by a state is presumed to entail the possession of certain rights and privileges in relation to other states. One such right, and the one most central to this discussion, is the right of nonintervention. But how could the possession of sovereignty grant a political organization an entitlement to oppress, exploit, and even kill its own inhabitants without the fear of interference from other states?

To answer this question one must understand what it means for a state to have sovereignty. I will begin with the classical account provided by Thomas Hobbes as it serves as the starting point for much of the contemporary discussion of sovereignty. ${ }^{256}$ The sovereign comes into existence and is granted such powers through the creation of a

\footnotetext{
${ }^{256}$ Hobbes, Chs. 17-18.
} 
social contract. ${ }^{257}$ What is important to Hobbes is that the "commonwealth" created provide internal peace and security from outside interference. ${ }^{258}$ These are the necessary and sufficient conditions for the political organization in question to be sovereign. As Hobbes states,

The only way to erect such a Common Power, as may be able to defend them from the invasion of Forraigners, and the injuries of one another and thereby to secure them in such sorts as that by their owne industrie, and by the fruites of the Earth, they may nourish themselves and live contentedly; is, to conferre all their power and strength upon one Man, or upon one Assembly of men, that may reduce all their Wills, by plurality of voices into one Will ... $^{259}$

Sovereignty, for Hobbes, is comprised of the powers and rights possessed by the sovereign. ${ }^{260}$

A more contemporary assessment of the classical account is provided by Robert Keohane. According to Keohane, "[t]he classic unitary conception of sovereignty is the doctrine that sovereign states exercise both internal supremacy over all other authorities within a given territory, and external independence of outside authorities." ${ }^{.261}$ Keohane's statement is an example of Christopher Morris' recognition that "[i]t is common to

${ }^{257}$ Ibid., Ch. 17, pp. 111-115.

${ }^{258}$ Ibid., Ch. 20, pp. 135-139.

${ }^{259}$ Ibid., Ch. 18, p. 114.

${ }^{260}$ Ibid., Ch. 18, pp. 115-120.

${ }^{261}$ Robert O. Keohane, "Political Authority after Intervention: Gradations in Sovereignty," from, Holzgrefe and Keohane, Humanitarian Intervention: Ethical, Legal, and Political Dilemmas, p. 282. 
distinguish internal and external aspects of sovereignty" ${ }^{262}$

The difference between the relationships that define internal and external sovereignty helps to explain which is relevant to the normative framework. As Morris notes, "[i]nternal sovereignty pertains to the governance of the realm; external sovereignty, to independence of other states." 263 Internal sovereignty is related to the internal affairs of a political organization, and the relevant parties to the constitutive relationship are the governmental institutions of states and those they govern. ${ }^{264}$

Under the classical account of sovereignty, a state has internal sovereignty only if it is the supreme political authority within a particular territory. ${ }^{265}$ So what exactly does that mean? To have internal sovereignty under the classical account, a state's claimed authority must be the source of all other political authority within a given territory and the state must claim a monopoly on the legitimate use of force within that territory. ${ }^{266}$ As internal sovereignty is a matter of internal relations within a state, and the understanding of the normative framework of international relations under discussion is concerned with the relations between states, internal sovereignty is largely irrelevant to our understanding of the relationship between sovereignty and the normative framework of international relations.

${ }^{262}$ Christopher W. Morris, An Essay on the Modern State (Cambridge: Cambridge University Press, 1998), p. 172.

${ }^{263}$ Ibid.

${ }^{264}$ Roger Scruton, "Sovereignty” from A Dictionary of Political Thought (London: The Macmillan Press, 1982), p. 441.

${ }^{265}$ Morris, p. 14.

${ }^{266}$ Ibid, p. 178. 
External sovereignty, on the other hand is concerned with the relations between states; it is "an attribute which political bodies possess in relation to other such bodies. ${ }^{267}$ As a consequence, the normative framework of international relations is most directly related to this aspect of sovereignty. To understand external sovereignty and the role it plays in the normative framework of international relations, it is important to understand the difference between external sovereignty as a descriptive matter and external sovereignty as an attribution of normative status. The two notions may, as Hobbes seemed to think, be inexorably tied together in that having sovereignty in the descriptive sense made a political organization sovereign which, in turn, served as the basis for the possession of the rights and duties of which the normative notion of sovereignty is comprised. ${ }^{268}$ For reasons that I discuss below, I find such an account to be untenable.

To possess external sovereignty in the descriptive sense is a matter of meeting certain factual conditions. A state possesses external sovereignty if it stands in the requisite relationship to other similar political organizations - that a state is politically independent of other states. ${ }^{269}$ On the other hand, under the normative use of the term, sovereignty is intended to signify a complex web of rights and duties possessed by political organizations with external sovereignty; most important to this discussion is the right of nonintervention. The normative status ascribed to states that possess external sovereignty is a conventional matter institutionalized in international relations and

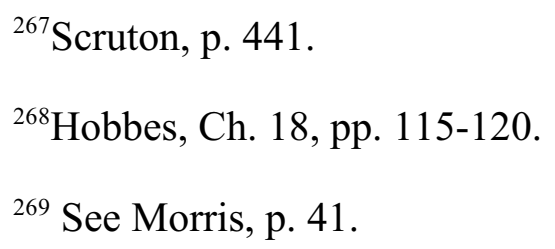


international law. Without an argument connecting the two, the normative status associated with the ascription of sovereignty is distinct from the descriptive satisfaction of the conditions necessary for the possession of sovereignty.

\subsubsection{Right of Nonintervention}

The normative framework of international relations is based on the relationship between external sovereignty and the right of nonintervention. However, before we can assess the nature of this relationship, we must understand the right of nonintervention. Rights are typically constituted by claims (legal, conventional, or moral) held by one entity against another which are a source of duties borne by the latter and owed to the former. They are, in Hohfeldian terms, jural correlatives. ${ }^{270}$ As a consequence, and as was discussed in Chapter 3, the explication of a right will include the identification of the content, strength, and scope of the right. ${ }^{271}$

Beginning with the scope, as the right of nonintervention is a fundamental principle governing the normative framework of international relations it should be consistent with the scope of the normative framework itself. In this vein, the right of nonintervention is presumed to be held by sovereign states, and the correlative duty to refrain from intervening is also presumed to be held by states, both individually and collectively. Under the normative framework of international relations operative in 1994, the only relevant actors are presumed to be sovereign states.

With regard to the strength of the right, other than the maintenance of international order, the right of nonintervention is presumed to be the weightiest second

\footnotetext{
${ }^{270}$ Hohfeld, pp. 35-39. See also Rodin, p. 18.

${ }^{271}$ Sumner, pp. 11, 13.
} 
order exclusionary reason to be considered in the practical deliberations of states. ${ }^{272}$ Provided international order is not at stake, the duty to refrain from intervening correlative to the right of nonintervention is presumed to be a conclusive reason for states not to interfere in the internal affairs of another state. It is both a first order reason for non-interference and a second order reason to exclude from consideration reasons for action the fulfillment of which would require intervention.

Finally, what is the content of the right of nonintervention and its correlative duty? The right of nonintervention is presumed to give a right-holding state a claim to be free from outside interference, and that it be allowed to govern its internal affairs as it sees fit. The claimed liberty, though absolute with regard to the internal affairs of a state, does admit of certain limitations with regard to actions affecting other states. Under the right of nonintervention, actions of a state are limited much like the actions of an individual under Mill's harm principle. ${ }^{273}$ Similarly, with regard to its internal affairs, under the right of nonintervention a sovereign state has a protected liberty to engage in any action that does not harm another state or threaten international order.

As to the correlative duty, states, as bearers of the duty, are under an obligation to refrain from engaging in actions that interfere with the protected liberty of the right holder. The duty, however, does not require the bearer of the duty to refrain from interfering when the actions engaged in by the right holder go beyond the protected sphere of liberty governed by the right of nonintervention. Thus, the duty demands that

${ }^{272}$ For a discussion of second-order reasons, see Raz, Practical Reason and Norms, pp. 39-45.

${ }^{273}$ For Mill's discussion of the harm principle see John Stuart Mill, On Liberty, from On Liberty and Other Essays (Oxford: Oxford University Press, 1991), p. 14. 
the duty bearer not intervene in the internal affairs of another state provided that the right holding state's actions are not going to harm the duty bearer, or pose a threat to international order.

The right of nonintervention is a right held by sovereign states to govern their internal affairs as they see fit free from outside interference, and it gives rise to a correlative duty borne by all other sovereign states not to consider reasons for action that would require the violation of another state's sovereignty. This is a fairly crude understanding of the nature of the right of nonintervention; however, the provision of a more explicit and detailed account would require more space than I can allot here, and for my present purposes this account should be sufficient.

\subsubsection{The Relationship between the Right of Nonintervention and State Sovereignty}

Let us return to the relationship between the right of nonintervention and the possession of external sovereignty. Under the normative framework of international relations, the right of nonintervention is argued to be either implied by or derived from the possession of external sovereignty. If the right of nonintervention is to be implied by the possession of external sovereignty, the general argument must run as follows:

If a state has the ability to protect and maintain its political independence then it has a claim held against other states to remain politically independent without the threat of intervention.

This can't be correct. The ability to do something does not imply a right as a protected liberty to engage in that action. It would make no more sense to say that a state has a right to be politically independent because it has the ability to remain so, than it would be to say that I have the right to torture puppies because I have the ability to do so.

One might contend that in assessing this argument I have focused on the wrong 
notion of sovereignty. The objection might run as follows:

Of course, the possession of state sovereignty doesn't imply the right of nonintervention. The possession of state sovereignty is a descriptive fact, and can not, without more, imply a normative principle. However, as was noted previously, in addition to the descriptive notion, sovereignty often refers to the normative status one state has in relation to other states, and one important aspect of a sovereign state's normative status is that sovereign states have the right of nonintervention. Thus, the right of nonintervention is not only implied by the possession of state sovereignty under this normative understanding, it is constitutive of sovereignty.

I take Hobbes's understanding of the relationship between being a sovereign and possessing the rights and duties associated with the normative understanding of sovereignty to be captured by the argument underlying this objection. Nonetheless, the objection would fail as it begs the very question that I am seeking to answer - whether the right of nonintervention, as an aspect of sovereignty under this normative connotation, can be justified.

How else might a state's possession of external sovereignty imply a right of nonintervention? According to Mark W. Janis, the relationship between the right of nonintervention and external sovereignty arose out of the peace of Westphalia. ${ }^{274}$ Under this account, the relationship is the result of a set of legal accords designed to provide peace and security and is based upon the idea that respect for the external sovereignty of each state would be the best means to providing peace and security. ${ }^{275}$ Hans Morgenthau argues that the right of nonintervention was actually a result of the French revolution and the claim by the French that under international relations other states were obligated to

${ }^{274}$ See Janis, p. 157. See also Treaties of Peace Between Sweden and the Holy Roman Empire and Between France and the Holy Roman Empire, 1 C.T.S. 119-356.

${ }^{275}$ Janis, pp. 159-160. 
refrain from interfering in the internal affairs of France. ${ }^{276}$ Under either account it is claimed that the right of nonintervention is related to external sovereignty through conventional rules, and not by some sort of inherent or necessary implication.

It might be contended that an implication based on a conventional set of rules should be sufficient. However, conventional systems and the rules of which they are comprised are open to our adjustment or elimination should they prove to be unjustified, morally or practically. Such systems require justification with regard to the purposes they are intended to serve and the rules of which they are comprised. Consequently, the existence of a conventional system can't provide the justification for the principles which are constitutive of the system itself.

This lack of necessary implication should not be taken as a denial of the moral significance of the right of nonintervention. Rather, the lack of implicature refocuses the discussion. The right of nonintervention is a normative principle that needs to be justified, and as it is not necessarily implied by the possession of external sovereignty, it needs to be defended by arguments that explain why the possession of external sovereignty should entail a right of nonintervention.

At this point, one might contend that I have abandoned the descriptive project with which I am at present concerned. The claim is that my contention that the right of nonintervention is not implied by state sovereignty is more a matter of conceptual criticism than simply a description of the relationship that is presumed to exist. Such an objection, however, would miss the point. A failure to recognize the lack of implication

${ }^{276}$ Hans Morgenthau, “To Intervene or Not to Intervene," Foreign Affairs, Vol. 45 No. 3 (April 1967), pp. 425-436. 
between the possession of state sovereignty and the right of nonintervention, and a failure to acknowledge the conventional relationship between state sovereignty and the right of nonintervention would render the descriptive account a mere strawman argument. In providing this alternative view of the relationship, the proper focus of analysis has been identified - the justificatory arguments for the right of nonintervention as a conventional rule of the normative framework of international relations.

\subsection{Justifying the Right of Nonintervention}

The justifications offered in support of the right of nonintervention fall into three basic categories: arguments from autonomy, arguments from the principle of antipaternalism, and instrumental arguments. In order to avoid confusion, I would like to note that I am using the term 'instrumental' to refer to arguments that are based on the contention that a right of nonintervention is instrumental to the provision and protection of international peace and security. I point this out because many of the arguments to be discussed are instrumental arguments of one sort or another. ${ }^{277}$

\subsubsection{Arguments from Autonomy}

Justifications for the right of nonintervention based on autonomy come in at least three forms, two of which are based on the domestic analogy. Beitz, though not a proponent of the analogical argument, succinctly captures the underlying analogy,

like persons in domestic society, states in international society are to be treated as autonomous sources of ends, morally immune from external interference, and morally free to arrange their internal

${ }^{277}$ One example of such an argument might be an argument from autonomy in which it is claimed that, like noninterference is instrumentally valuable to individual autonomy, nonintervention is instrumentally valuable to political independence and state sovereignty. 
affairs as their government sees fit. ${ }^{278}$

One version of analogical form of the argument is founded on the claim that international relations is like a Hobbesian state of nature. For Hobbes the state of nature is a war of all against all. ${ }^{279}$ Morality, as demanding constraint on self-interested behavior, does not exist because no individual agent can be certain that others would respect such demands. ${ }^{280}$ Since in the state of nature no one has reason to abide by a moral code that would require them to act against their own best interest, the natural law that exists in the state of nature is for each individual to act prudentially. ${ }^{281}$ Men join together to form societies as a matter of self-interest, and morality is created when the reigns of authority and power of enforcement are granted to a sovereign through the formation of a social contract. ${ }^{282}$ If, however, no contract were created and no sovereign were to arise, the only guiding principle for individual action would remain prudence.

This form of the argument is based upon the presumption that international relations is like the Hobbesian state of nature. ${ }^{283}$ There is no sovereign in international relations to enforce the demands morality might place on states, sovereign states are like

${ }^{278}$ Beitz, p. 65-66.

${ }^{279}$ Hobbes, Ch. 13, pp. 82-84.

${ }^{280}$ Hobbes, pp. 82-86. See also, David Hume’s discussion of “Justice." Hume, An Inquiry Section III, pp. 15-38. For a more contemporary version of the Humean argument regarding the nature of morality, see David Gauthier, Morals by Agreement (Oxford: Oxford University Press, 1986).

${ }^{281}$ Hobbes, Ch. 13, pp. 85, 86.

${ }^{282}$ Ibid., Chs. 15-17.

${ }^{283}$ See Raymond Aron, Peace and War: A Theory of International Relations, translated by Richards Howard and Annette Baker Fox (Garden City, NY: Doubleday and Co., 1966), p. 580. 
individuals in a Hobbesian state of nature, and as Hobbes states,

every commonwealth, (not every man) has an absolute liberty, to do what it shall judge (that is to say, what that man, or assembly that representeth it, shall judge) most conducing tho their benefit. ${ }^{284}$

As a consequence, the only principles guiding a state's actions are self-interest and prudence. To act otherwise would be irrational.

It's hard to see how such an account could imply a right of nonintervention. In a circumstance in which a state could benefit by intervening in the internal affairs of another state it would entail the opposite - that as a matter of self-interest or prudence, a state would be obligated to intervene. In fact, under such an account, if self-interest demanded it, a state would be obligated to engage in an aggressive war. I will not consider this argument further.

An alternative, and more promising, form of the argument from autonomy is based upon John Stuart Mill's understanding of the nature and value of autonomy to individuals. ${ }^{285}$ This argument again invokes the domestic analogy. ${ }^{286}$ The central feature of this account is the recognition that the value of individual autonomy is so important that it ought not be interfered with. As Mill states,

In the part [of an individual's conduct] which merely concerns himself, his independence is, of right absolute. Over himself, over his own body and mind, the individual is sovereign. ${ }^{287}$

The argument proceeds by claiming that the value of state sovereignty is analogous to the

${ }^{284}$ Hobbes, Ch. 21, p. 142.

${ }^{285}$ Mill, On Liberty, pp. 5-130.

${ }^{286}$ See Benn and Peters, pp. 429-431. And see Vincent, p. 345.

${ }^{287}$ Mill, On Liberty, p. 14. 
value of individual autonomy, and as such it ought not be interfered with. ${ }^{288}$

The third and final form of the argument from autonomy is not analogical.

Michael Walzer argues that the right of nonintervention can be justified by appeal to Mill's arguments regarding self-determination. ${ }^{289}$ Those familiar with Walzer's work may wonder why I am not discussing the "legalist paradigm." Walzer employs the legalist paradigm to defend a state's right to defend itself, and not necessarily the right of nonintervention. ${ }^{290}$ Walzer explicitly recognizes that acts by a state or a government that "shock the conscience" may, as an exception to the right of nonintervention, justify intervention. ${ }^{291}$ I agree with Walzer's conclusion that we are permitted to intervene when events internal to another state shock the conscience of mankind, but find his arguments and methodology lacking, and his standard unnecessarily demanding and too vague to be useful.

A standard that relies on what actually "shocks the conscience" is too reliant on intuitions and subjective evaluation to serve any useful purpose. If what Walzer means is that intervention is permitted when actions internal to another state should "shock the conscience of mankind," then an argument is needed to explain why one act should shock the conscience while another should not. It is not enough to look to the international community's reaction after a genocide. For, as a matter of historical fact, at the time of

${ }^{288}$ See Benn and Peters, pp. 429-431. And see Vincent, p. 345.

${ }^{289}$ See Walzer, Just and Unjust Wars, pp. 87-91. See also Mill, “A Few Words on Nonintervention."

${ }^{290}$ Walzer, Just and Unjust Wars, pp. 61-62.

${ }^{291}$ Michael Walzer, "The Argument about Humanitarian Intervention," Dissent (Winter 2002), pp. 29-37, 29-31. 
the perpetration of a genocide the consciences of a sufficient number of people were not shocked.

In addition, Walzer's argument for the permissibility of humanitarian intervention is built around the claim that a stringent right of nonintervention is justified and that the occasions that "shock the conscience" are exceptions to the rule. One could accept Walzer's argument for the right of nonintervention, but reject his claim that it admits of any exceptions.

Lastly, Walzer's standard is disturbingly post hoc, as if the only way we can be reasonably sure that a horrific event that ought to be prevented is going to occur is to wait for its actual occurrence. For these reasons, I am focusing on the underlying argument, but also thought it only fair to recognize that Walzer shares the intuition that humanitarian intervention is, under certain circumstances, at least permissible.

Returning to Walzer's argument, in defense of the right of nonintervention, to be self-determined

The members of a political community must seek their own freedom, just as the individual must cultivate his own virtue. They cannot be set free, as he cannot be made virtuous, by any external force. Indeed political freedom depends upon the existence of individual virtue, and this the armies of another state are most unlikely to produce .... ${ }^{292}$

For Walzer, the importance of self-determination in political matters gives rise to the duty on states to refrain from interfering in the internal affairs of another state. As Walzer goes on to state the value of self-determination gives rise to the right of a people "to become free by their own efforts" if they can,

${ }^{292}$ Walzer, Just and Unjust Wars, p. 87. See also Beitz's discussion of Walzer's argument, Beitz, p. 85. 
and nonintervention is the principle guaranteeing that their success will not be impeded or their failure prevented by the intrusions of an alien power. ${ }^{293}$

To respect the liberty of the individual inhabitants of another state, the inhabitants of that state must be allowed to "seek their own freedom" free from the interference of other states.

\subsubsection{Anti-Paternalism as a Justification for the Right of Nonintervention}

A second form of justificatory argument for the right of nonintervention is based upon various arguments against paternalism in international relations. ${ }^{294}$ Much like Mill's contention that paternalism with regards to individual liberty cannot be justified, ${ }^{295}$ Walzer notes, "[a]s with individuals, so with sovereign states: there are things that we cannot do to them, even for their own ostensible good." 296 One of these "things we cannot do to them" is to intervene in their internal affairs. This argument depends upon the successful defense of the principle of anti-paternalism in international relations.

The argument from anti-paternalism may be based on Mill's arguments against paternalism. Alternatively, the argument may be based on the contention that the principle of anti-paternalism in international affairs is justified because it is a valueneutral principle that recognizes that there are competing conceptions of the good, and that each sovereign state should be left to choose its own conception of the good from amongst such competing conceptions. It is important to note that I am using "the good"

${ }^{293}$ Walzer, Just and Unjust Wars, p. 88.

${ }^{294}$ For a detailed discussion, see Beitz, pp. 83-92.

${ }^{295}$ Mill, On Liberty, pp. 83-103.

${ }^{296}$ Walzer, Just and Unjust Wars, p. 89. 
or "conceptions of the good" in a very loose sense. All that is meant is the moral system that people accept to guide their behavior. This could include a conception of the good that is rights-based. I believe that my usage is consistent with those whose arguments I am discussing.

Regarding the first form of the argument, its proponents are S.I. Benn, R. S. Peters, ${ }^{297}$ and R. J. Vincent. ${ }^{298}$ Their argument in support of the principle of antipaternalism is similar to Mill's argument for the rejection of paternalism as it relates to individual agents. As Benn and Peters claim,

The duty of non-interference rests on the assumption that the claims of a state's members will generally be better served if they are left to work out their own salvation. ${ }^{299}$

The reasons offered by Benn and Peters are analogous to the reasons offered by Mill to justify why a state should not interfere with the self-regarding actions of an individual. ${ }^{300}$ The justifications can be categorized as either based on the claim that individuals are in an epistemically privileged position when it comes to what is in their best interest, or that the harm caused by interference with individual liberty, even if intended to benefit the individual, will outweigh any potential benefits. ${ }^{301}$

According to Beitz, Benn and Peters contend that intervention in a state's internal affairs cannot be justified on paternalistic grounds because the intervening state is unlikely to be

\footnotetext{
${ }^{297}$ See Benn and Peters, pp. 429-431.

${ }^{298}$ See Vincent, p. 345.

${ }^{299}$ Benn and Peters, p. 431. See also Beitz, p. 84.

${ }^{300}$ Mill, On Liberty, pp. 91-96.

${ }^{301}$ Ibid.
} 
impartial and because, in any event, a state is more likely to know its own best interests than any other state. ${ }^{302}$

Like Mill's reasons for rejecting paternalism with regards to individuals, Benn and Peters's reasons are contingent, and the success of the argument depends on the truth of its underlying factual claims.

The other version of the argument takes two distinct forms. One is offered by William E. Hall, and the other by Jovan Babic. Hall seeks to justify the application of the principle of anti-paternalism to international relations by first noting that there are competing conceptions of the good, and that, with regard to individuals, the principle of anti-paternalism is generally recognized as a neutral position that allows individuals to pursue their own conceptions of the good. ${ }^{303}$ Hall then invokes the domestic analogy, claiming that states in international relations are analogous to individuals in domestic society. ${ }^{304}$ Therefore, if the principle of anti-paternalism is a principle governing the treatment of individuals in domestic society, it is, by analogy, a principle that ought to govern the way states treat one another in international relations.

Babic's argument, on the other hand, does not rely on the domestic analogy. Rather, Babic offers an argument rooted in respect for individual human rights. ${ }^{305}$ Babic contends that states ought to refrain from interfering in the internal affairs of other states, even if such interference is intended to serve the interests of the latter state's inhabitants,

${ }^{302}$ Beitz, p. 84.

${ }^{303}$ I am relying on Beitz's account of Hall's argument. Beitz, p. 88. But see Hall, International Law, p. 347.

${ }^{304}$ See Beitz, p. 88.

${ }^{305}$ Jovan Babic, pp. 45-70, 52-54. 
because the former's "value system" or "definition of 'good" is but one amongst a number of different competing conceptions. ${ }^{306}$ Respect for individual human rights requires that states show tolerance for the conceptions of the good chosen by individuals in other states even if such choices appear to be morally or practically wrong. ${ }^{307}$

\subsubsection{Instrumental Justification for the Right of Nonintervention}

The final justificatory argument that I would like to discuss is based on the claim that the right of nonintervention as respect for the sovereignty of states is instrumental to achieving the goal of international order. As Janis has pointed out, the pre-Westphalian interactions between states were violent and anarchic:

The conflicting allegiances of Europe had contributed to the terrible toll of confusion, death, and destruction from 1618 to 1648. In the mid-seventeenth century many Europeans sought a simpler, and it was hoped, safer set of loyalties. ${ }^{308}$

It is argued that the right of nonintervention as respect for the sovereignty of states converted the chaos of the pre-Westphalian world into "international order". ${ }^{309}$

If we look to the UN Charter for some guidance as to what is meant by international order, one of the fundamental "Purposes of the United Nations" is to "maintain international peace and security." $" 310$ Analogous at the domestic level is

${ }^{306}$ Ibid., pp. 53-54.

${ }^{307}$ Ibid., pp. 52, 64-66.

${ }^{308}$ Janis, p. 159.

${ }^{309}$ Smith, p. 274.

${ }^{310}$ U.N. Charter art. 1, para. 1. See also Smith, p. 274. 
Michael Taylor's account of social order. ${ }^{311}$ For Taylor, domestic social order "refers to an absence, more or less complete, of violence, a state of affairs in which people are relatively safe from physical attack." 312 According to Taylor, it is the desire for social order which underlies the Hobbesian social contract. ${ }^{313}$ The analogous desire upon which the instrumental argument would be based is the desire by states for international order. I will assume that international order and international peace and security are similar enough to be treated as equivalent for my purposes.

It is important that one also understand what is meant by international peace and security. The relevant notion of peace should be consistent with the presumed scope of the normative framework of international relations that the only relevant actors are sovereign states. As such, threats to international peace are threats to the peace between states. Similarly, international security refers to the security of a state from aggression or intervention by other states. A state is secure if other states refrain or are prevented from engaging in either aggressive action toward the state or intervention into the internal affairs of the state. If states refrained from acting on reasons the fulfillment of which would require intervention, then international peace and security would, at the very least, be more likely.

In recent times, other concerns have been introduced. These contemporary concerns have less to do with worry over aggressive war, and more to do with the concern that intervention into the internal affairs of another state may be used as a pretext for

${ }^{311}$ Michael Taylor, Community, Anarchy, \& Liberty (Cambridge: Cambridge University Press, 1982), pp. 44-45.

${ }^{312}$ Ibid., p. 44.

${ }^{313}$ Ibid., p. 45. 
aggressive war. As Stanley Hoffmann has pointed out:

in a world of states, sovereignty [and the right of nonintervention] protects one against outsiders trying to topple the government or to set up a puppet regime or to impose their views of what is good and right - hence the particularly strong attachment of countries recently liberated from colonial rule to the principle of nonintervention. ${ }^{314}$

The right of nonintervention is also argued to prevent the possibility of a state using a humanitarian or other proffered moral justification as a pretext for an aggressive war.

\subsection{Critically Assessing the Justificatory Arguments}

In the remainder of this chapter I will argue that none of the justificatory arguments succeed. I will first address the various Millian analogical arguments, from autonomy and anti-paternalism, and demonstrate that the analogical strategy fails. I will then turn my attention to the argument from self-determination offered by Walzer, and the arguments from anti-paternalism offered by Hall and Babic. Lastly, I critically assess the instrumental argument.

\subsubsection{Criticizing the Millian Analogical Arguments}

For an analogical argument to succeed it must be the case that the grounding claim or argument is sufficiently similar to the proposition or argument being justified by the analogy. As the analogical arguments being discussed rely on the domestic analogy, it must be the case that individuals in domestic society are sufficiently similar to states in international relations, and that the relationship between the relevant parties and the identified properties and principles are sufficiently similar as well.

The grounding proposition of the arguments discussed is that individuals are the

${ }^{314}$ Hoffmann, p. 19. See also Smith (that a rule against intervention is necessary because the costs of intervention when it should not occur are too high), pp. 284-285 
paramount, if not the only, relevant moral agents in the domestic sphere. Thus, to be analogous, states in the international arena must be the paramount, if not the only, relevant moral agents in the international arena. One can assume that, as a matter of convention, states are the only relevant moral agents in international relations. However, as was noted above, one cannot rely on the conventions one is seeking to justify to justify the conventions themselves. In addition, the claim that states are the only relevant moral agents in international relations is contradicted by actual practice. As Charles Beitz has pointed out, there are a multitude of non-governmental organizations and secondary associations that are given moral consideration when a state is determining what it ought to do. ${ }^{315}$

What is needed is an argument demonstrating that states ought to be considered paramount in the international arena. Any such argument would have to demonstrate that individual moral agents, when juxtaposed with states, are not of paramount moral concern. If we make the assumption that a state's moral legitimacy is determined by the degree to which the state serves the interests of its inhabitants, then, in the domestic case, the moral value of the state can't be greater than the moral value of the individuals it is intended to serve. As a consequence, to support the analogy, one would have to explain why the value of the individual is trumped by the value of the state at the international level without relying on the claim that states are paramount in international relations.

If I am correct, and states aren't the only relevant moral agents in the international arena, there are further problematic implications for the analogical arguments. Common to both Millian analogical arguments is the claim that an individual's right to non-

\footnotetext{
${ }^{315}$ Beitz, pp. 36-37.
} 
interference is limited by the rights of other relevant moral agents to be free from harm or interference. ${ }^{316}$ The rights of states in international relations are limited by the rights of other states; however, states are not the only relevant moral agents. Thus, when a state's actions pose a threat of harm to the rights of other relevant moral agents, including individuals, the state does not have a claim to a right of nonintervention. In the cases that would give rise to an obligation of humanitarian intervention, individuals are being harmed or are being threatened with harm and thus the state cannot claim a right of nonintervention.

As to the principle of anti-paternalism in particular, according to Mill, with regard to the individual in domestic society, the principle is justified by the fact that an individual knows what is in his/her own interest better than anyone else could, and/or that any interference with the individual's autonomy is likely to produce a greater harm than it prevents. ${ }^{317}$ Even if we assume that this is true in the individual case, it would seem to have very little empirical support when it comes to states who are violating or allowing the violation of their citizens' basic rights. In addition, in such cases, the advent of mass communication, globalization and growing intercultural exchange makes the claim that a state always knows, better than outsiders, what is in the best interests of its inhabitants an unlikely proposition. ${ }^{318}$ Lastly, in any case where it is clear that the state is acting against the better interests of its inhabitants, e.g. failing to respect the basic right to physical security, the justification fails. The contingent nature of the justification is incompatible

\footnotetext{
${ }^{316}$ Mill, On Liberty, p. 83.

${ }^{317}$ Ibid., pp. 91-96.

${ }^{318}$ See Luban, "Romance of the Nation-State," p. 395.
} 
with a right of nonintervention.

As to the analogical argument from autonomy, we can accept for the sake of argument that Mill is correct in his claim that the value of autonomy to individual agents is inherent. We can also assume that Mill is correct in his claim that there are actions in which an individual engages that only effect the individual him / herself. Since individual autonomy is inherently valuable, interference with an individual's exercise of their autonomy in such self-regarding cases would be an unjustified infringement.

For the analogy to hold, it must be demonstrated both that the relationship that exists between sovereignty and the state and autonomy and an individual moral agent are sufficiently similar; and that the value of sovereignty is sufficiently similar to the value of individual autonomy. I will assume that as a matter of convention the first proposition is true; however, even if we assume that the value of sovereignty to a state is analogous to the value of autonomy to an individual human agent this fails to entail a right of nonintervention. The analogy employed tells us little about what might be implied by state sovereignty or what its value is. The argument points out nothing more than that the relationship that exists between sovereignty and states is analogous to the relationship that exists between autonomy and individual human agents, it must also be the case that the value of sovereignty is similar enough to the value of autonomy such that it ought not be interefered with.

For Mill, autonomy is a set of capacities possessed by an individual. ${ }^{319}$ It is the possession and exercise of such capacities which make the individual's choice of action

${ }^{319}$ Mill, On Liberty, pp. 83-86. 
of paramount, if not inherent, value. ${ }^{320}$ The possession of sovereignty by a state is a matter of the state possessing certain capacities, viz. the ability to maintain its political independence. However, the ability to maintain political independence fails, without more, to render a sovereign state's choice of action of paramount, nevertheless inherent, value. The ability of a state to maintain its political independence is valuable to the extent that it serves the interests of the moral agents of which it is comprised. As a consequence, sovereignty is only instrumentally valuable. As such its value can be neither paramount nor inherent.

\subsubsection{Criticism of Walzer's Argument from Self-Determination}

For Walzer, the right of a political community to self-determination is based on the right held by each individual to create a political community of their own choosing. ${ }^{321}$ Thus, according to Walzer the principle of nonintervention is necessary to respect the right of political communities to self-determination which is itself justified by its instrumental role in respecting each individual's right to political self-determination.

Regarding the right of nonintervention, since for Walzer, the right of a political community to self-determination is derived from the right held by each individual to political self-determination, unless it can be demonstrated that the right of individuals to political self-determination outweighs the basic right to physical security, a political community's right to self-determination cannot entail a principle or norm that fails to respect the other rights held by individuals.

Additionally, the claim that the right of a political community to self-

${ }^{320}$ Ibid.

${ }^{321}$ Michael Walzer, “The Moral Standing of States,” pp. 209-229, p. 211. 
determination implies a right of nonintervention is internally inconsistent. Since a political community's right to self-determination is based upon the right to political selfdetermination held by each individual, the role a political community's right to selfdetermination should play in the practical deliberations of states depends upon the degree to which respecting that right would serve the underlying individual right. Consequently, since the effect of the right of nonintervention is the preclusion of moral considerations related to the respect or disrespect for individual rights, a right of nonintervention cannot be implied by the right of political communities to self-determination, at least not as Walzer understands that right.

Lastly, the right of a political community to self-determination fails to justify a preclusive principle of nonintervention for much the same reason that the value of sovereignty to states failed to justify such a principle. The principle of noninterference with individual liberty is derived from the value of individual self-determination which is, according to Walzer, essential to the development of individual virtue. ${ }^{322}$ Similarly, the principle of nonintervention is supposed to be derived from the value of the political selfdetermination of communities which is essential to the political development of a community. The value of individual development is inherent, whereas the value of the development of a political community is instrumental and is dependent on the degree to which the political community actually developed serves the goals and purposes from which its value is derived.

So, again, a preclusive principle of nonintervention is not justified; rather we are left with a reason for not intervening. In cases where refraining from intervention would

\footnotetext{
${ }^{322}$ Walzer, Just and Unjust Wars, p. 87.
} 
further the goals intended to be served by self-determination that reason would be weighty. In cases where respecting a political community's right to self-determination would undermine the very goals that justify the right, the reasons in support of nonintervention would be weaker and more susceptible to being outweighed by countervailing reasons.

\subsubsection{Criticism of Hall's and Babic's Arguments from Anti-Paternalism}

Hall's argument is analogical, but what distinguishes Hall's argument from the Millian analogical arguments discussed above is that Hall argues that the value of the principle of anti-paternalism is derived from its value-neutrality. ${ }^{323}$ Such value-neutrality is argued to be necessary at the domestic level because it allows individuals to develop their own conceptions of the good, and by analogy should also govern the interactions of states at the international level. Hall's argument fails because it is simply not the case that all conceptions of the good are equally valuable and deserving of respect.

To support a preclusive principle of noninterference at the individual level it would have to be the case that we are not capable of making judgments about competing conceptions of the good between the various conceptions that individuals adopt. Due to epistemic uncertainty over which is correct, there may be a wide range of conceptions of the good that ought to be tolerated. However, this does not imply that all conceptions of the good are deserving of such toleration. If a conception of the good involves the violation of others' basic rights then such conceptions ought not to be tolerated. Thus, the grounding proposition that the value of the principle of anti-paternalism to individuals in domestic society is its value-neutrality fails at the domestic level.

${ }^{323}$ For a discussion of Hall's argument, see Beitz, p. 84. 
In addition, the effort to analogize this proposition to the international arena only magnifies its flaws. First, even if we assume that individuals can have conceptions or definitions of the good, the idea that states qua states can have a conception of the good borders on the absurd. There may exist a consensus amongst the inhabitants of a state over a conception of the good, but if the underlying principle of this argument is respect for the pluralistic nature of the good, then a consensus should in no way define a state's conception, as there are those who subscribe to competing conceptions. More importantly, in the cases that we are concerned with here, the basic right to physical security is being violated, and conceptions of the good that involve such violations do not deserve toleration.

Turning to Jovan Babic's argument that respect for individual human rights justifies a principle of anti-paternalism in international relations, first, as noted with regards to Hall's argument, there may be a plurality of conceptions of the good, and one could even admit that one ought to be tolerant of a wide range of such conceptions; however, this does not imply that no judgments can be made about others' conceptions of the good. Tolerance is only a virtue if we are being tolerant of reasonable differences differences based on reasonable disagreement. If we are concerned with human rights, conceptions of the good that involve the denial of basic rights are conceptions that are unreasonable and ought not be tolerated. When we tolerate atrocity, injustice, or the violation of basic rights, tolerance is apathy in the face of evil.

In addition, under Babic's argument, the applicability of the principle of antipaternalism to international relations is, like Walzer's argument regarding the value of self-determination, based on an aggregation of individual rights. This argument relies 
upon the truth of the following claim: that there exists a conception of the good to which the individuals of a state are committed. ${ }^{324}$ In the circumstances under which there would be a moral demand for the violation of sovereignty, it is possible that a majority of the individuals in the state in question may have arrived at a consensus on a conception of the good; however, this fails to imply that there is a single conception of the good to which the individuals of the state are committed. Babic does raise a number of relevant concerns, but he fails to support the claim that a principle of anti-paternalism is appropriate for international relations.

In either case, a right of nonintervention is not justified by the principle of antipaternalism. Rather, the principle that is justified by anti-paternalism is one that recognizes that there are numerous conceptions of the good deserving of toleration and to the extent that a conception is reasonable and does not violate the basic right to physical security it should be respected.

\subsubsection{Criticism of the Instrumental Argument}

We are left to consider the instrumental justification. The right of nonintervention is argued to be implied by the claim that respect for state sovereignty is instrumental to the provision and maintenance of international peace and security. The success of the instrumental justification for the right of nonintervention depends on the truth of two propositions. First, it must be the case that without nonintervention international peace and security could not be provided or maintained - that nonintervention is necessary for international peace and security. Second, it must also be the case that international peace and security is either the only relevant value in international relations, or that it is the

${ }^{324}$ Ibid., pp. 52-54. 
paramount value to be considered.

First, it would seem to be reasonable to assume that if states were to adhere to a right of nonintervention, such restraint would make international peace and security more likely. This does not imply, however, that nonintervention is necessary for international peace and security. There may, in fact, be instances under which adherence to the right of nonintervention either undermines international peace and security, or in which violation of the right would not affect international peace and security. In either of these cases, the preclusive nature of the right is not justified because the means-ends relationship upon which the justification depends does not exist.

Some might contend that it is incoherent to claim that intervention for any reason can either promote or not affect international peace and security. The underlying claim would be that, as a matter of simple quantification, before the intervention there was less violence than after the intervention, and thus more peace and security before the intervention and less after the intervention has begun. Such an understanding of what is meant by international peace and security is mistaken. The quantity of violence or lack thereof may be one relevant aspect of international peace and security, but there must also be a qualitative aspect that is at least as important. The justness or durability of the peace should matter. Humanitarian intervention could improve international peace and security, or at least not diminish it, in this qualitative respect.

Second, even if we assume that the right of nonintervention is necessary for international peace and security, it does not follow that the right of nonintervention is justified. For the right of nonintervention to be justified by the instrumental argument it must be the case that international peace and security is either the only relevant goal to be 
served in international relations or it must be the weightiest goal to be served. If it is not the only relevant goal, then it could be possible that a more fundamental or weightier goal is served by violating international peace and security.

However, international peace and security is neither the only relevant goal nor the weightiest. International peace and security is pursued for its extrinsic value - it is valuable because it is a means to the promotion of or respect for other more fundamental values. If we look to the underlying motivation for the international community to pursue international peace and security, it was not for the sake of international peace and security itself. Rather, the peace and security between states was being pursued so that individuals and communities could flourish. ${ }^{325}$ As such, it cannot be the only relevant goal to be pursued in international relations. In addition, since the value of international peace and security is derived from its instrumental value, it can't be the paramount or weightiest goal of international relations. For this to be the case the instrumental relationship between international peace and security and the values it is intended to serve would have to justify the elimination of considerations of those more fundamental values when such considerations conflicted with international peace and security.

Admittedly, I am assuming that the proposition that international peace and security is extrinsically valuable is relatively uncontroversial and that my critique is based upon this assumption. One might, however, object to this assumption. It could be claimed that though international peace and security may have extrinsic value its value is not solely instrumental - there is value in international peace and security for its own sake. Even if this were true it would remain to be demonstrated that international peace

\footnotetext{
${ }^{325}$ See Smith, p. 274.
} 
and security was of paramount value. 


\section{Chapter 5 - A Reconstruction of THE NORMATIVE FrameWORK OF INTERNATIONAL RELATIONS}

\subsection{Introduction}

The discussion in this chapter is built around the assumption that for various reasons the practical deliberations of states need to be governed by rules. ${ }^{326}$ I will offer reasons in defense of this assumption below. The one rule that is no longer justifiable is a right of nonintervention with an exclusionary effect on the practical deliberations of states. However, many of the arguments offered as justifications for a right of nonintervention were based upon relevant moral considerations for which a rule governing the practical deliberations of states should account. In the section that follows I will explicate what I take to be the most relevant considerations that are gleaned from the critical analysis of the justificatory arguments, and I will then explain how a presumption of nonintervention can accommodate such concerns, and why a presumption of nonintervention ought to be adopted.

But is this really any different from Walzer's exception to the legalist paradigm that intervention is permissible if it "shocks the conscience of mankind?" 327 In the preceding discussion of Walzer's argument from self-determination I noted some of the reasons I found his methodology, if not his conclusion, problematic. Notwithstanding these aforementioned concerns, I do believe that a presumption of nonintervention is distinct from Walzer's rule. First, for Walzer, humanitarian intervention is only

${ }^{326}$ Hoffmann, p. 19 (that a rule is needed to prevent states from using humanitarian concerns as a pretext for aggressive war). See also Smith, pp. 284-285 (that a rule against intervention is necessary because the costs of intervention when it should not occur are too high).

${ }^{327}$ See Walzer, “The Argument about Humanitarian Intervention,” pp. 29-31. 
permissible as an exception to the rule. It is a circumstance which requires us to violate the rule. Under a presumption, the possibility of the permissibility of a humanitarian intervention is within the purview of the rule. Second, the "shock the conscience" standard is post facto. We are only permitted to intervene if the atrocities have reached such a horrific level that the "conscience of mankind" has been shocked. Under a presumption of nonintervention, one need not wait until the massacres have reached such levels of barbarity. In fact, under a presumption of nonintervention, much of the bloodshed required for Walzer's exception could be avoided.

\subsection{Lessons Learned}

One might be concerned that my argument in the preceding chapter is intended to demonstrate that when it comes to humanitarian intervention the practical deliberations of states ought to be unencumbered by any rules that are not themselves directly related to such humanitarian concerns. Such an understanding would be based on a false choice: that either the normative framework of international relations is to be governed by a right of nonintervention; or that the normative framework is to be governed by no rules at all. I will argue for an alternative proposition, that a moderate principle ought to be adopted; in particular, a principle that recognizes the values to be served by nonintervention, but also allows for other moral reasons for action to receive their proper consideration in the practical deliberations of states.

The rejection of the right of nonintervention as the governing principle of the normative framework is not a rejection of the goals and values to be served by such a rule. In fact, perhaps the most valuable lesson we learn from the critical analysis that led to the rejection of the right of nonintervention, apart from the fact that the rule is not 
justified, is that respect for state sovereignty is not devoid of value. But the value of respecting state sovereignty is limited as opposed to absolute, and instrumental as opposed to inherent two characteristics that lend support to the adoption of a presumption of nonintervention.

I would like to now turn my attention to the specific arguments discussed and lessons learned from the critical discussion in Chapter 4. Beginning with the analogical arguments (the arguments from autonomy and anti-paternalism) we learn first that the values and principles relevant to the international arena are not analogous to the domestic. Simply extrapolating from the domestic to the international - claiming that states in the international arena are analogous to individuals in domestic society - fails to account for the fact that there is a wide array of different moral agents and relationships at the international level. Any principle which is expected to govern the practical deliberations of states in the international arena should recognize and accommodate such complexity.

Second, we learn that the value of respecting state sovereignty is limited, at least in the same way that respecting the autonomy of individuals and individual choice is limited rather than absolute. If respect for an individual's exercise of his liberty was absolute, we would never be justified in interfering with his exercise of his liberty. However, even Mill concedes that when such exercise of one's liberty unjustifiably infringes upon the rights and interests of other relevant moral agents interference becomes permissible. Similarly, when the exercise of state sovereignty involves harm to another relevant moral agent, whether to interfere or not should be treated as an open question. Our principle should reflect this limitation on sovereignty.

Considering the argument from self-determination pressed by Walzer, I think it 
reasonable to assume that the political self-determination of a community is valuable; however, its value is extrinsic. Political self-determination to a community is valuable to the extent that it serves individual political self-determination. Respect for the sovereignty of a state is valuable to the extent that it promotes political selfdetermination. Thus, in relation to political self-determination, the value of respecting state sovereignty is extrinsic. As a consequence, the value of respecting state sovereignty is dependent, at least in part, on the degree to which such respect would serve the goal of political self-determination. I believe that in most cases respecting state sovereignty will promote both the political self-determination of communities and individual political selfdetermination. The principle governing the normative framework should reflect this instrumental relationship between political self-determination and state sovereignty.

Turning next to the arguments from anti-paternalism from Hall and Babic, if we assume that there is epistemic uncertainty over which conception or definition of the good is correct, and that there is something morally valuable in allowing agents to exercise their autonomy in choosing a conception of the good, then respecting state sovereignty is likely to render the ability to make such choices more secure. Intervention when such choice is being exercised in a reasonable manner could be considered an unjustified imposition of one conception of the good for another, an act of unjustified moral imperialism by the interveners.

However, it is not always the case that neutrality is the best policy in moral matters. Nor is moral imperialism inherently wrong. In some cases, the desire to avoid moral imperialism and to allow an individual or a group of individuals to exercise their autonomy in choosing their conception of the good will pale in comparison to the harm 
that would be caused by not intervening - the unjustified violation of the basic right to physical security being just one example. Our principle should allow individuals to choose their conception of the good from amongst the plurality of reasonable conceptions of the good.

What lessons do we learn from the critical discussion of the instrumental argument? Before answering this question, I would like to note that there is something particularly paradoxical about the instrumental argument. For various reasons, the instrumental argument is likely the most compelling of the justificatory arguments. The instrumental argument explicitly recognizes the extrinsic value of respecting the sovereignty of a state. In addition, the instrumental argument is based on the proposition that respect for the sovereignty of a state is instrumental to a variety of intuitively valuable goals of international relations. However, it is the instrumental nature of the justification that renders it incapable of supporting a right of nonintervention. Under the instrumental argument the most that can be claimed - and one of the lessons we learn - is that the sovereignty of a state should be respected to the extent that such respect would actually fulfill the goals upon which the instrumental justification relies.

The specific goals to which the instrumental justification is directed are international peace and security. Thus, the value of respecting state sovereignty is dependent on the degree to which respecting state sovereignty would serve the goals of international peace and security, which may in turn be dependent on the degree to which the fulfillment of such goals furthers the promotion of more fundamental values, such as human flourishing. Nonetheless, in most cases international peace and security is going to be a worthwhile, even if not the weightiest, goal to be pursued, and respecting the 
sovereignty of states will in most cases be instrumentally valuable to the achievement of that goal. Thus, the principle governing the normative framework of international relations should account for the fact that respect for the sovereignty of states will often be instrumental to the achievement of international peace and security.

Lastly, there were a number of other concerns that arose in the discussion of the justificatory arguments for a right of nonintervention. Perfidy and pretext to name two. All are relevant considerations that should be accounted for by the principle governing the normative framework.

\subsection{Reasons in Support of a Presumption of Nonintervention}

One might, at this point, think that I would argue for a presumption of intervention in cases in which the moral obligation of humanitarian intervention arises or, at least, wonder why a presumption at all. Before proceeding to the defense of a presumption of nonintervention, there is at least one prior question that must be addressed. Throughout I have argued against the one rule that has been presumed to govern international relations, the right of nonintervention. One might, at this point, wonder why there is a need for a rule at all?

The considerations weighing in favor of the adoption of a rule are ones that have already been discussed at great length, and understanding that I am repeating myself to a certain degree, I will try to keep such repetition to a minimum. Without a rule (or set of rules) of some sort, the relations between states are likely to be chaotic and unstable undermining both international order and the conditions necessary for human flourishing. If such reasons are compelling, then we need a rule to provide structure to the interactions between states. 
In addition to the avoidance of the negative implications that could arise in an international arena not governed by any rules, the adoption of a rule (or set of rules) will have a number of positive effects. A rule governing the behavior of states may not lead to peace, but it will likely lead to the predictability of behavior and provide a basis for reasonable expectations on the part of others in the global community. In turn, such predictability and stability are likely to promote other valuable ends. If individuals and communities know what to expect to a reasonable degree of certainty, then they can set goals for themselves and engage in efforts at achieving those goals without the constant fear that the actions of another state will unexpectedly interfere with their plans.

Neither the need for a rule, nor the advantages of having the international arena governed by a rule as opposed to having no rule at all, identifies what that rule should be. However, what rule is adopted is as important as the adoption of a rule. If the wrong rule is adopted the stability and predictability that is afforded by the rule may be oppressive and exploitive, if not patently unjust. So why a presumption of nonintervention? Why not a presumption of intervention? Why a presumption at all?

Before offering reasons in support of the claim that a rebuttable presumption of nonintervention should be adopted, it is necessary that one have an understanding of the role the presumption would play in the practical deliberations of states. A presumption is a rule or principle that governs our deliberations about a particular practical or theoretical matter. The role played by a presumption is one of burden-shifting. A presumption privileges a particular belief or action above other alternative or opposing options. The starting point for our practical deliberations, if we are deliberating about a matter governed by a presumption, is in favor of the presumed action. It is not an open question. 
For the presumption to be rebutted it must be demonstrated that it is outweighed by countervailing considerations. The presumption being discussed would privilege the option of nonintervention; however, the presumption could be rebutted if it could be demonstrated with sufficient certainty that an injustice is occurring, that the injustice demands and could be rectified by intervention (of some sort), and the most effective means to fulfilling the demands of justice is intervention.

The question of why there would be a presumption at all is conceptually prior to which way the presumption should go; for that reason I will address this question first. A presumption, by its very nature, does not preclude countervailing considerations from being considered and allows for the possibility that the presumption will be rebutted. As such, it provides a common framework for deliberation, and a degree of stability and predictability. But since it also allows for countervailing considerations to rebut the presumption it does not succumb to the same criticisms that are raised against rules that are exclusionary in nature.

But should the presumption be for or against intervention? There are a number of relevant considerations that, when considered, lend support to the proposition that a presumption of nonintervention ought to be adopted. Specifically, there are certain general principles of morality that can only be accommodated by a presumption of nonintervention. The presumption of nonintervention is also able to accommodate the lessons learned from Chapter 4, and is able to protect against the moral hazards previously identified.

I take it to be a general principle of morality that one needs to justify one's interference with the actions of, or harm that one's actions may cause to, another. In the 
case of humanitarian intervention, or intervention of any sort employing military means, the act of intervention is likely to interfere with the activities of other relevant moral agents. At the very least it is, by definition being conducted against the wishes of the sovereign government. More importantly, since intervention of the sort at issue employs physical violence to achieve its goals it will likely involve harm to others. As such, the act of intervening needs to be justified. A presumption in favor of intervention places the burden, not on those interfering with the actions of others or causing harm, but on those who may be harmed or whose actions are being interfered with. On the other hand, a presumption of nonintervention would place the burden on the intervener to demonstrate the justifiability of the interference or the harm being caused. Thus, the presumption of nonintervention is consistent with the moral requirement that such interference be justified.

One might, at this point, argue that either humanitarian intervention is justified by or it is not; and whether a justification exists is not going to depend on who bears the burden of persuasion. Such criticisms fail to account for the practical reality of the situation relevant to the discussion. First, this is a matter of how states should interact with one another in the global arena, and the question is one of justification to another party, not simply whether a justification exists. Second, the question at the heart of the issue is epistemological and not ontological in nature. The matter of justification is in most cases going to be debated. The question is not whether a justification exists, but in the midst of such debate what should the status quo be, and who should have to argue against it. If the rule is to provide structure to the interactions between states and guide the behavior of states in those interactions, it can't simply be to act when one is justified 
in doing so. That is the very issue the resolution of which the rule is intended to govern. Another principle of morality, and one that can be found in traditional just war theory as well, is that military force should not be considered as a first option. It should be a last resort. ${ }^{328}$ Such a constraint on the use of military force allows for the possibility of diplomatic efforts to resolve the problem without violent conflict and the damage it inevitably causes. A presumption of nonintervention respects this principle in a way that a presumption of intervention cannot. Under a presumption of intervention we are privileging the option of conflict, thus undermining the last resort constraint and the diplomatic alternatives for which it allows.

One might object that the circumstances under consideration - the violation of basic human rights - is such a pressing moral demand that the international community cannot wait for diplomatic efforts to run their course, and that the reasons which support the last resort condition are either outweighed or not even relevant. In most cases, however, this is what is at issue - whether the circumstances warrant intervention. As a consequence, we cannot simply assume that the conditions are such that intervention is warranted. Second, if it is patently obvious that the basic human rights of individuals are being violated, then, all other things being equal, the presumption against intervention will be easily rebutted. Thus, a presumption against intervention will, in questionable cases, allow for the possibility of a diplomatic resolution and avoid unnecessary violence, but in those cases in which the violation of the basic right to physical security is obvious the presumption will not stand in the way of quick action.

${ }^{328}$ Brian Orend, "War", The Stanford Encyclopedia of Philosophy (Winter 2005 Edition), Edward N. Zalta (ed.), URL = $<$ http://plato.stanford.edu/archives/win2005/entries/war/>. 
Turning now to the ability of a presumption of nonintervention to accommodate the lessons learned in Chapter 4, one of the most important lessons learned is that the principle we adopt should acknowledge that the value of respecting state sovereignty is not absolute. A presumption of nonintervention privileges respect for state sovereignty, but it also recognizes the limitations of the value of respecting state sovereignty. By its very nature a presumption of nonintervention recognizes the limited value of respecting state sovereignty. However, the rule we adopt should also recognize the instrumental value of state sovereignty. Much of the discussion to follow will explain how a presumption of nonintervention can also accommodate this concern.

The principle we adopt to govern the normative framework of international relations, and specifically the question of intervention, should also be compatible with the complexity of international relations. What this means is that the rule adopted should provide the structure necessary to guide the behavior of states, but also be flexible enough to accommodate the varied demands on the actions of states including the demands of morality in the international arena. With regard to humanitarian intervention, the rule adopted must provide the basis for reasonable expectations of behavior while recognizing that in certain circumstances the demands of morality will require intervention. A presumption of nonintervention accomplishes both of these tasks. States can expect to be free from intervention if they abide by certain basic moral demands - basic human rights. Yet, if they violate the basic rights of the individuals inhabiting the state, the state becomes the possible subject of intervention. I say the "possible" subject of intervention because the inclusion of a reason for action in an agent's practical deliberations does not mean that the reason will be conclusive. 
Another lesson that we learn from the critical discussion of the justificatory arguments is that there are good instrumental reasons for adopting a presumption of nonintervention. The right of nonintervention arguably serves many important values and valuable states of affairs - political self-determination, international order, and reasonable pluralism. In most cases, respect for state sovereignty will promote international order, self-determination, and reasonable pluralism, and will not conflict with the moral demands of basic human rights. Thus, as a general rule, it would make sense to presume that state sovereignty should be respected in order to promote those values and valuable states of affairs.

In those cases in which the violation of the basic human right to physical security demands the violation of state sovereignty, the presumption places the burden of proof on those seeking to challenge the presumption. It is presumed that the proper course of action is nonintervention unless those advancing the interventionist cause can demonstrate that there are sufficient countervailing considerations which show either that the values associated with state sovereignty or the goal of international order are outweighed or not relevant to the particular case at issue.

In addition to the specific lessons learned from the critical discussion of Chapter 4, there are numerous epistemological problems with acting on reasons related to matters internal to another state. As was discussed previously in Chapter 2, despite their ultimate disagreement, Michael Walzer and David Luban seem to agree that "the lack of fit between government and people should be 'radically apparent' to justify intervening, 
because intervention based on misperceptions is horribly wrong." 329

However, if our concern is with the demands of the basic right to physical security as they relate to matters internal to another state, we need to be certain that what is triggering the action are violations of the basic right to physical security and not merely a case of moral imperialism, perfidy, or pretext. A presumption that places the burden of proof on those in favor of intervention, would protect against such epistemically based moral hazards.

There is at least one additional moral hazard associated with interference in the internal affairs of another state. Jovan Babic argues that if we were to abandon a stringent normative principle against intervention and allow for the permissibility of intervention in the internal affairs of another state in cases where the basic right to physical security would demand such action, there would be an inevitable slide to the acceptability of intervention as a tool to pursue state interests in foreign affairs. ${ }^{330}$ Slippery slope arguments are only as good as each step in the slide from the intuitively morally acceptable to the intuitively morally troubling. Here the presumption of nonintervention would allow for the intuitively acceptable proposition that the demands of basic human rights should be accounted for in the practical deliberations of states without allowing the unfettered slide to a general acceptance of intervention as a tool of foreign relations.

\subsection{Reconstruction of the Normative Framework and Implications}

${ }^{329}$ Luban, "Romance of the Nation State", p. 395. See also Walzer, "Moral Standing”, p. 214.

${ }^{330}$ Babic, pp. 64-66. See also Smith, pp. 284-285. 
So, what exactly would the normative framework look like if it was governed by a presumption as opposed to a right of nonintervention? The question may be more complicated than it might at first appear. It might be the case that one is concerned with the structure of the practical deliberations of states and not necessarily concerned with the practical difference between the two alternatives for the governing principle - the presumption of nonintervention and the right of nonintervention. On the other hand, one might be concerned primarily with such practical implications - what practical difference does it make to adopt a presumption as opposed to a right of nonintervention? Understanding the practical implications is inexorably tied to one's understanding of the implications the adoption of a presumption of nonintervention would have on the structure of a state's practical deliberations.

Beginning with the structural perspective first, under the right of nonintervention certain moral reasons for action, including the moral obligation of humanitarian intervention, are precluded from consideration if they are related to matters internal to another state and would require interference with the internal matters of another state. As discussed above, there seems to be no justification for the preclusion of relevant moral reasons from consideration. Under the presumption, no morally relevant reasons are precluded from consideration.

In the figures below (Fig. 1 The Normative Framework for the Practical Deliberations of States, and Fig. 2 Reconstructed Normative Framework for the Practical Deliberations of States) the structure of the practical deliberations of states under the right of nonintervention is juxtaposed with the structure of the practical deliberations of states under a presumption of nonintervention. The structural differences implied by the 
adoption of a presumption of nonintervention should be readily apparent. In Fig. 1 the right of nonintervention acts as a filter, excluding from consideration certain moral reasons for action. However, in Fig. 2 the presumption of nonintervention allows moral demands on a state's action to be considered, and whether intervention is what the state ought to do, all things considered, is not ruled out before deliberation even begins. 
Fig. 1

THE NORMATIVE FRAMEWORK FOR THE PRACTICAL DELIBERATION OF STATES

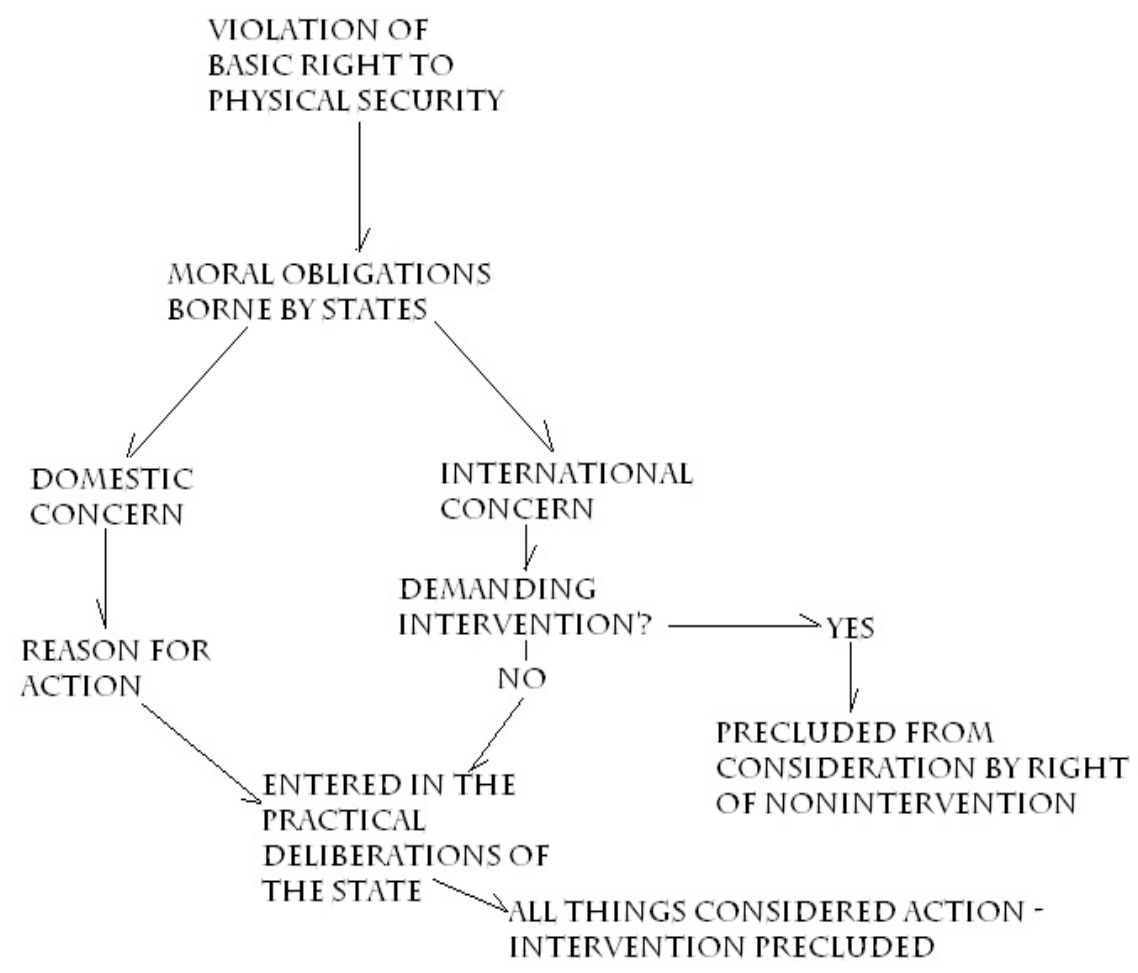


Fig. 2

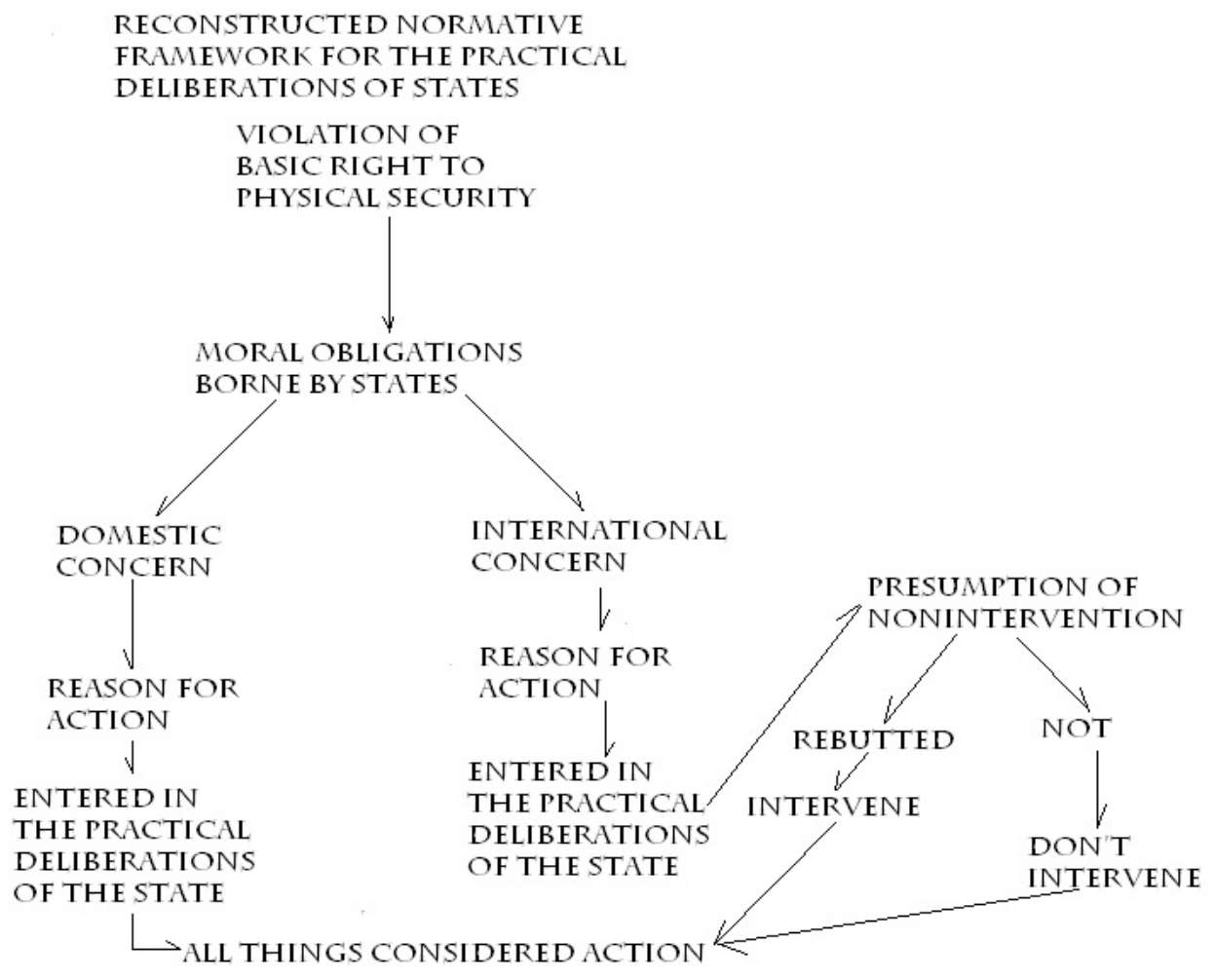


Turning to the practical implications the adoption of a presumption of nonintervention will have, the most obvious implication is that if intervention is not precluded from consideration at the outset, there is a possibility that under the right circumstances what a state ought to do, all things considered, will be to intervene. Thus, as a practical matter, under the right of nonintervention, the actions of states would (or should) never be based on moral reasons that demand interference with matters internal to another state. However, under the presumption, it would be the case that in at least some instances intervention would be based on moral reasons related to matters internal to another state.

In the final chapter, I will assess the practical difference the adoption of a presumption of nonintervention would have made in Rwanda. If the normative framework was governed by the right of nonintervention, or even if those who had power to do anything believed that it was so governed, this would explain the international community's refusal to intervene. I will argue that under the reconstructed normative framework of international relations the international community had an all things considered obligation to intervene in Rwanda.

Intervening in the internal affairs of another state is not an act that should be taken lightly. However, the normative weight that is given to state sovereignty and international order is often misplaced. I do not deny the value of either, but do question the degree to which views that sanctify their value are justified. A presumption of nonintervention allows for the value of state sovereignty and international order to be given their proper weight without unjustifiably denying the basic demands of morality. 


\section{Chapter 6 - Conclusion: An All-Things-Considered OBLIGATION TO INTERVENE IN RWANDA}

\subsection{Introduction}

Did the international community, as a collection of duty-bearing states, have an all-things-considered obligation to intervene in Rwanda in 1994? Answering this question has been the overarching goal of this project. In addressing the question, I have defended the existence of a moral obligation of humanitarian intervention in Rwanda. I have argued that the obligation was owed to the individual victims of the Rwandan genocide, and that the obligation was borne by states individually and the international community as a collection of duty-bearing states.

This, however, was only the first step in addressing the question. I have demonstrated that the normative framework, accepted by many at the time of the Rwandan genocide, precluded such moral reasons for action from consideration in the practical deliberations of states, and that the right of nonintervention which governed the practical deliberations of states was unjustified. In its stead, I have offered a reconstructed normative framework of international relations under which deliberation over questions of intervention are governed by a presumption of nonintervention. Thus, what remains to be discussed is the application of the reconstructed normative framework to the circumstances of the Rwandan genocide.

\subsection{Application of the Reconstructed Normative Framework}

Application of the reconstructed normative framework is a two-step process.

First, the delineation of the relevant considerations must be completed before the reconstructed normative framework can be employed. Only then can the second step in the process - the actual application of the reconstructed normative framework to the 
circumstances of the Rwandan genocide - begin. Thus, it is to the delineation of the relevant considerations in support of the presumption of nonintervention to which I now turn.

\subsubsection{What are the relevant considerations - when is the presumption rebutted.}

As the reconstructed normative framework is governed by a presumption, the identification of the considerations relevant to the question at hand is a matter of identifying the conditions under which the presumption would be rebutted. The relevant considerations are gleaned from the considerations in favor of a presumption of nonintervention discussed in Chapter 5. It is important to note that questions of rebuttal will, in wider practice, be a matter of degree, but I will argue that as applied to Rwanda the rebuttal of the presumption can not be reasonably disputed.

The first set of considerations are based upon the valuable states of affairs that are claimed to be served by the presumption. First, nonintervention is instrumental to political self-determination, either individual or communal. Thus, one relevant consideration in determining whether the presumption is rebutted is whether those advocating intervention can demonstrate that political self-determination is not being infringed upon, or that the infringement is justified.

Another instrumental goal to be served by the presumption of nonintervention is the protection of reasonable pluralism and protection against unjustified moral imperialism. Specifically, intervention should not be the imposition of one conception of the good for another reasonable conception of the good. Determining whether this consideration in support of the presumption has been rebutted is more complex consideration than it may at first appear. The advocates of intervention must demonstrate 
either that the bases for intervention are principles or conceptions of the good to which those whose actions are to be interfered with are also committed, or that the actions which are claimed to give rise to the demand for intervention are not based on a reasonable conception of the good.

One additional way in which a conception of the good can fail to be reasonable is in its application. Those against whom intervention is being sought may be committed to a reasonable conception of the good, and they may believe that their actions are in accordance with the reasonable conception of the good to which they are committed; however, if the connection between the conception of the good and the actions they take in accordance with that conception is not reasonable then the application is unreasonable. If the intervention being contemplated in such an instance is based on the very conception of the good that the targeted individuals are committed to, then intervention would not be an imposition of another conception of the good, but would actually be in accordance with the conception of the good to which the targets of intervention are committed. One final comment with regards to this consideration, the advocates of intervention must also demonstrate that intervention is not going to cause more harm than the conception of the good under attack.

The final instrumental goal to be served by the presumption of nonintervention is the maintenance of international peace and security. First, there is the question of whether intervention in any particular instance is likely to undermine international peace and security. This consideration can be met and no more need be required of the advocate of intervention if it can be demonstrated that intervention will either have no discernable effect on international peace and security, or that international peace and 
security will actually be served by intervention.

However, and as was discussed above, international peace and security is itself of instrumental value. It is only valuable to the extent that maintaining international peace and security serves other more fundamental goals. Thus, consideration of the effect of intervention on international peace and security in the determination of whether the presumption has been rebutted is not simply a matter of assessing whether or not international peace and security will be undermined by intervention. If the advocate of intervention can demonstrate that the goals to be served by international peace and security will be better served by intervention, even if intervention undermines international peace and security, then this consideration in favor of the presumption will have been rebutted.

One might be concerned that the complexity of assessing the presumption with regard to the goal of international peace and security identifies an inherent flaw. Specifically, the complexity of this consideration, especially if deliberation reaches this level of analysis, is likely to prove problematic. First, it may prove problematic because there may be disagreement over the goals to be served by international peace and security, and even if there is agreement over the goals to be served there may be differing ideas about whether intervention serves such goals better. I do not find this to be a determinative problem for the presumption. If anything, it demonstrates that presumption has some teeth to it, and is not likely to be blown over by the slightest consideration in favor of intervention. In addition, there are likely to be gray areas in which we should not expect there to be a clear and decisive answer. Any principle that claims that there are always easy answers to moral questions related to international relations is one of which 
we should be wary.

The second set of considerations are those based upon concerns one may have over any rule that weakens the prohibition on intervention in international relations. Specifically, one may be concerned over the possibility of perfidy, that one group is engaging in actions against the state and provoking retaliation by the state with the specific goal of enticing the international community to intervene to fight their battle for them. In addition, there is a concern over the generation of perverse results, that the intervention will lead to greater harm and a larger humanitarian crisis than the one it is intended to resolve. How can we be certain, or certain enough, that the intervention is not the result of perfidy? How can we know with sufficient certainty that intervention will not simply make the crisis worse?

As to perfidy, the concern is that if intervention is attempted in one case in which the humanitarian crisis giving rise to and justifying the intervention was caused by perfidious action, then others will be encouraged, in the future, to engage in such action to further their causes. One might think that this should lead us to conclude that the advocate must demonstrate that the humanitarian crisis that justifies the intervention was not a matter of perfidy. Such a standard would, however, place the emphasis on the wrong aspect of intervention. The concern ought to be with how the intervention is carried out, and not whether it is carried out. For that reason, those advocating intervention must demonstrate with reasonable certainty that the intervention will be carried out in such a way that perfidy is not encouraged.

As to the possibility of perverse results, the advocate of intervention must demonstrate that the intervention will alleviate the humanitarian concern without causing 
a greater one. This too is a condition that is more complicated than it may, at first, appear. Intervention, by its very nature, carries with it, not of necessity but of probability, the use of violence to accomplish its ends. Harm will be caused. Specifically, harm will be caused to those violating the rights of others. However, there exists a moral asymmetry between the violators of rights and the victims of such violation. I will not argue that any and all means may be used against the violators, but the concern over perverse results must be understood to be concerned with harm that may befall those who the intervention is intended to help.

Before moving on to the application of the reconstructed normative framework to the circumstances of the Rwandan genocide a clarificatory remark about the nature of the considerations identified is in order. One may ask the following: Are the considerations delineated necessary conditions for rebuttal of the presumption? Sufficient? Jointly, or individually? I do not think that each is necessary. Some are likely to be more important than others. For example, the causation of perverse results - the worsening of the situation for the victims - ought to be a very weighty consideration in the practical deliberations of a state, and concerns over moral imperialism, less so. However, if there were a situation in which the advocate for intervention were able to demonstrate that each of the considerations in favor of the presumption were rebutted, that would certainly be sufficient for a determination that the presumption had been rebutted.

\subsubsection{Application of the Reconstructed Normative Framework to the Circumstances of the Rwandan Genocide}

What should have been done in Rwanda? Was there an all-things-considered obligation to intervene? There is a growing consensus that the answer to this question is an emphatic, "Yes". Here, in applying the reconstructed normative framework to the 
circumstances of the Rwandan genocide, I will provide one answer why. We begin with the presumption that states ought to refrain from interfering in the internal affairs of other states, and with the recognition that there was a moral obligation to intervene in Rwanda to protect the basic right to physical security held by each individual Rwandan. We are now faced with the question, would the presumption have been rebutted?

First, as to the goals to be served by the presumption, would intervention in Rwanda have undermined the political self-determination of individuals or political groups? I must admit that I find the answer to this question obvious. It would seem absurd to claim that interference with attempted genocide is an infringement upon the right to political self-determination, nevertheless an unjustified infringement on that right. The genocide itself is a violation of the right to political self-determination held by each individual victim. Thus, intervention cannot be a violation of their right to political selfdetermination. Similarly, the genocide is a violation of the right of the Tutsi, as a people, to their political self-determination, and intervention would serve their right to political self-determination, not undermine it.

The question then becomes, would intervention undermine the right of the Hutu to political self-determination? The right to political self-determination of any individual or group, to be consistent, must be limited by the same right held by others. Thus, the right of the Hutu to political self-determination cannot involve the denial of that right to others. As a consequence, their right does not include the right to violate the rights of Tutsis and Tutsi sympathizers.

Nonetheless, one might object that the underlying purpose behind the Rwandan genocide was political in nature - to protect one regime favored by the majority of the 
inhabitants of the state against the possibility of a Tutsi dominated government - and thus that it was a matter of political self-determination. This may be true as an explanation of the motivation underlying the actions of the Rwandan Hutu, but the fact that the action engaged in is directed at a political end does not mean that it falls within the protected sphere of the right of political self-determination. There are limitations to what one may do in furtherance of their rights, including the right of political self-determination. I do not offer this objection as one that ought to be taken seriously, but rather as one that demonstrates the absurdity of the proposition that the right to political self-determination includes a permission to commit large-scale violence against others.

Would intervention in Rwanda have involved, or been an act of, unjustified moral imperialism? The consideration in favor of the presumption can be rebutted, either by demonstrating that the principle under which the intervention is being carried out is one that is shared by those who are likely to be harmed by the intervention, or that the conception of the good that is being imposed upon is an unreasonable conception of the good.

Rwanda acceded to the Convention on the Prevention and Punishment of the Crime of Genocide on April 16, 1975, and the only exception that was noted by the Rwandan government was that they did not consider themselves bound by article IX of the Convention. ${ }^{331}$ Article IX is a procedural matter related to the handling of disputes, and in substance states that disputes over the Convention are to be decided by the

${ }^{331}$ Convention on the Prevention and Punishment of the Crime of Genocide, art. IX (1948). 
International Court of Justice. ${ }^{332}$ What the Rwandan government did commit itself, and its state to, was the principle that genocide was and remains a crime. The Rwandans never withdrew from the convention. This provides at least one indication that, as a general proposition about the conception of the good shared by the Rwandan people, they viewed genocide as morally wrong.

One might claim, however, that what was occurring in Rwanda was not genocide, not for the various semantic reasons given by many of the Western powers, but rather because the violence against the Tutsis was justified. Is there a reasonable system of moral values or conception of the good that may provide the justification for the killing of Tutsis and Tutsi-sympathizers? One argument was that the Tutsi deserved to be killed because they were less than human, that they were a pest to be eradicated. ${ }^{333}$ One might find the claim that they were pests to be a mere metaphor, but the dehumanization of the Tutsi by the Hutu majority was clear in their propaganda. ${ }^{334}$ We may disagree about whether or not a stem cell is a person, or a fetus, or any other non-paradigm human, but it is unreasonable to claim that men, women, and children are not human because of their ethnic background.

There is an alternate moral basis upon which the actions of the Hutu may have been based which, at first glance, may appear reasonable. Namely, it might be claimed that the Hutu population had a right to defend itself. They may have believed that the interim government which was to be installed in accordance with the Arusha Accords,

${ }^{332}$ Ibid.

${ }^{333}$ Powers, pp. 336-340, 371-372.

${ }^{334}$ Ibid. 
and the death of President Habyarimana, were merely the first steps in a reclamation of power by exiled Tutsis and the Tutsi minority. Thus, in furtherance of their right to defend themselves the Hutu may have thought it necessary to exterminate the Tutsi.

There are at least two ways in which this underlying basis and its application fail the test of reasonableness. It is not the principle itself that is unreasonable. We can accept, at least for the sake of argument, that political groups are permitted to defend themselves. The first failure is related to the factual basis upon which the actions of the Hutu were founded. There must have been a threat, or at least a justified basis for believing that a threat existed for the right to defend themselves to be implied. There was no such threat. Second, even if we assume that the state's propaganda would have provided the Hutu population with a basis for the belief that they were being threatened, it is unreasonable to claim that the Hutu right to defend themselves included the permissibility to kill every Tutsi - man, woman, and child.

The last instrumental consideration in support of the presumption is the concern over international peace and security. As noted above, the assessment of this consideration begins with the question of whether international peace and security would be undermined by intervention. It would be inappropriate to employ our historical knowledge of the ramifications on international peace and security of the choice to not intervene, rather, since our concern is with the practical deliberations of states, we must assess this consideration from the perspective of states at the time.

The Arusha Accords, under which a power-sharing government of Rwanda was to be implemented, was an agreement between the ruling Hutu-led government and the Rwandan Patriotic Front (RPF). The power-sharing agreement was intended to bring an 
end to civil war and help promote stability and peace in the region. The genocidal efforts of the Hutu-led government disrupted the implementation of the Arusha Accords and from the onset of violence brought instability to the region, and increased the likelihood of war between various states, including Rwanda and its neighbors. Assuming Dallaire was correct, $5000 \mathrm{UN}$ peace keepers with the ability to use force to protect the Rwandan Tutsis from attack would have halted the genocide and put the Arusha Accords back on track. Obviously we can't know with certainty whether or not such actions would have served international peace and security, but it seems reasonable to conclude that widespread massacre of innocent civilians and renewed hostilities in an already volatile region were no less a threat.

Turning to the instrumental value of international peace and security, it is valuable to the extent that it serves other more fundamental goals. One that I have asserted as such a goal, and which will use as an example here is human flourishing. Even if we assume that intervention would not have served international peace and security and may even have undermined it, if it can be demonstrated that human flourishing or other such goals are actually served by intervention and are not being served by the maintenance of international peace and security, then this consideration in favor of the presumption will have been rebutted. There are a number of reasons why one ought to believe that intervention on behalf of the victims of the Rwandan genocide would have promoted human flourishing far better than the choice not to intervene. First, as a matter of probability, unjustified violence against individuals is an unlikely avenue to human flourishing.

Second, if we focus on individual human flourishing, the fear and uncertainty that 
ruled Rwanda during the genocide made it virtually impossible for individuals to flourish. As for the Rwandan society, the instability and chaos that erupted and continued throughout the genocide prevented the society from moving forward. Recall, that the genocide broke out just prior to the implementation of the Arusha Accords.

It would seem that the advocate of humanitarian intervention would have been able to rebut the various instrumental considerations in favor of the presumption of nonintervention. I would now like to turn to the considerations in favor of the presumption of nonintervention based on perfidy and perverse results. As to perfidy, during the first days of the genocide the RPF refrained from reacting to give the United Nations the opportunity to get the Arusha Accords back on track. In addition to the fact that there was no incentive for the Tutsi and the RPF to entice violence, the facts known at the time indicated that the violence was the result of the activities of the Hutu extremists, both inside and outside of the government. ${ }^{335}$

Turning finally to the concern over perverse results, one might point to the fact that Operation Turquoise had dreadful humanitarian consequences - a refugee crisis, more deaths from hunger and disease, and more violence in the areas controlled by the French. It must be noted, however, that Operation Turquoise was not a humanitarian intervention to stop the genocide, but an intervention to prevent the growing regional humanitarian crisis from becoming worse. It may not even be appropriate to call it an intervention as the RPF had control of most of the country, had stopped the genocide, and the greatest beneficiaries of the French activities were the genocidaires.

But could such perverse results have been avoided? Again, taking the perspective

${ }^{335}$ Powers, pp. 337-345. 
of those deliberating at the time, it is impossible to know with certainty what the counterfactual outcome would have been; however, there is good reason to believe that had intervention been pursued early on that the genocide of the Tutsi and the eventual broader humanitarian crisis would have been avoided. As noted previously, Lt. General Romeo Dallaire believed that a small and well-equipped United Nations force would have been able to stop the killing. In addition, the genocide was not carried out by a wellorganized military force, rather it was carried out by civilians and civilian militias, and on many occasions any show of force was sufficient to stop the mobs from carrying out their genocidal "work". For example, a Ugandan official who worked with Dallaire's UN contingent, saved many Tutsi lives by simply telling the militias that they could not have them. ${ }^{336}$ Additionally, in a now famous example, Paul Rusesabagina, the manager of a hotel in Kigali, saved thousands of Tutsis by simply refusing to let the Hutu militia into his hotel. ${ }^{337}$ Thus, it is more likely than not that an intervention in Rwanda to protect the basic right to physical security would not have resulted in perverse results.

\subsection{Conclusion}

So what have I demonstrated? In this chapter, I have shown that under the reconstructed normative framework the presumption of nonintervention would have been rebutted in the case of Rwanda, and as a consequence, there was an all things considered obligation to intervene in Rwanda. I readily admit that the historical and counterfactual nature of this claim renders it somewhat speculative, but, at the very least, I have given a

${ }^{336}$ Dallaire.

${ }^{337}$ Paul Rusesabagina with Tom Zoellner, An Ordinary Man: An Autobiography (New York: Penguin Group, 2006). 
plausible explanation as to why the international community ought to have intervened in Rwanda and not one that is dependent on the historical knowledge of the atrocity.

Even if one denies that the presumption of nonintervention was rebutted in the case of Rwanda and that there was not an all things considered obligation borne by the international community to intervene in Rwanda - both propositions I find highly dubious - there are a number of other conclusory implications that can be gleaned from this project. First, I have defended, from a relatively weak moral principle - the basic human right to physical security - further attenuated by other reasonable concerns, the claim that one can derive that set of conditions under which no one could reasonably deny that a moral obligation of humanitarian intervention exists.

Second, joining a growing number of commentators, I have argued for a weakening of the normative force of external sovereignty and a rejection of a normative framework for the practical deliberations of states accepted by many that is governed by a right of nonintervention. In contrast I have offered a reconstructed normative framework, in which questions of intervention are governed by a presumption of nonintervention that is able to serve the functional goals upon which the right to nonintervention was claimed to be justified. Lastly, I have argued that the application of the weak principle and the reconstructed normative framework would have dramatic implications for the role of basic moral concerns in international relations.

There were, however, a number of relevant matters that were not covered. First, in furtherance of the justificatory nature of the project I have dealt only with a weak principle. The methodological reasons for this choice were discussed at length previously, but there may exist other moral bases which could include stronger principles 
with wider and more pervasive implications. A limitation on the second half of the project is that I only addressed certain theories in support of right of nonintervention. There may be others, but I would contend that in light of the arguments presented above, those who would claim that the right of nonintervention is supported by some alternate and unconsidered argument bear the burden. It would also have been useful to assess other cases in international relations in which intervention has been considered. It would be particularly useful to assess situations in which we would think that intervention ought not occur to see what the application of the presumption of nonintervention tells us.

Lastly, at the very least, I hope I have raised some interesting questions for those who are skeptical of global ethics and a role for morality in international relations. 


\section{Bibliography}

Howard Adelman, "Theory and Humanitarian Intervention," from Michael Keren and Donald A. Sylvan, eds., International Intervention: Sovereignty versus Responsibility (Portland, OR: Frank Cass \& Co. Ltd., 2002).

Sharon Anderson-Gold, Cosmopolitanism and Human Rights (Cardiff, Wales: University of Wales Press, 2001).

Raymond Aron, Peace and War: A Theory of International Relations, translated by Richards Howard and Annette Baker Fox (Garden City, NY: Doubleday and Co., 1966)

Kenneth Arrow, Social Choice and Individual Values, $2^{\text {nd }}$ ed. (New York: Wiley, 1963).

Jovan Babic, "Foreign Armed Intervention: Between Justified Aid and Illegal Violence,"from Humanitarian Intervention: Moral and Philosophical Issues, ed. Aleksandar Jokic (Peterborough, Ontario: Broadview Press, 2003).

Brian Barry, "Humanity and Justice in Global Perspective," from, Robert E. Goodin and Philip Pettit, eds., Contemporary Political Philosophy: An Anthology (Oxford: Blackwell Publishing, 1997).

Charles R. Beitz, Political Theory and International Relations (Princeton, NJ: Princeton University Press, 1999).

Charles R. Beitz, Marshall Cohen, Thomas Scanlon, and A. John Simmons, eds., A Philosophy \& Public Affairs Reader: International Ethics (Princeton, NJ: Princeton University Press, 1985).

S. I. Benn and R. I. Peters, The Principles of Political Thought: Social Principles and the Democratic State (New York: Free Press, 1965).

Jeremy Bentham, An Introduction to the Principles of Morals and Legislation.

Isaiah Berlin, Four Essays on Liberty (Oxford: Oxford University Press, 1969).

Luigi Bonanate, Ethics and International Politics (Columbia, SC: University of South Carolina Press, 1995).

Chris Brown, "International Affairs," from, Robert E. Goodin and Philip Pettit, eds., $A$ Companion to Contemporary Political Philosophy (Oxford: Blackwell Publishing, 1995).

Ian Brownlie, ed., Basic Documents in International Law (Oxford: Oxford University 
Press, 2002).

- $\quad$ Basic Documents on Human Rights (Oxford: Oxford University Press, 2002).

Allen Buchanan, "From Nuremberg to Kosovo: The Morality of Illegal International Legal Reform," from Humanitarian Intervention: Moral and Philosophical Issues, ed. Aleksandar Jokic (Peterborough, Ontario: Broadview Press, 2003).

- $\quad$ “Justice and Charity”, Ethics 97 (1987), pp. 558-75.

Michael Byers, Custom, Power, and the Power of Rules (Cambridge: Cambridge University Press, 1999).

Charter of the United Nations.

Deen K. Chatterjee, The Ethics of Assistance: Morality and the Distant Needy (Cambridge: Cambridge University Press, 2004).

Deen K. Chatterjee and Don E. Scheid, Ethics and Foreign Intervention (Cambridge: Cambridge University Press, 2003).

Cicero, On Obligations (Oxford: Oxford University Press, 2000).

Marshall Cohen, "Moral Skepticism and International Relations," Philosophy and Public Affairs, Vol. 13, No. 4 (Autumn, 1984), pp. 299-346.

Jean-Marc Coicaud and Daniel Warner, eds., Ethics and International Affairs: Extent \& Limits (New York: United Nations University Press, 2001).

Gustav Daniker, "Intervention as a Challenge for the Military," from Michael Keren and Donald A. Sylvan, eds., International Intervention: Sovereignty versus Responsibility (Portland, OR: Frank Cass \& Co. Ltd., 2002).

Michael C. Davis, Wolfgang Dietrich, Bettina Scholdan, and Dieter Sepp, eds., International Intervention in the Post-Cold War World (Armonk, NY: M. E. Sharpe, Inc., 2004).

- $\quad$ "The Emerging World Order: State Sovereignty and Humanitarian Intervention," from Michael C. Davis, Wolfgang Dietrich, Bettina Scholdan, and Dieter Sepp, eds., International Intervention in the Post-Cold War World (Armonk, NY: M. E. Sharpe, Inc., 2004).

Declaration on Principles of International Law Concerning Friendly Relations and CoOperation Among States in Accordance with the Charter of the United Nations, Oct. 24, 1970. 
Jack Donnelly, Universal Human Rights: In Theory \& Practice (Ithaca, NY: Cornell University Press, 2003).

Patrick Dunleavy, “The State," from, Robert E. Goodin and Philip Pettit, eds., $A$ Companion to Contemporary Political Philosophy (Oxford: Blackwell Publishing, 1995).

Gerald Elfstrom, International Ethics: A Reference Handbook (Santa Barbara, CA: ABCCLIO, Inc., 1998).

- $\quad$ Ethics for a Shrinking World (New York: St. Martin's Press, 1990).

Anthony Ellis, "War, Revolution, and Humanitarian Intervention," from Humanitarian Intervention: Moral and Philosophical Issues, ed. Aleksandar Jokic (Peterborough, Ontario: Broadview Press, 2003).

Richard A. Epstein, “A Theory of Strict Liability,” 2 The Journal of Legal Studies 160189 (1973).

Toni Erskine, ed., Can Institutions Have Responsibilities?: Collective Moral Agency and International Relations (New York: Palgrave Macmillan, 2003).

Joel Feinberg, Doing and Deserving (Princeton, NJ: Princeton University Press, 1970).

- $\quad$ ed., Moral Concepts (Oxford: Oxford University Press, 1969).

Mary Gore Forrester, Persons, Animals, and Fetuses: An Essay in Practical Ethics (Boston, MA: Kluwer Academic Publishers, 1996).

David P. Forsythe, Human Rights in International Relations (Cambridge: Cambridge University Press, 2000).

Mervyn Frost, Ethics in International Relations: A Constitutive Theory (Cambridge: Cambridge University Press, 1996).

Alton Frye, Project Director, Humanitarian Intervention: Crafting a Workable Doctrine (New York: Council on Foreign Relations, 2000).

Stephen A. Garrett, Doing Good and Doing Well: An Examination of Humanitarian Intervention (Westport, CT: Praeger Publishers, 1999).

Raymond D. Gastil, "Beyond a Theory of Justice”, Ethics, 85:3 (1975).

David Gauthier, Morals by Agreement (Oxford: Oxford University Press, 1986). 
General Assembly Resolution of 1962 on Permanent Sovereignty over Natural Resources, Dec. 14, 1962.

Robert E. Goodin and Philip Pettit, Contemporary Political Philosophy: An Anthology (Oxford: Blackwell Publishing, 1997).

- $\quad$ A Companion to Contemporary Political Philosophy (Oxford: Blackwell Publishing, 1995).

Philip Gourevitch, We Wish to Inform You that Tomorrow We Will be Killed with Our Families: Stories from Rwanda (New York: Farrar, Straus, and Giroux, 1998).

Pablo De Greiff and Ciaran Cronin, eds., Global Justice \& Transnational Politics: Essays on the Moral and Political Challenges of Globalization (Cambridge, MA: The MIT Press, 2002).

Gordon Graham, Ethics and International Relations (Oxford: Blackwell Publishers, 1997).

Leslie Green, "Legal Obligation and Authority", The Stanford Encyclopedia of Philosophy (Spring 2004 Edition), Edward N. Zalta (ed.), URL = $<$ http://plato.stanford.edu/archives/spr2004/entries/legal-obligation/>.

William E. Hall, International Law, $8^{\text {th }}$ Ed. (Oxford, Clarendon Press, 1924).

Jean Hampton, Political Philosophy (Boulder, CO: Westview Press, 1997).

Garrett Hardin, "Life Boat Ethics” from Psychology Today (September, 1974).

H.L.A. Hart, The Concept of Law, Second Edition (Oxford: Oxford University Press, 1994).

- $\quad$ Essays on Bentham (Oxford: Clarendon Press, 1982).

- "Legal and Moral Obligation," in A.I. Melden, ed., Essays in Moral Philosophy. (Seattle, WA: University of Washington Press, 1966), pp. 82-107.

- $\quad$ “Are There Any Natural Rights?” The Philosophical Review, Vol. 64, No. 2 (Apr., 1955), pp. 175-191, 185.

Thomas Hobbes, Leviathan (1651) (Oxford: Oxford University Press, 1996).

Stanley Hoffman, The Ethics and Politics of Humanitarian Intervention (Notre Dame, IN: University of Notre Dame Press, 1996). 
J.L. Holzgrefe, “The Humanitarian Intervention Debate," from, J. L. Holzgrefe and Robert O. Keohane, eds., Humanitarian Intervention: Ethical, Legal, and Political Dilemmas (Cambridge: Cambridge University Press, 2003).

J. L. Holzgrefe and Robert O. Keohane, eds., Humanitarian Intervention: Ethical, Legal, and Political Dilemmas (Cambridge: Cambridge University Press, 2003).

Brad Hooker, "Rule Consequentialism", The Stanford Encyclopedia of Philosophy (Spring 2004 Edition), Edward N. Zalta, URL = $<$ http://plato.stanford.edu/archives/spr2004/entries/consequentialism-rule/>.

John Hospers, "What Libertarianism Is" from Tibor R. Machan, ed., The Libertarian Alternative: Essays in Social and Political Philosophy (Chicago, IL: Nelson Hall Company, 1974), pp. 3-20.

David Hume, An Enquiry Concerning the Principles of Morals (1751) (La Salle, IL: Open Court Publishing Company, 1966).

- $\quad$ A Treatise of Human Nature (1737) (Oxford: Oxford University Press, 2000).

Micheline R. Ishay, ed., The Human Rights Reader: Major Political Essays, Speeches, and Documents from the Bible to the Present (New York: Routledge, 1997).

Mark W. Janis, An Introduction to International Law, $3^{\text {rd }}$ Ed. (New York: Aspen Law \& Business, 1999).

Aleksandar Jokic, ed., Humanitarian Intervention: Moral and Philosophical Issues, (Peterborough, Ontario: Broadview Press, 2003).

Charles Jones, Global Justice: Defending Cosmopolitanism (Oxford: Oxford University Press, 1999).

Immanuel Kant, Practical Philosophy, Mary J. Gregor, ed. (Cambridge: Cambridge University Press, 1996).

Robert Keohane, "Introduction," from, J. L. Holzgrefe and Robert O. Keohane, eds., Humanitarian Intervention: Ethical, Legal, and Political Dilemmas (Cambridge: Cambridge University Press, 2003).

- $\quad$ "Political Authority after Intervention: Gradations in Sovereignty," from, J. L. Holzgrefe and Robert O. Keohane, eds., Humanitarian Intervention: Ethical, Legal, and Political Dilemmas (Cambridge: Cambridge University Press, 2003).

Michael Keren and Donald A. Sylvan, eds., International Intervention: Sovereignty versus Responsibility (Portland, OR: Frank Cass \& Co. Ltd., 2002). 
Clea Koff, The Bone Woman: A Forensic Anthropologist's Search for Truth in the Mass Graves of Rwanda, Bosnia, Croatia, and Kosovo (New York: Random House, 2004).

Anthony F. Lang Jr., Agency and Ethics: The Politics of Military Intervention (Albany, NY: State University of New York Press, 2002).

Paul Gordon Lauren, The Evolution of International Human Rights: Visions Seen (Philadelphia, PA: University of Pennsylvania Press, 1998).

Lauren E. Lomasky, Persons, Rights, and the Moral Community (Oxford: Oxford University Press, 1987).

David Luban, "Intervention and Civilization: Some Unhappy Lessons of the Kosovo War," from, Pablo De Greiff and Ciaran Cronin, eds., Global Justice \& Transnational Politics: Essays on the Moral and Political Challenges of Globalization (Cambridge, MA: The MIT Press, 2002).

- $\quad$ "Just War and Human Rights" reprinted in Charles R. Beitz, Marshall Cohen, Thomas Scanlon, and A. John Simmons, eds., A Philosophy \& Public Affairs Reader: International Ethics (Princeton, NJ: Princeton University Press, 1985), pp. 195-216.

- $\quad$ "The Romance of the Nation-State," Philosophy \& Public Affairs Vol. 9, No. 4 (Summer, 1980), pp. 392-397.

Alisdair MacIntyre, After Virtue (Notre Dame, IN: Notre Dame University Press, 1981).

Mahmood Mamdani, When Victims Become Killers: Colonialism, Nativism, and the Genocide in Rwanda (Princeton, NJ: Princeton University Press, 2002).

L. R. Melvern, A People Betrayed: The Role of the West in Rwanda's Genocide (London: Zed Books Ltd., 2004).

John Stuart Mill, On Liberty, from On Liberty and Other Essays (1859) (Oxford: Oxford University Press, 1991).

- $\quad$ “A Few Words on Nonintervention," Dissertations and Discussions, Vol. III (London: Longmans, Green, Reader, and Dyer, 1867).

Hans Morgenthau, Politics Among Nations (New York: Alfred A. Knopf, Inc., 1968).

Christopher W. Morris, An Essay on the Modern State (Cambridge: Cambridge University Press, 1998).

Jan Narveson, Respecting Persons in Theory and Practice: Essays on Moral and Political 
Philosophy (Lanham, MD: Rowman \& Littlefield Publishers, Inc., 2002).

Robert Nozick, Anarchy, State, and Utopia (New York: Basic Books, Inc., 1974).

Onora O’Neill, “Agents of Justice,” from, Thomas Pogge, ed., Global Justice (Oxford: Blackwell Publishing, 2001).

- $\quad$ "The Great Maxims of Justice and Charity," Constructions of Reasons: Explorations of Kant's Political Philosophy (Cambridge, Cambridge University Press, 1989).

- $\quad$ Faces of Hunger (London: Allen \& Unwin (Publishers) Ltd, 1986).

Claus Offe and Volker Ronge, "Theses on the Theory of the State," from, Robert E. Goodin and Philip Pettit, eds., Contemporary Political Philosophy: An Anthology (Oxford: Blackwell Publishing, 1997).

Orend, Brian, "War", The Stanford Encyclopedia of Philosophy (Winter 2005 Edition), Edward N. Zalta (ed.), URL = $<$ http://plato.stanford.edu/archives/win2005/entries/war/>.

Thomas L. Pangle and Peter J. Ahrensdorf, Justice Among Nations: On the Moral Basis of Power and Peace (Lawrence, KA: University Press of Kansas, 1999).

Michael Philips, "Humanitarian Intervention and Moral Theory," from Humanitarian Intervention: Moral and Philosophical Issues, ed. Aleksandar Jokic (Peterborough, Ontario: Broadview Press, 2003).

Thomas Pogge, "Preempting Humanitarian Interventions," from Humanitarian Intervention: Moral and Philosophical Issues, ed. Aleksandar Jokic (Peterborough, Ontario: Broadview Press, 2003).

- $\quad$ World Poverty and Human Rights (Oxford: Blackwell Publishing, 2002).

- $\quad$ "Human Rights and Human Responsibilities," from, Pablo De Greiff and Ciaran Cronin, eds., Global Justice \& Transnational Politics: Essays on the Moral and Political Challenges of Globalization (Cambridge, MA: The MIT Press, 2002).

- $\quad$ ed., Global Justice (Oxford: Blackwell Publishing, 2001).

- $\quad$ "Introduction: Global Justice," from, Thomas Pogge, ed., Global Justice (Malden, MA: Blackwell Publishing, 2001).

Samantha Powers, "A Problem from Hell": America and the Age of Genocide (New York: Perennial, 2003). 
John Rawls, The Law of People (Cambridge, MA: Harvard University Press, 1999).

Joseph Raz, Practical Reason and Norms (Oxford: Oxford University Press, 1999).

- $\quad$ Engaging Reasons: On the Theory of Value and Action (Oxford: Oxford University Press, 1999)

- $\quad$ The Morality of Freedom (New York: Clarendon Press, 1986).

Joel H. Rosenthal, Ethics \& International Affairs: A Reader, $2^{\text {nd }}$ Ed. (Washington, DC: Georgetown University Press, 1999).

Alfred P. Rubin, "Humanitarian Intervention and International Law," from Humanitarian Intervention: Moral and Philosophical Issues, ed. Aleksandar Jokic (Peterborough, Ontario: Broadview Press, 2003).

Michael Sandel, Liberalism and the Limits of Justice (Cambridge: Cambridge University Press, 1982)

T. M. Scanlon, What We Owe to Each Other (Cambridge, MA: Harvard University Press, 1998).

Roger Scruton, "Sovereignty" from A Dictionary of Political Thought (London: The Macmillan Press, 1982).

Amartya Sen, Development as Freedom (New York: Anchor Books, 2000).

Samuel Scheffler, "Relationships and Responsibilities", Philosophy \& Public Affairs, 26 (1997), pp. 189-209.

Henry Shue, "Limiting Sovereignty," from, Jennifer M. Welsh, Humanitarian Intervention and International Relations (Oxford: Oxford University Press, 2004).

- $\quad$ Basic Rights (Princeton, NJ: Princeton University Press, 1996).

Henry Sidgwick, The Methods of Ethics (London: Macmillan, 1907).

Peter Singer, "Outsiders: Our Obligations to Those Beyond Our Borders," The Ethics of Assistance: Morality and the Distant Needy (Cambridge: Cambridge University Press, 2004), pp. 11-32.

- $\quad$ One World (New Haven, CT: Yale University Press, 2002).

- $\quad$ "Famine, Affluence, and Morality," Philosophy \& Public Affairs 1:2 (1972), pp. 231-232. 
Quentin Skinner, "The State,” from, Robert E. Goodin and Philip Pettit, eds., Contemporary Political Philosophy: An Anthology (Oxford: Blackwell Publishing, 1997).

Michael J. Smith, "Humanitarian Intervention: An Overview of the Ethical Issues" from, Joel H. Rosenthal, ed., Ethics \& International Affairs (Wahsington, DC: Georgetown University Press, 1999).

Roger D. Spegele, Political Realism in International Theory (Cambridge: Cambridge University Press, 1996).

L. Wayne Sumner, The Moral Foundation of Rights (Oxford: Oxford University Press, 1986).

Fernando Teson, “The Liberal Case for Humanitarian Intervention,” from J. L. Holzgrefe and Robert O. Keohane, eds., Humanitarian Intervention: Ethical, Legal, and Political Dilemmas (Cambridge: Cambridge University Press, 2003), pp. 93-129.

- $\quad$ A Philosophy of International Law (Boulder, CO: Westview Press, 1998).

- Humanitarian Intervention (Irvington-on-Hudson, NY: Transnational Publishers, Inc., 1996).

Kenneth W. Thompson, ed., Ethics and International Relations: Ethics in Foreign Policy, Vol. 2 (New Brunswick, NJ: Transaction, Inc., 1985).

Treaties of Peace Between Sweden and the Holy Roman Empire and Between France and the Holy Roman Empire (Peace of Westphalia, October 14, 1648), 1 C.T.S. 119356.

R. J. Vincent, Nonintervention and International Order (Princeton, NJ: Princeton University Press, 1974).

Gregory Vlastos, "Human Worth, Merit, and Equality," from Joel Feinberg, ed., Moral Concepts (Oxford: Oxford University Press, 1969).

Michael Walzer, Arguing about War (New Haven, CT: Yale University Press, 2004).

- $\quad$ "The Argument about Humanitarian Intervention," Dissent (Winter 2002), pp. 2937.

- $\quad$ Just and Unjust Wars: A Moral Argument with Historical Illustrations, $3^{\text {rd }}$ Ed. (New York: Basic Books, 2000).

- $\quad$ Thick and Thin: Moral Argument at Home and Abroad (Notre Dame, IN: 
University of Notre Dame Press, 1994).

- $\quad$ "The Moral Standing of States," Philosophy and Public Affairs, Vol. 9, No. 3 (Spring, 1980), 209-229.

Mary Anne Warren, Moral Status: Obligations to Persons and Other Living Things (Oxford: Oxford University Press, 1997).

Ernest J. Weinrib, “The Case for a Duty to Rescue," 90 Yale Law Journal 247 (1980).

Thomas G. Weiss and Cindy Collins, Humanitarian Challenges \& Intervention (Boulder, CO: Westview Press, 2000).

Jennifer M. Welsh, Humanitarian Intervention and International Relations (Oxford: Oxford University Press, 2004).

- "Taking Consequences Seriously: Objections to Humanitarian Intervention," from, Jennifer M. Welsh, Humanitarian Intervention and International Relations (Oxford: Oxford University Press, 2004).

Nicholas J. Wheeler, Saving Strangers: Humanitarian Intervention in International Society (Oxford: Oxford University Press, 2000).

C. H. Whitley, “On Duties,” from Joel Feinberg, ed., Moral Concepts (Oxford: Oxford University Press, 1969).

Burleigh Wilkins, "Humanitarian Intervention: Some Doubts," from Humanitarian Intervention: Moral and Philosophical Issues, ed. Aleksandar Jokic (Peterborough, Ontario: Broadview Press, 2003).

Rudiger Wolfrum, "The UN Experience in Modern Intervention," from Michael Keren and Donald A. Sylvan, eds., International Intervention: Sovereignty versus Responsibility (Portland, OR: Frank Cass \& Co. Ltd., 2002).

Veronique Zanetti, “Global Justice: Is Interventionism Desirable?" from, Thomas Pogge, ed., Global Justice (Oxford: Blackwell Publishing, 2001). 